\title{
Genetics of externalizing behavior and structural brain devel- opment in adolescence
}

\author{
Jalmar Teeuw 1,*, Marieke Klein ${ }^{2,3,6}$, Nina Roth Mota ${ }^{3,6}$, Rachel M. Brouwer 4,1, Dennis van 't Ent ${ }^{5}$, Zyneb Al- \\ Hassaan 1, Barbara Franke 3,6,7, Dorret I. Boomsma 5,8 and Hilleke E. Hulshoff Pol 9,1
}

1 Department of Psychiatry, Brain Center Rudolf Magnus, University Medical Center Utrecht, Utrecht, The Netherlands

2 Department of Psychiatry, University of California, San Diego, La Jolla, CA, United States

3 Department of Human Genetics, Radboud University Medical Center, Nijmegen, The Netherlands

4 Department of Complex Trait Genetics, Center for Neurogenomics and Cognitive Research, Amsterdam Neuroscience, Vrije Universiteit Amsterdam, The Netherlands

5 Department of Biological Psychology, Vrije Universiteit Amsterdam, Amsterdam, The Netherlands

6 Donders Institute for Brain, Cognition and Behaviour, Radboud University, Nijmegen, The Netherlands

7 Department of Psychiatry, Radboud University Medical Center, Nijmegen, The Netherlands

8 Amsterdam Public Health (APH) Research Institute, Amsterdam, The Netherlands

9 Department of Psychology, Utrecht University, Utrecht, The Netherlands

* Correspondence: Jalmar Teeuw. E-mail: j.teeuw@umcutrecht.nl. Telephone: +31 (088) 75 53 387. Mail: University Medical Center Utrecht, Department of Psychiatry A01.126, attn. Jalmar Teeuw, Heidelberglaan 100, 3584 CX Utrecht, Netherlands.

\begin{abstract}
Externalizing behavior in its more extreme form is often considered a problem to the individual, their families, teachers and society as a whole. Several brain structures have been linked to externalizing behavior and such associations may arise if the (co)development of externalizing behavior and brain structures share the same genetic and/or environmental factor(s). We assessed externalizing behavior with the Child Behavior Checklist and Youth Self Report, and brain volumes and white matter integrity (FA and MD) with magnetic resonance imaging in the BrainSCALE cohort, consisting of twins and their older siblings from 112 families measured longitudinally at ages 10,13 , and 18 years of the twins. Genes influenced externalizing behavior and changes therein $\left(h^{2}\right.$ up to $88 \%$ ). More pronounced externalizing behavior was associated with higher FA (observed correlation $r_{\mathrm{ph}}$ up to +0.20 ) and lower MD ( $r_{\mathrm{ph}}$ up to -0.20$)$; with sizeable genetic correlations (FA $r_{\mathrm{a}}$ up to +0.42 ; $\mathrm{MD} r_{\mathrm{a}}$ up to -0.33 ). Cortical gray matter (CGM; $r_{\mathrm{ph}}$ up to -0.20 ) and cerebral white matter $\left(\mathrm{CWM} ; r_{\mathrm{ph}}\right.$ up to +0.20$)$ volume were phenotypically but not genotypically associated with externalizing behavior. These results suggest a potential mediating role for global brain structures in the display of externalizing behavior during adolescence that are both partially explained by the influence from the same genetic factor.
\end{abstract}

Keywords: externalizing behavior; adolescence; gray matter volume; white matter integrity; heritability; genetic correlation; longitudinal; magnetic resonance imaging.

\section{Introduction}

Externalizing behavior is characterized by a multitude of antisocial and disruptive behaviors in the form of acting out, aggression, hostility, delinquency, or criminal acts that can be costly and potentially harmful to the individual, their family and friends, and society [1]. Externalizing behavior in children and adolescents can be assessed by the broad Externalizing scale from the parent-reported Child Behavior Checklist (CBCL) and the self-reported Youth Self Report (YSR) [2]. The age of onset of externalizing behavior varies between individuals, but occurs most often during childhood and adolescence, and the trajectory may present with different profiles of disruptive behavior throughout development [3-5]. Externalizing behavior occurs in both sexes, although boys are at increased risk of disruptive behavior [6-7]. Around 5\% to $10 \%$ of Dutch children and adolescents 
eventually receive a clinical diagnosis of oppositional defiant disorder (ODD) and/or conduct disorder (CD) [8-10]. Externalizing behavior can desist on its own or after successful intervention [11]. However, externalizing behavior that is allowed to escalate or continues to persist after adolescence may lead to a diagnosis of antisocial personality disorder (ASPD) or psychopathy during adulthood, especially in combination with callous-unemotional traits [12-14]. These psychopathic traits are elevated in early offenders and incarcerated youth [15]. As such, understanding the etiology and development of externalizing behavior during childhood and adolescence is important for developing methods for early diagnosis and treatment to prevent escalation of antisocial behavior.

Twin and family studies have revealed a heritable factor for externalizing behavior [16-22; reviews 23-25], that is largely determined by the same genetic factor throughout child and adolescent development [26-28]. A recent longitudinal twin study has shown that the rate of change in the development of externalizing behavior is also in part heritable [29], but this has not been consistently reported [30]. However, it remains unclear through which biological pathways the genetic influences on externalizing behavior might act, and if changes in externalizing behavior is mediated through other developmental changes occurring during adolescence, such as structural brain development [31].

The human brain continues to develop considerably during adolescence [32-33]. Although total brain volume has nearly reached its adult size by late childhood [34], the gray matter of the cerebral cortex shows a distinctive developmental trajectory during adolescence [35-37], and myelination of white matter continues well into adulthood [38-40]. Many properties of the structural brain are highly heritable throughout the lifespan [reviews 41-44]. This includes their longitudinal change rates during adolescent brain development which share a common genetic etiology with psychiatric disorders and cognition [45-51]. Externalizing behavior has been linked to alterations in the structure and functioning of the brain; for reviews see [52-56]. Overall, various forms of externalizing behavior and psychopathology have been associated with reduced gray matter volume in structures of the frontal and temporal cortex and the limbic system [57-61], and with increased white matter volume and reduced white matter integrity of the brain [62-67]. This pattern of reduced gray matter volume and increased white matter volume is often associated with more mature brain features as a result of synaptic pruning and continued myelination of the brain [68-70]. Several studies have reported an association between (longitudinal changes in) externalizing behavior with (longitudinal changes in) regional gray matter [71-77], and white matter structures [67,78-80]. However, the extent and even the direction of the association between externalizing behavior and brain structures differ between studies, especially in youth [54,75], which could be explained by the continuous development of the brain during childhood and adolescence that in particular affects studies on cross-sectional data. This emphasizes the need for longitudinal studies to analyze the association between brain and behavior within the context of their developmental trajectories in an individual [81].

Here we report on a longitudinal study of adolescent twins and an older sibling from 112 families, who were assessed around the ages 10, 13, and 18 years. Externalizing behavior was assessed by the Child Behavior Checklist (CBCL) and Youth Self Report (YSR), and gray matter volumes and white matter integrity (FA and MD) of the brain were assessed by structural magnetic resonance imaging (MRI) and diffusion tensor imaging (DTI). The longitudinal design allowed to control for developmental effects within the individual, and to assess to what extent brain structures and externalizing behavior are associated, including the association between their longitudinal change rates. The inclusion of twins and siblings allowed for an application of the classical twin design to decompose variation in externalizing behavior and brain measures into genetic and environmental components, and to assess the extent to which shared genetic and environmental factors determine the covariation of externalizing behavior and these brain measures.

\section{Results}




\subsection{Phenotypic development of externalizing behavior}

Endorsement of externalizing behavior on the Child Behavior Checklist (CBCL) and Youth Self Report (YSR) was low overall (Table 2; Supplementary Figure S1), as is to be expected for a cohort of typically developing children. The twins and siblings were more likely to endorse items on the self-reported YSR than their parents reported on the CBCL (Table 2; Supplementary Figure S1). Parents reported a slight decrease in externalizing behavior with age that is in contrast with the slight increase in externalizing behavior reported by their offspring (Figure 1). Differences in externalizing behavior between the sexes were negligible, and were only significant for the externalizing scale on the YSR but not on the CBCL (Figure 1). Between assessments of the same instrument at the different ages, the phenotypic correlation is moderate to strong, but also indicates considerable individual variation between the ages (correlation range CBCL: +0.52 to +0.64 ; correlation YSR: +0.46; Supplementary Table S4).
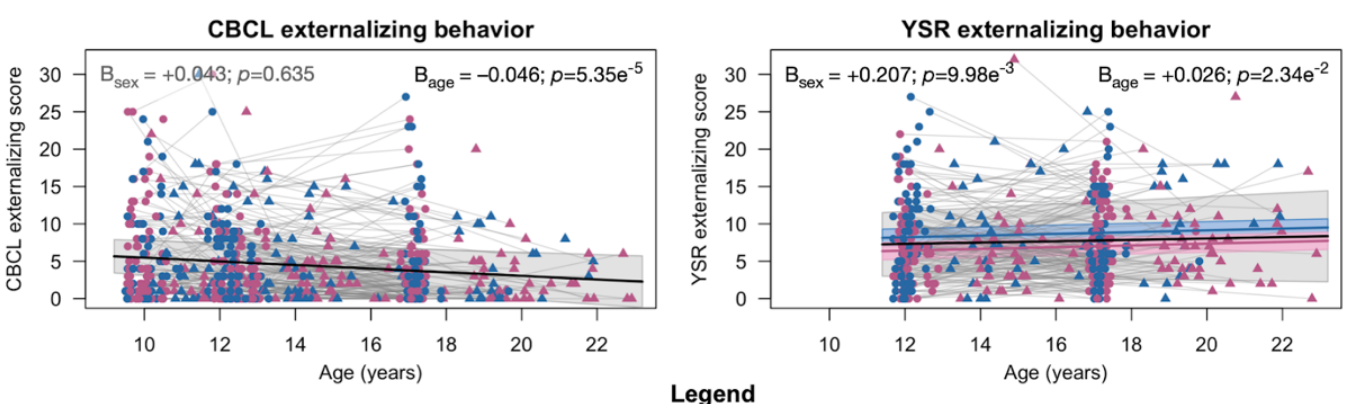

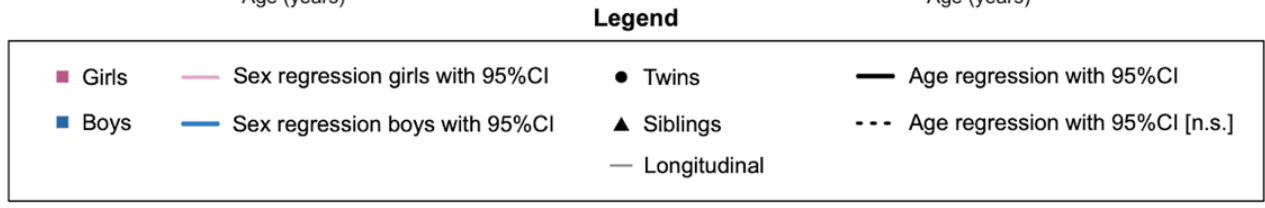

Figure 1. Phenotypic development of externalizing behavior throughout adolescence. Measurements are based on the externalizing scale of the Child Behavior Checklist and Youth Self Report. Data points are plotted for the untransformed scores on the y-axis. Estimates of sex and age regression coefficients and $p$-value were obtained from the longitudinal genetic model on the $\log _{10}$-transformed scores. Abbreviations (in alphabetical order): $\mathrm{CBCL}=$ child behavior checklist; $\mathrm{CI}=$ confidence interval; n.s. = not significant; YSR = youth self report.

\subsection{Heritability of externalizing behavior}

Genetic influences on externalizing behavior were generally strong at all ages $\left(h^{2}\right.$ range: $42 \%$ to $88 \% ; p<0.030$; Table 2 ), and heritability estimates were similar across the ages for the parent-reported CBCL $(p>0.128)$. Heritability estimates for the externalizing score on the self-reported YSR dropped significantly at age 18 years $(p<0.024)$. Influences from the common environment on externalizing scores were small across all ages and did not reach the significance threshold ( $c^{2}$ range: $0 \%$ to $9 \% ; p>0.237$ [n.s.]; Table 2). The high heritability estimates were supported by the correlations within MZ, DZ twin pairs, and between twin-sibling pairs (Supplementary Table S2). A similar pattern of genetic and environmental influences existed for the untransformed scores, but with slightly lower heritability estimates and slightly higher common environmental influences (Supplementary Table S3).

Strong genetic influences were also found for the longitudinal changes between assessments of externalizing behavior for the parent-reported CBCL $\left(h_{\Delta}^{2}\right.$ range: $78 \%$ to $86 \%$; $p<4.12 \mathrm{E}-04$; Table 2). The genetic influences on the longitudinal changes of externalizing behavior measured with the YSR did not reach significance $\left(h_{\Delta}^{2}: 26 \% ; p=0.060\right.$ [n.s.]; Table 2). Analysis of the genetic correlation between assessments of externalizing behavior with the parent-reported CBCL at different ages showed substantial but incomplete overlap between genetic factors, indicating the presence of shared and distinct genetic factors influencing externalizing behavior at specific ages throughout adolescence $(r$ range: +0.53 
to $+0.63 ; p<3.73 \mathrm{E}-05$; incomplete pleiotropy $p<8.74 \mathrm{E}-04$; Supplementary Table S4). For the self-reported YSR, the genetic correlation suggested a single genetic factor influencing behavior at both ages $\left(r_{\mathrm{a}}:+0.86 ; p=7.12 \mathrm{E}-04\right.$; incomplete pleiotropy $p=0.484$ [n.s.]; Supplementary Table S4).

Table 2. Externalizing behavior on the Child Behavior Checklist (CBCL) and Youth Self Report (YSR).

\begin{tabular}{|c|c|c|c|}
\hline Instrument & Age 10 years & Age 13 years & Age 18 years \\
\hline CBCL & $\begin{array}{c}\text { Score }=5.31 \pm 6.1[0 ; 30] \\
h^{2}=80 \%[57 \% ; 92 \%] \\
c^{2}=9 \%[0 \% ; 29 \%] \\
e^{2}=12 \%[7 \% ; 21 \%]\end{array}$ & $\begin{array}{c}\text { Score }=4.35 \pm 5.1[0 ; 30] \\
\begin{array}{c}h^{2}=88 \%[70 \% ; 96 \%] \\
c^{2}=7 \%[0 \% ; 25 \%] \\
e^{2}=5 \%[3 \% ; 8 \%]\end{array}\end{array}$ & $\begin{array}{c}\text { Score }=3.46 \pm 4.9[0 ; 27] \\
h^{2}=82 \%[63 \% ; 91 \%] \\
c^{2}=5 \%[0 \% ; 22 \%] \\
e^{2}=13 \%[9 \% ; 22 \%]\end{array}$ \\
\hline YSR & $\mathrm{N} / \mathrm{A}$ & $\begin{array}{c}\text { Score }=7.57 \pm 6.0[0 ; 32] \\
h^{2}=76 \%[58 \% ; 86 \%] \\
c^{2}=0 \%[0 \% ; 10 \%] \\
e^{2}=24 \%[14 \% ; 40 \%]\end{array}$ & $\begin{array}{c}\text { Score }=7.64 \pm 5.3[0 ; 27] \\
h^{2}=42 \%[15 \% ; 59 \%] \\
c^{2}=0 \%[0 \% ; 18 \%] \\
e^{2}=58 \%[41 \% ; 80 \%]\end{array}$ \\
\hline Instrument & Age 10 to 13 years & Age 13 to 18 years & Age 10 to 18 years \\
\hline CBCL & $\begin{array}{c}h_{\Delta}^{2}=86 \%[70 \% ; 92 \%] \\
c_{\Delta}^{2}=0 \%[0 \% ; 7 \%] \\
e_{\Delta}^{2}=14 \%[7 \% ; 29 \%] \\
\text { N/A }\end{array}$ & $\begin{array}{c}h_{\Delta}^{2}=84 \%[69 \% ; 90 \%] \\
c_{\Delta}^{2}=0 \%[0 \% ; 13 \%] \\
e_{\Delta}^{2}=16 \%[10 \% ; 26 \%] \\
h_{\Delta}^{2}=26 \%[0 \% ; 47 \%] \\
c_{\Delta}^{2}=0 \%[0 \% ; 17 \%] \\
e_{\Delta}^{2}=74 \%[53 \% ; 94 \%\end{array}$ & $\begin{array}{c}h_{\Delta}^{2}=\mathbf{7 8 \%}[55 \% ; 88 \%] \\
c_{\Delta}^{2}=1 \%[0 \% ; 12 \%] \\
e_{\Delta}^{2}=22 \%[12 \% ; 38 \%]\end{array}$ \\
\hline
\end{tabular}

The mean, standard deviation, and range are reported for the untransformed scores of the externalizing scales on the CBCL and YSR. Heritability $\left(h^{2}\right)$, common environment $\left(c^{2}\right)$, unique environment $\left(e^{2}\right)$ and their $95 \%$ confidence intervals are reported for the longitudinal genetic model on the log $\operatorname{lo}_{10}$-transformed scores of the externalizing scale of the CBCL and YSR and their longitudinal change in scores $\left(h_{\Delta}^{2}, c_{\Delta}^{2}\right.$, and $\left.e_{\Delta}^{2}\right)$. Heritability and common environment estimates printed in boldface are significant $(p<0.05)$; exact $p$-values are reported in Supplementary Data File F1. No YSR is collected at baseline assessment \#1 (10 years). Results for the genetic analysis on the untransformed scores are reported in Supplementary Table S3. Abbreviations (in alphabetical order): $C B C L=$ child behavior checklist; $Y S R=$ youth self report.

\subsection{Phenotypic development and heritability of brain structures}

We have previously described the developmental patterns and reported the heritability of brain structure and function throughout adolescent for this cohort; this included the longitudinal changes in brain structures that were also partially influenced by genetic factors [37,39,45-46,82-87].

The developmental pattern and heritability estimates of the six global brain measures are in line with our previous reports (Figure 2; Supplementary Table S7; Supplementary Table S8; Supplementary Data File F2). Total brain volume, subcortical gray matter volume, cerebral white matter volume, and global mean fractional anisotropy and mean diffusivity continued to increased and/or level out nearing the end of adolescence, and cortical gray matter volume decreased steadily with age $(p<0.005)$. There were significant differences between the sexes, with higher gray matter volumes and global mean diffusivity but lower global mean fractional anisotropy for boys than for girls $(p<0.025)$. Heritability of global brain measures was high ( $h^{2}$ range: $34 \%$ to $93 \% ; p<0.001$ ), with negligible effects of common environment except for global mean diffusivity ( $c^{2}$ range: $10 \%$ to $28 \%$; $p<0.025)$. Longitudinal changes in total brain volume were also heritable ( $h^{2}$ range: $33 \%$ to $64 \% ; p<0.013$ ), and longitudinal changes in global mean diffusivity was influenced by common environment ( $c^{2}$ range: $35 \%$ to $55 \% ; p<0.020$ ). 

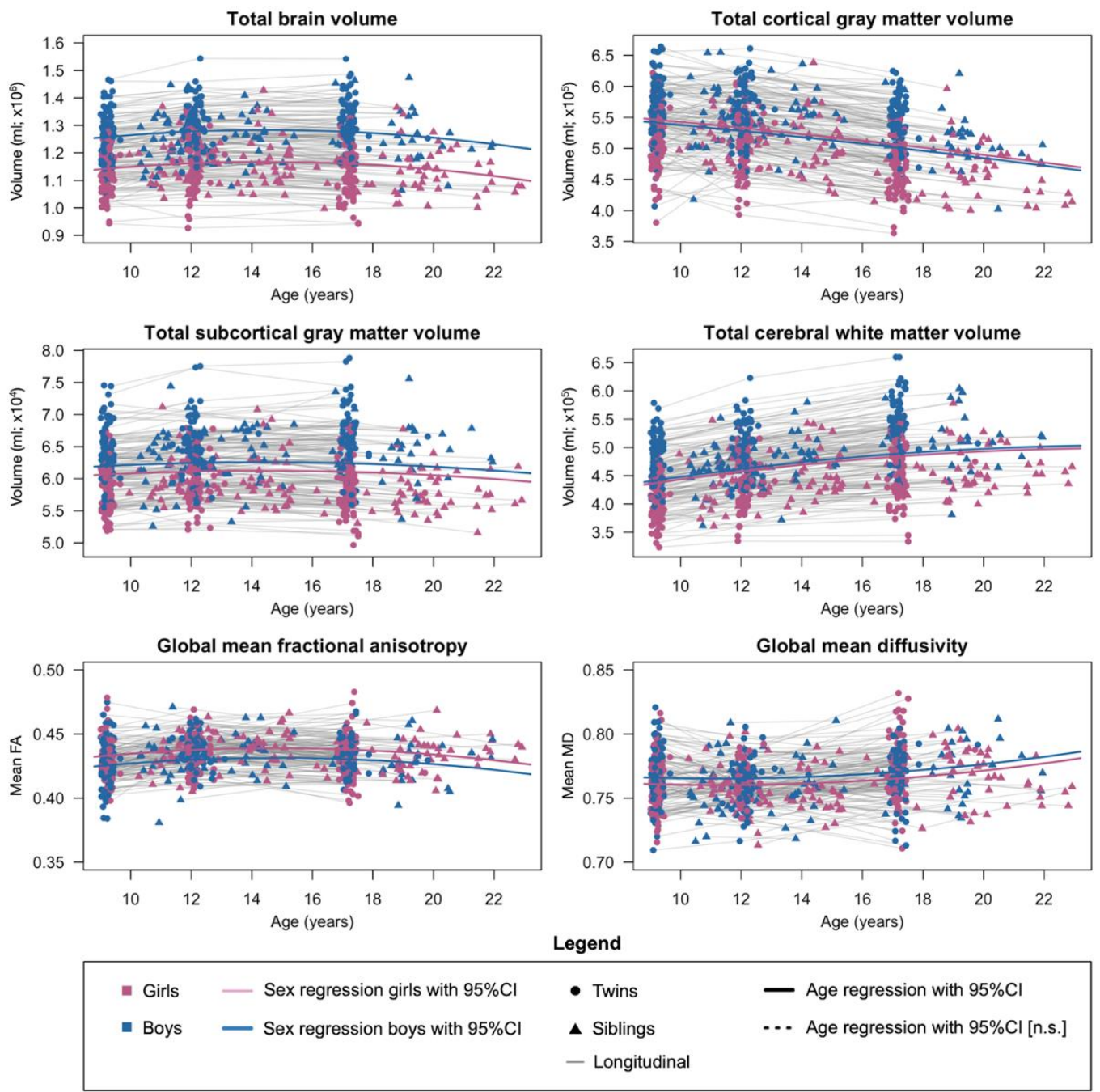

Figure 2. Development of global brain structures for boys and girls throughout adolescence. Sex effects for total (sub)cortical gray matter volume and cerebral white matter volume are plotted after simultaneous regression of total brain volume. The effect of sex was significant for all six global brain structures; the exact effect sizes and $p$-values of sex and age are reported in Supplementary Data File F2. Abbreviation (in alphabetical order): $\mathrm{CI}=$ confidence interval; n.s. = not significant.

The longitudinal profiles of the regional brain structures followed mostly similar patterns as the global brain structures (Supplementary Figure S5; Supplementary Figure S6; Supplementary Data File F2). Most cortical regions showed a decrease in gray matter volume with age, with an occasional sex effect. In contrast, the gray matter volume of the amygdala and hippocampus slightly increased with age. The maturation of the mean fractional anisotropy of the white matter tracts started to slow down nearing the end of adolescence, whereas maturation of the mean diffusivity of the white matter tracts mostly increased throughout adolescence. Most regional brain measures were strongly influenced by genetics ( $h^{2}$ up to $84 \% ; p<0.05$ ). On some occasions, influences from the common environment played a role as well ( $c^{2}$ up to $\left.42 \% ; p<0.05\right)$. Genetics played a considerable role in the longitudinal changes rate of gray matter volume and white matter integrity during adolescent development $\left(h_{\Delta}^{2}\right.$ up to $67 \% ; p<0.05$ ). Occasionally, there were also significant influences from the common environment on the longitudinal change rates $\left(c_{\Delta}^{2}\right.$ up to $66 \% ; p<0.05)$. Associations between longitudinal assessments of the same brain measures indicated strongly overlapping genetic factors throughout adolescent brain development (Supplementary Data File F2). 

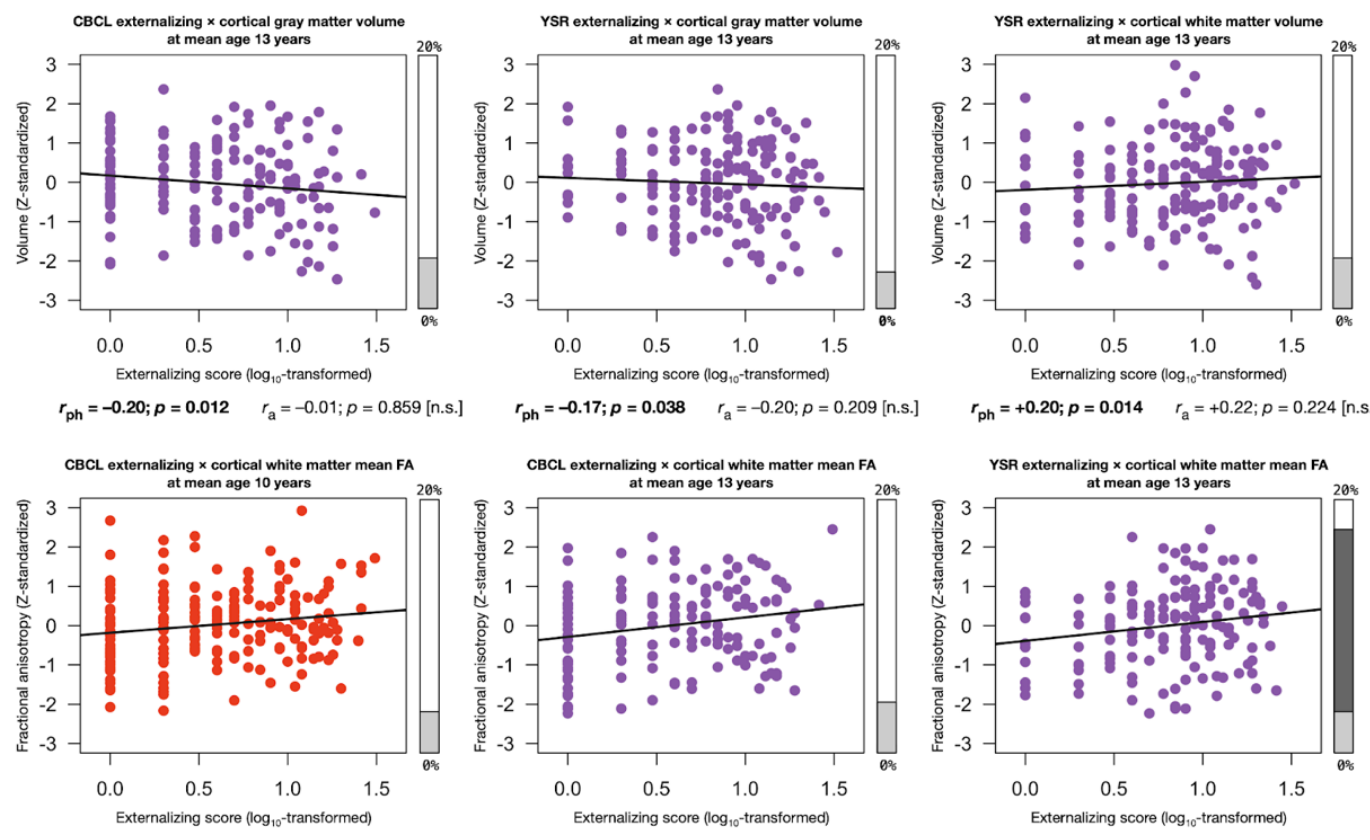

$r_{\mathrm{ph}}=+0.18 ; p=0.024 \quad r_{\mathrm{a}}=+0.09 ; p=0.478[$ [n.s.
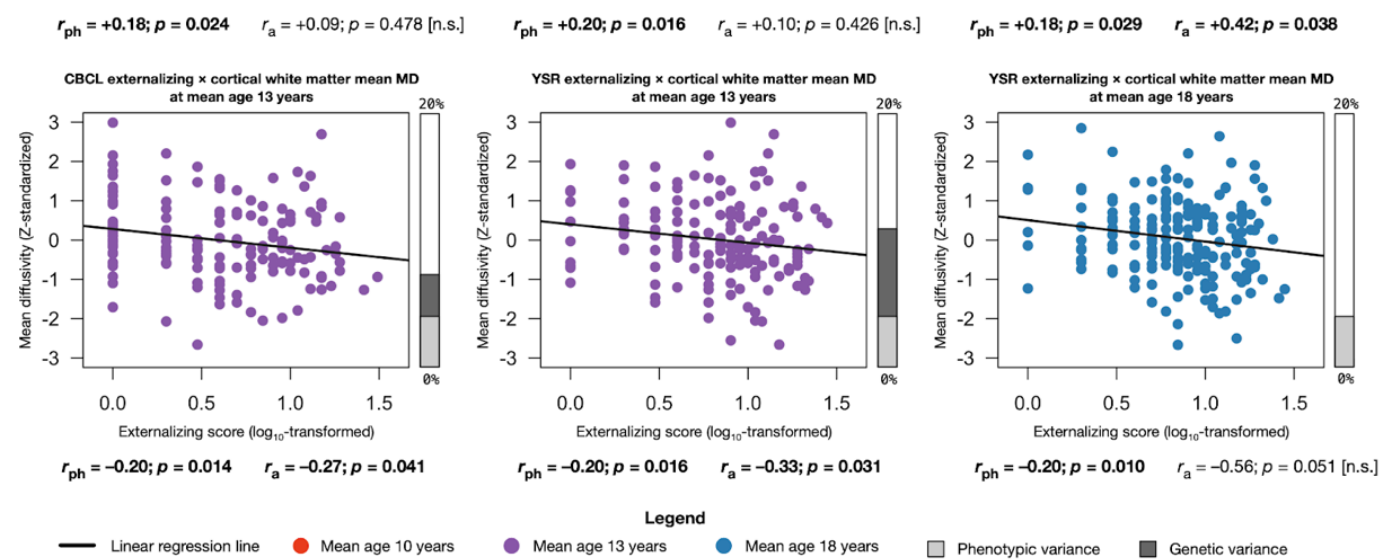

Figure 3. Associations between externalizing behavior and global brain structures throughout adolescence. Phenotypic association $\left(r_{\mathrm{ph}}\right)$ of the $\log _{10}$-transformed scores of externalizing behavior on the CBCL or YSR questionnaire with Z-standardized measures of global brain structures (only listing uncorrected $p<0.05$ significant associations). Bar charts display the total variance explained by the phenotypic (light gray) and genetic (dark gray) associations. Abbreviations (in alphabetical order): $\mathrm{CBCL}=$ child behavior checklist; $\mathrm{FA}=$ fractional anisotropy; $\mathrm{MD}=$ mean diffusivity; $\mathrm{YSR}=$ youth self report.

\subsection{Assocations between externalizing behavior and global brain structures}

Significant associations between brain structures and externalizing behavior mainly occurred during mid-adolescence around age 13 years. We note that the direction and magnitude of the associations were overall consistent throughout adolescence (Figure 3; Supplementary Figure S7; Supplementary Table S9; Supplementary Data File F3).

\subsubsection{Phenotypic associations}

Significant phenotypic associations between externalizing behavior and global brain structures were found primarily at age 13 years (Figure 3; Supplementary Figure S7; Supplementary Table S9; Supplementary Data File F3). Global cortical gray matter volume was significantly associated with externalizing behavior on the CBCL $\left(r_{\mathrm{ph}}=-0.20 ; p=\right.$ $0.012)$ and YSR $\left(r_{\mathrm{ph}}=-0.17 ; p=0.038\right)$ at age 13 years. Total cerebral white matter was significantly associated with externalizing behavior on the YSR at age 13 years $\left(r_{\mathrm{ph}}=+0.20\right.$; $p=0.014)$. Global mean fractional anisotropy was significantly associated with externalizing behavior on the CBCL at ages $10\left(r_{\mathrm{ph}}=+0.18 ; p=0.024\right)$ and $13\left(r_{\mathrm{ph}}=+0.20 ; p=0.016\right)$ years and at age 13 years for the YSR $\left(r_{\mathrm{ph}}=+0.18 ; p=0.029\right)$. Global mean diffusivity was 
significantly associated with externalizing behavior on the CBCL at age 13 years $\left(r_{\mathrm{ph}}=-\right.$ $0.20 ; p=0.014)$, and at ages $13\left(r_{\mathrm{ph}}=-0.20 ; p=0.016\right)$ and $18\left(r_{\mathrm{ph}}=-0.20 ; p=0.010\right)$ years for the YSR. No significant associations were found between longitudinal change rates in externalizing behavior on the CBCL or YSR and change rates in global brain measures (Supplementary Data File F3).

\subsubsection{Genetic associations}

Significant genetic associations between externalizing behavior and three global brain measures were found at age 13 years (Figure 3; Supplementary Figure S7; Supplementary Table S9; Supplementary Data File F3). The association between global mean fractional anisotropy and externalizing behavior on the YSR at age 13 years was partially due to the same additive genetic factor $\left(r_{\mathrm{a}}=+0.42 ; p=0.038\right)$. Similarly, the association between global mean diffusivity and externalizing behavior on the CBCL was partially due to the same additive genetic factor $\left(r_{\mathrm{a}}=-0.27 ; p=0.041\right)$ and YSR $\left(r_{\mathrm{a}}=-0.33 ; p=0.031\right)$ at age 13 years.

\subsubsection{Environmental associations}

The phenotypic associations between total cortical gray matter volume and externalizing behavior on the CBCL at age 13 years were partially due to the same common environmental factor $\left(r_{c}=-0.97 ; p=0.026\right.$; Supplementary Figure S7; Supplementary Table S9; Supplementary Data File F3). In addition, the phenotypic association between the longitudinal change rates in global mean fractional anisotropy and changes in externalizing behavior on the CBCL between ages 10 and 18 years were partially explained by the same unique environmental factor $\left(r_{\mathrm{e}}=+0.44 ; p=0.032\right.$; Supplementary Data File F3).

\subsection{Assocations between externalizing behavior and regional brain measures}

A more nuanced pattern was suggested at the level of regional brain measures in an exploratory analysis (Supplementary Figure S7; Supplementary Data File F3), but results for regional brain structures did not survive correction for multiple comparisons and should be interpreted with caution.

\section{Discussion}

In this study, we measured externalizing behavior and brain measures in a longitudinal cohort at ages 10,13, and 18 years and tested to what extent gray and white matter structural brain measures were associated with externalizing behavior. Because the data were collected in twin families, we could also test the etiology of associations, i.e., if the same genetic and environmental factors, influence both brain development and behavior. We found that a higher mean white matter fractional anisotropy (FA) and a lower mean white matter diffusivity (MD) were associated with more pronounced externalizing behavior during adolescence ( $r_{\mathrm{ph}}$ up to $\left.-0.20 /+0.20\right)$. These associations were due to same additive genetic factors ( $r$ a u to $-0.33 /+0.42$ ) influencing both traits. Total brain volume was not significantly associated with externalizing behavior. Lower total gray matter volume and increased cerebral white matter volume were phenotypically, but not genetically, associated with more pronounced externalizing behavior around mid-adolescence $\left(r_{\mathrm{ph}}\right.$ up to -0.20). Both externalizing behavior and white matter structure were partly heritable, and genetically correlated, imply that during adolescent brain development genetic factors are involved in white matter integrity, that are also involved in externalizing behavior.

Heritability of externalizing problems was influenced by genetics ( $h^{2}$ up to $88 \%$ ); although a remarkable drop in heritability was observed for self-reported externalizing behavior around age 18 years. In parent-reported externalizing behavior during adolescence a decrease in externalizing problems was observed, which was not seen in self-reports, though we note that these were collected twice, rather than three times. The decrease in parent-reported externalizing problems was influenced by genetics ( $h_{\Delta}^{2}$ up to $86 \%$ ). This discrepancy between parent- and self-reported behavior might reflect differences in 
reliability or construct validity, but could also reflect unique views of each rater on the behavior of the individual [88]. Differences between parent- and self-reported behavior were also observed in association with brain structures. Overall, we found that the phenotypic association between white matter integrity and externalizing behavior had the same direction and magnitude during adolescence but was most prominently present around age 13 years. However, the association disappeared around age 18 years for parent-reported externalizing behavior, but remained present for self-reported externalizing behavior. Previous research in twins showed that longitudinal stability of externalizing behavior is partially due to a general age-independent genetic factor [26,88-90]. For brain structure and function, we have previously shown in the BrainSCALE cohort that an ageindependent genetic factor also explains stability $[37,45,85]$. Thus, despite the developmental changes in both brain and behavior, there might be a more prominent overlap between the age-independent genetic factors for externalizing behavior and white matter integrity throughout adolescence.

We found that whole-brain global white matter integrity was both phenotypically and genotypically associated with externalizing behavior. White matter integrity has often been associated with behavior and cognition, with a more pronounced white matter integrity being associated with more mature behavior or higher cognitive skills [70,87,91; review 40]. The association of higher white matter integrity with more pronounced externalizing behavior has been reported before, particularly in children with conduct disorder and adults with psychopathic traits [63,66,92-97], but mixed results are reported for a broader range of externalizing behavior, especially for studies in developmental cohorts $[54,64,67,78,98-99]$. In addition, we found that a larger global cortical gray matter volume was associated with less pronounced externalizing behavior around age 13 years, that was due to a correlated common environment factor. Cortical gray matter volume has been reported before in relation to externalizing behavior [57-59], including in a very large cohort of early adolescents around age 9 to 10 years $[60,61]$, and in adults with callous or psychopathic traits [52-53]. Of note, we found that total brain volume and subcortical brain volume did not significantly associate, either phenotypically or genotypically, with externalizing behavior during adolescence. Thus, overall brain size could not explain the phenotypic and genotypic associations we found between externalizing behavior with global white matter integrity and cortical gray matter during adolescent development.

In our exploratory analysis of regional brain structures, we found that, for local white matter integrity, a phenotypic association was most reliably and consistently found for the anterior thalamic radiation, the cingulum, forceps minor, and the corticospinal tract bilaterally. We add that these associations are due to correlated genetic influences. Similarly, for local gray matter volumes, the rostral middle frontal gyrus in particular was most reliably and consistently associated with externalizing behavior both phenotypically and genetically. However, these findings did not survive multiple comparison corrections and thus have to be interpreted with caution. This absence of significant findings at the regional brain level might be due to the correction for the effect of the global brain in our analyses, where the sum of small effects in regional brain structures contribute to an overall effect at the global brain level. Indeed, the associations between externalizing behavior and brain structure gray and white matter seem mostly related to individual differences for global brain structures. Our results suggest that the same genes are involved in both externalizing behavior and (global) brain structures, and that these brain structures could play a mediating role between the genetic liability and demonstration of externalizing behavior.

The quest to identify genetic variants related to externalizing behavior [100-103], brain structures [104-106], and longitudinal changes in brain structures [107], is an ongoing effort. Neuroimaging-related phenotypes may aid in identifying subsets of genes associated with externalizing behavior that elucidate biological pathways most relevant to the developmental trajectories of externalizing behavior, including those of relevance during childhood and adolescence. 
There are some limitations in this study including sample size. For a longitudinal neuroimaging study with three measurements sample size is decent, but it is only modest for genetic analyses. A larger study sample may be required to detect more of the generally weak associations between brain structure and externalizing behavior [54,60,75], especially for the regional analysis of many local brain measures that require proper correction for the multiple comparisons to suppress the false positives rate. Second, this study was performed with an MR scanner at 1.5 Tesla. Higher MR field strengths may yield better tissue contrasts and/or allow for more advanced acquisition protocols. However, the field strength was intentionally not upgraded to higher field strengths to minimize effects of scanner differences for longitudinal data acquisition. Third, this study was performed in a longitudinal cohort of typically developing children and adolescents, showing low overall endorsement of externalizing behavior, as expected for the Dutch population [8-9]. Studies with enrichment of clinical samples and extremes of the population might be more sensitive to detect changes in brain structures related to antisocial behavior.

\section{Materials and Methods}

\subsection{Participants}

This project is part of the longitudinal BrainSCALE study on development of brain and cognition in twins and siblings [108], a collaborative project between the Netherlands Twin Register (NTR) [109-111] at the Vrije Universiteit (VU) Amsterdam and University Medical Center Utrecht (UMCU). The BrainSCALE cohort is a representative sample of typically-developing children from the Dutch population. A total of 112 families with twins and an older sibling participated in the study. The twins and siblings were assessed with a battery of cognitive and behavioral tests and extensive neuroimaging protocol when the twins were 9 years old [82]. Two additional waves of follow-up assessments were conducted with largely similar study protocol when the twins were 12 and 17 years old $[37,46,85-87]$.

The BrainSCALE study was approved by the Central Committee on Research Involving Human Subjects of The Netherlands (CCMO), and studies were performed in accordance with the Declaration of Helsinki. Children and their parents signed informed consent forms. Parents were financially compensated for travel expenses, and children received a present or gift voucher at the end of the testing days. In addition, a summary of cognition scores and a printed image of their $\mathrm{T}_{1}$-weighted brain MRI scan, when available, were provided afterwards.

Here, we analyzed the longitudinal data of 221 twins and 99 older siblings that had diffusion MRI scans and/or reports on externalizing behavior from the Child Behavior Checklist (CBCL) or Youth Self Report (YSR) available at any of the three assessments (Table 1). Both the twins and sibling groups were well balanced to investigate potential sex effects. The siblings were on average 2.7 years older than the twins. Structural $\mathrm{T}_{1}$ weighted and diffusion-weighted MRI scans and behavioral assessment by CBCL or YSR were available for most participants (Table 1). Fewer MRI scans were available at the second assessment due to the presence of dental braces incompatible with the magnetic field of the MR scanner. The Youth Self Report (YSR) was not collected at baseline assessment because the twins were below the age for which the YSR was developed (i.e. 11-18 years) [2].

Table 1. Demographics and background information for the BrainSCALE twin cohort

\begin{tabular}{cccc}
\hline Trait & $\begin{array}{c}\text { Assessment \#1: } \\
\text { Age 10 years }\end{array}$ & $\begin{array}{c}\text { Assessment \#1: } \\
\text { Age 13 years }\end{array}$ & $\begin{array}{c}\text { Assessment } \# \mathbf{1 :} \\
\text { Age 18 years }\end{array}$ \\
\hline Families & 112 & 102 & 93 \\
Participants & 311 & 283 & 253 \\
& 214 twins and 97 sib- & 203 twins and 80 sib- & 182 twins and 71 sib- \\
& lings & lings & lings
\end{tabular}




\begin{tabular}{cccc} 
Sex & $149 \mathrm{M}$ and $162 \mathrm{~F}$ & $133 \mathrm{M}$ and $150 \mathrm{~F}$ & $109 \mathrm{M}$ and $144 \mathrm{~F}$ \\
Age $^{1}$ & $10.0 \pm 1.4[9.0 ; 15.0]$ & $13.0 \pm 1.5[11.7 ; 18.0]$ & $18.0 \pm 1.4[16.8 ; 22.9]$ \\
MRI scans & 283 & 178 & 232 \\
CBCL data & 247 & 264 & 241 \\
YSR data & N/A & 253 & 243 \\
\hline
\end{tabular}

${ }^{1}$ Age in years; mean \pm s.d. and range.

No YSR was collected at baseline assessment \#1. At assessment \#1 and assessment \#2, the CBCL was filled out by the mother. At assessment \#3, the CBCL was filled out by either the mother $(179 ; 74 \%)$, the father $(55 ; 23 \%)$, or both parents $(5 ; 2 \%)$, or unknown $(2 ;<1 \%)$. The number of participants for the scores on the scales of the CBCL and YSR might be slightly lower due to missing items (average: 3\%; range: $0 \%$ to 6\%). Abbreviations (in alphabetical order): $C B C L=$ child behavior checklist; $F=$ female; $M=$ male; $M R I=$ magnetic resonance imaging; s.d.= standard deviation; $Y S R=$ youth self report.

\subsection{Externalizing behavior}

Externalizing behavior of the participants was reported by the parents on the Child Behavior Checklist (CBCL) and the participants on the Youth Self Report (YSR) [2]. The CBCL was distributed to the parents at all three assessments; the questionnaire was completed by the mother at the baseline and second assessment, and by either the mother $(74 \%)$, the father $(23 \%)$, or both parents simultaneously $(2 \%)$ at the third assessment. The YSR was distributed to the twins and siblings at the second and third assessment because the twins were below the age for which the YSR was developed (i.e. 11-18 years) at the baseline assessment. Both instruments have largely similar items for the 'Externalizing' scale (Supplementary Table S1). However, three items on the CBCL were not available on the YSR (see supplementary information). In addition, three items were not available on the older 1999 version of the CBCL administered at the baseline assessment to rate the behavior of the older siblings, and were excluded from analysis for the CBCL at all three assessments of the CBCL (see supplementary information). Items were scored on a scale of 0-2 (0: never; 1: occasionally; 2: often). The summary scores for the 'Externalizing' scale were computed by summing the scores of the relevant items (Supplementary Table S1). The scores of individual items with either incomplete, ineligible or ambiguous responses were excluded from analysis, resulting in missing summary scores for some participants (average: 3\%; range: $0 \%$ to $6 \%$ ). Because the families represent a typical cross-section of the Dutch population, the endorsement of externalizing behavior is low overall, and prevalence of clinical disruptive behavioral disorders (DBD) in the participants (i.e. exceeding a raw sum score of approximately 18, depending on sex and age of the participant) is about 5 to $10 \%$; conform expectation within the Dutch population [8-9]. The distributions of the sum scores on the CBCL and YSR scales are positively skewed and may have inflated zero responses (mean skewness: +1.48 ; range skewness: +0.96 to +2.20 ; zero responses: 3\% to 36\%; Supplementary Figure S2). A log-normal distribution described the data better than a normal distribution for the sum scores, which therefore were transformed with a 10-base logarithmic function (Supplementary Figure S2).

\subsection{Brain imaging}

\subsubsection{MRI protocol}

Longitudinal MRI scans of the brain were acquired at the University Medical Center Utrecht on 1.5 Tesla Philips Achieva scanners (Philips, Best, The Netherlands) using the same protocol to minimize the impact of unwanted variation between assessments. A three-dimensional anatomical T1-weighted scan (Spoiled Gradient Echo; TE=4.6 ms; $\mathrm{TR}=30 \mathrm{~ms}$; flip angle $30^{\circ} ; 160-180$ contiguous coronal slices of $1.2 \mathrm{~mm}$; in-plane resolution $1 \times 1 \mathrm{~mm} 2$; acquisition matrix $256 \times 256$ ) of the whole head was made of each individual. Two series of diffusion-weighted (DWI) scans with opposite phase encoding direction (Single Shot Echo Planar Imaging [SS-EPI]; 32 diffusion-weighted volumes with diffusion weighting $b=1000 \mathrm{~s} / \mathrm{mm} 2$ and 32 noncollinear diffusion gradient directions; 4 diffusionunweighted $[\mathrm{b}=0 \mathrm{~s} / \mathrm{mm} 2]$ scans; $\mathrm{TE}=88 \mathrm{~ms} ; \mathrm{TR}=9822 \mathrm{~ms}$; parallel imaging SENSE factor 
2.5; flip angle $90^{\circ} ; 60$ transverse slices of $2.5 \mathrm{~mm}$, no gap, FOV $240 \mathrm{~mm} ; 128 \times 128$ reconstruction matrix; $96 \times 96$ acquisition matrix, no cardiac gating) were acquired for optimal signal-to-noise ratio.

\subsubsection{Volumetric brain measures}

Volumetric brain measures were obtained with FreeSurfer version 5.3 [112]. The structural $\mathrm{T}_{1}$-weighted scans were processed with the cross-sectional pipeline using the default parameters but with a custom brain mask for the individual scans. In this study, we limit ourselves to subcortical structures and cortical regions of the frontal, temporal, and insular cortex based on previous research [55-56,60,103,114]; see Supplementary Figure S3 and Supplementary Table S5 for details. In addition, the following global brain measures were included in the analysis: total brain volume, total cortical gray matter volume, total subcortical gray matter volume, and total cerebral white matter volume.

\subsubsection{White matter microstructural integrity brain measures}

The diffusion-weighted (DWI) scans were processed with the FSL software suite version 6.0.3 [115]. First, the two DWI scans were combined and corrected for possible gradient-induced distortions and motion-related displacement with eddycorrect [116]. The diffusion gradient vectors were rotated accordingly [117]. Next, a diffusion tensor model was fitted to the diffusion pattern at each voxel with $d$ tifit, providing three eigenvectors (representing the three principal directions of diffusion) and corresponding eigenvalues. Fractional anisotropy (FA) and mean diffusivity (MD) values were calculated at each voxel as a measure of microstructural directionality from the eigenvalues [118]. The FA and MD maps were aligned to the FA template of the John Hopkins University (JHU) white matter atlas with $f s l \_r e g$ and applywarp using a non-linear transformation. Finally, mean FA and mean MD were extracted for all 20 major white matter tracts of the John Hopkins University (JHU) white matter tracts atlas provided with FSL; see Supplementary Figure S4 and Supplementary Table S6 for details. In addition, a global measure of mean FA and mean MD for white matter in the brain was extracted for the combined tracts in the atlas.

\subsection{Statistical analysis}

\subsubsection{Main analysis}

First, we analyzed the longitudinal profiles of the broad externalizing score on the Child Behavior Checklist and the Youth Self Report by longitudinal genetic modeling (Figure 4; described in the next section) to determine the dynamics of genetic and environmental factors influencing externalizing behavior throughout adolescence. In all analyses, the log 10 -transformed scores of the externalizing behavior were corrected for sex and linear age effects as fixed effects in the longitudinal genetic model.

Next, we briefly summarize the longitudinal patterns in global and regional brain measures and how they are influenced by genetic factors and the environment. The development and heritability of brain measures in the BrainSCALE cohort have been described elsewhere [37,39,45-46,82-87]. In all analyses, brain measures were corrected for sex, linear and quadratic age effects as fixed effects in the longitudinal genetic model. In addition, total (sub)cortical gray matter volume, total cortical white matter volume, and regional gray matter volumes and white matter integrity brain measures were corrected for their global brain measure (i.e. either total brain volume, global mean fractional anisotropy, or global mean diffusivity). Correcting the regional brain measures for the effect of global brain measures allows separation of region-specific effects from the effect reported in the analysis of the global brain measures.

Finally, we analyzed the phenotypic, genetic, and environmental associations between externalizing scores and brain structure characteristics at three ages in a longitudinal genetic model including variables for both brain and behavior (Figure 4). The associations of their longitudinal change rates, i.e. measured by the difference in behavioral score or brain measure between two assessments, was obtained from this longitudinal genetic model. The model was fitted to each combination of the broad externalizing score 
on the 2 questionnaires and the 6 global and 88 lateralized regional brain measures (21 cortical structures, 3 subcortical structures, and 11 white matter structures; for full list see: Supplementary Table S5 and Supplementary Table S6).

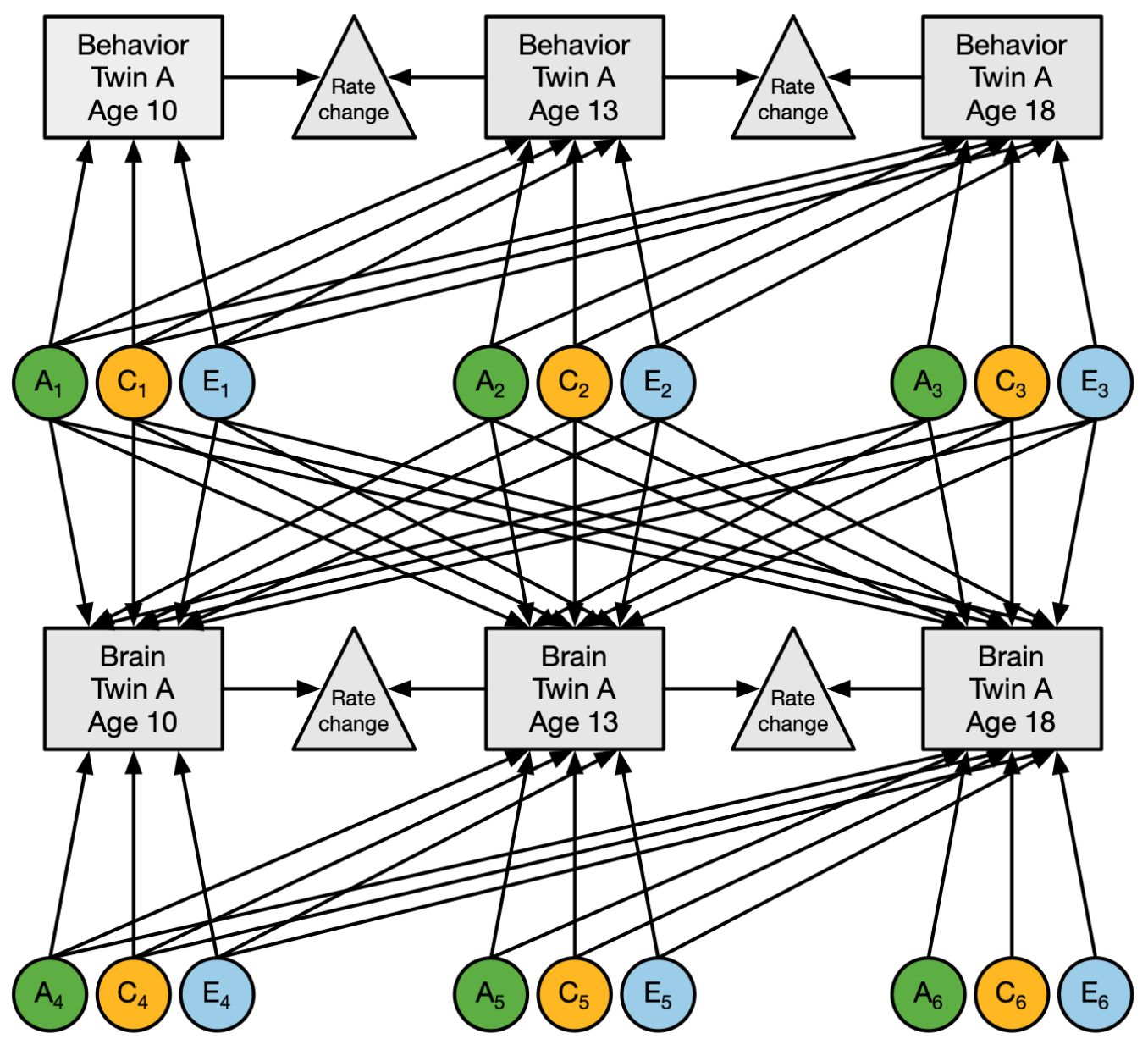

Figure 4. Longitudinal structural equation model applied to the longitudinal data on brain and behavior. Boxes represent observed measures of behavior and/or brain features; circles represent the latent factors for genetic (blue), common environment (orange), and unique environment (green). Path coefficients between the latent factors and observed measures are estimated by the model. For simplicity, this model is shown for only one member of the family. The full model includes three family members, where latent genetic factors between family members are correlated depending on their relationship (i.e., correlation of 1.0 for MZ twins, 0.5 for DZ twins and between twin and sibling pairs), common environmental factors between family members are always shared (i.e., correlation of 1.0), and unique environment factors are uncorrelated by definition.

\subsubsection{Genetic modeling}

Genetic modeling of twin and sibling data provides information on the extent that variation of a trait in the population is explained by genetic factors [119-120]. Monozygotic (MZ) twins share (nearly) 100\% of their genetic material and dizygotic (DZ) twins and full siblings share on average $50 \%$ of their segregating genes. Inclusion of these relatives into an extended twin design, i.e. twins and additional family members, enables decomposition of the phenotypic variance $\left(V_{\mathrm{P}}\right)$ of a trait into three variance components: additive genetic $\left(V_{\mathrm{A}}\right)$, common environmental $\left(V_{\mathrm{C}}\right)$, and unique environmental $\left(V_{\mathrm{E}}\right) \mathrm{com}$ ponents of variance. Additive genetic influences represent additive effects of multiple alleles at different loci across the genome that act upon the phenotypic trait. Common environment represents influences that are shared between twins and siblings from the same family and causes them to be more alike than children who grow up in different families. Unique environmental influences are not shared between family members and may 
include measurement error [121]. If MZ twins resemble each other more than DZ twins and siblings for a trait, then the hypothesis that the trait is influenced by genetic factors is supported. If both MZ and DZ twins are more alike in resemblance than expected based on genetics alone, common environment likely plays a role. This rationale for the analysis of univariate traits can be generalized to also analyze the covariance among multiple traits or multiple time points.

\subsubsection{Structural equation modeling}

The genetic and non-genetic variance components can be estimated by maximum likelihood analyses in a genetic structural equation model (SEM) by specifying a phenotype to be influenced by latent additive genetic factors, and common and unique environmental factors. These factors represent unobserved or latent variables with unit variance where path coefficients, symbolized by $a, c$, and $e$, go from a latent variable to an observed phenotype. The model is identified by putting constraints on the correlation $\boldsymbol{\rho}_{\mathrm{A}}$ between the latent variable A of family members; $\boldsymbol{\rho}_{\mathrm{A}}=1.0$ for $\mathrm{MZ}$ twins, and $\boldsymbol{\rho}_{\mathrm{A}}=0.5$ for DZ twins and twin-sibling pairs. The correlation $\boldsymbol{\rho}_{\mathrm{C}}$ between latent variable $\mathrm{C}$ of family members is constrained to $\boldsymbol{\rho}_{\mathrm{C}}=1.0$ for all twins and siblings from the same family. The latent variable $\mathrm{E}$ is uncorrelated between individuals by definition. The sum of the squared path coefficients $a^{2}, c^{2}$, and $e^{2}$, equals the variance explained by $A, C$, and $E$, where the phenotypic variance $(V)$ of a trait is $V=A+C+E=a^{2}+c^{2}+e^{2}$. Heritability $\left(h^{2}\right)$ of the trait is estimated as the proportion of phenotypic variance $(V)$ that is due to additive genetic variance $(A)$; i.e. $h^{2}=a^{2} /\left(a^{2}+c^{2}+e^{2}\right)$. Structural equation models were fitted to the data in OpenMx version 2.19.1 (https://openmx.ssri.psu.edu/) [122], a package for structural equation modeling in R version 4.0.3 (https://www.r-project.org/) [123]. Model fitting was performed on the raw data with full-information maximum likelihood (FIML).

4.4.4 Genetic and environmental influences on longitudinal externalizing behavior and brain measures

A longitudinal genetic model, with multiple measurements of the same trait acquired at different ages within the same individuals, allows for estimating the dynamics of genetic and environmental influences on traits over age. This model provides estimates of heritability at each age and the genetic and environmental correlations that explain the sources of stable variance between ages. Genetic correlations $\left(r_{a}\right)$ represent the extent to which the same genes influence a trait at different ages: $r_{a}(x, y)=$, $\operatorname{cov} A_{x, y} / \sqrt{\operatorname{var} A_{x} \cdot \operatorname{var} A_{y}}$; where $\operatorname{cov} A_{x, y}$ is the genetic covariance between the trait $x$ and $y$, and $\operatorname{var} A_{x}$ and $\operatorname{var} A_{y}$ the genetic variances of the traits $x$ and $y$; e.g. externalizing behavior at ages 10 and 13 years, or externalizing behavior at age 10 years and total brain volume at age 10 years. The genetic correlation can tell if the genetic factor is completely shared (i.e. pleiotropy), or only partially shared (i.e. incomplete pleiotropy) where at least one of the traits is influenced by a second factor unique to that trait. The longitudinal genetic model can also provide estimates on the heritability of the longitudinal change rates (e.g. changes in behavior or brain measures between repeated assessments) [47]. The heritability of changes rates can be an indication of fluctuating influences of the same genetic factor over time, or the presence of novel genetic influences (i.e. genetic innovation) unique to a specific age $[37,45,85]$. Similarly, the extent to which the same environment influences a trait at different ages can be determined by the correlation of common environmental $\left(r_{\mathrm{c}}\right)$ and unique environmental $\left(r_{\mathrm{e}}\right)$ factors.

\subsubsection{Statistical testing}

The significance of parameters in the longitudinal genetic model was determined by a log-likelihood ratio test by comparing the likelihood of the model with additional constraints on the parameters to the likelihood of the less constrained model. For bounded variance components, the difference in -2 times the log likelihood (-2LL) between models with a single constraint follows a 50:50 mixture of $\chi^{2}$ distributions with zero and one degree of freedom; effectively allowing $p$-values to be cut in half [124]. For the analysis of 
the regional brain measures, a correction for multiple comparison was performed using FDR [125].

\section{Conclusions}

In conclusion, in this study, we have shown the existence of a shared genetic factor between externalizing behavior and brain structures during adolescent development. This is a step towards understanding the genetic etiology of externalizing behavior and the potential mediating role of brain structures. Knowing those would allow research to target key actors in developing diagnostic instruments or interventional therapies to prevent antisocial behavior during childhood and adolescence from escalating and to avoid criminal behavior or incarceration in later life.

Supplementary Materials: The following supporting information can be downloaded at: www.mdpi.com/xxx/s1, Table S1: Items on the Child Behavior Checklist and the Youth Self Report; Figure S1: Endorsement of individual items on the parent-reported Child Behavior Checklist and the self-report Youth Self Report; Figure S2: Distribution of the scores on the externalizing scale of the Child Behavior Checklist and Youth Self Report; Table S2: Correlations between members of monozygotic and dizygotic twin pairs for externalizing behavior scales on the Child Behavior Checklist and Youth Self Report; Table S3: Heritability of externalizing behavior on the Child Behavior Checklist and Youth Self Report using untransformed scores; Table S4: Phenotypic, genetic and environmental correlations between longitudinal assessments of externalizing behavior on the Child Behavior Checklist and Youth Self Report; Table S5: List of cortical and subcortical gray matter volumes from FreeSurfer atlas; Table S6: List of the major white matter tracts in the John Hopkins University atlas; Table S7: Heritability estimates of global brain measures throughout adolescence; Table S8: Heritability estimates of longitudinal changes in global brain measures throughout adolescence; Figure S5: Development of cortical and subcortical gray matter volumes; Figure S6: Development of mean fractional anisotropy and mean diffusivity of the major white matter tracts; Table S9: Phenotypic, genetic, and environmental associations between global brain measures and externalizing behavior; Figure S7: Overview of phenotypic, genetic, and environmental associations between brain measures and externalizing behavior; Data File F1: the phenotypic summary statistics, the heritability estimates, the longitudinal phenotypic, genetic, and environmental associations, and the heritability of the longitudinal change scores of externalizing behavior on the Child Behavior Checklist and the Youth Self Report; Data File F2: the phenotypic summary statistics, the heritability estimates, the longitudinal phenotypic, genetic, and environmental associations, and the heritability of the longitudinal change scores of the global and regional brain measures; Data File F3: the phenotypic, genetic, and environmental associations between externalizing behavior on the Child Behavior Checklist or Youth Self Report with the global or regional brain measures, and phenotypic, genetic, and environmental associations between the longitudinal change scores in externalizing behavior and brain measures.

Author Contributions: Conceptualization, M.K., N.R.M., B.F., D.I.B. and H.E.H.P; methodology, J.T., R.M.B., M.K.; software, J.T., R.M.B., D.I.B.; validation, J.T., R.M.B., and D.I.B.; formal analysis, J.T., M.K., and Z.A.H.; investigation, J.T., M.K., R.M.B., Z.A.H., D.I.B., and H.E.H.P; resources, B.F., D.I.B., and H.E.H.P; data curation, R.M.B., D.E., D.I.B., H.E.H.P; writing-original draft preparation, J.T; writing - review and editing, J.T., M.K., N.R.M., R.M.B., D.E., Z.A.H., B.F., D.I.B., and H.E.H.P; visualization, J.T; supervision, B.F., D.I.B., and H.E.H.P.; project administration, B.F., D.I.B., and H.E.H.P.; funding acquisition, M.K,. B.F., D.I.B. and H.E.H.P.

Funding: This research was supported by funding from the Dutch National Science Agenda NeurolabNL project (grant number 400-17-602); the Consortium on Individual Development (CID) that is funded by the Gravitation program of the Dutch Ministry of Education, Culture, and Science and the Netherlands Organization for Scientific Research (NWO grant number 024.001.003) and the Dutch Research Council Rubicon fellowship (grant number 45219212). We acknowledge the Netherlands Organization for Scientific Research (NWO 51.02.061, NWO 51.02.062, NWO-NIHC Programs of excellence 433-09-220, NWO-MagW 480-04-004, and NWO/SPI 56-464-14192), the European Research Council (ERC-230374), FP7/2007-2013 - ACTION (Aggression in Children: Unraveling gene-environment interplay to inform Treatment and InterventiON strategies) Grant number 602768; Utrecht University (High Potential Grant), and the Netherlands Twin Registry Repository that is funded by the Netherlands Organization for Scientific Research (NWO 480-15-001/674). 
Institutional Review Board Statement: The study was conducted in accordance with the Declaration of Helsinki, and approved by the Institutional Review Board (or Ethics Committee) of University Medical Center Utrecht (CCMO P3.1800C; METC 04/100).

Informed Consent Statement: Informed consent was obtained from all subjects involved in the study.

Data Availability Statement: Requests for access to the data and code used in this study should be directed to the corresponding author.

Acknowledgments: We very warmly thank all participants from the twin families who take part in the Netherlands Twin Register.

Conflicts of Interest: The authors declare no conflict of interest. The funders had no role in the design of the study; in the collection, analyses, or interpretation of data; in the writing of the manuscript, or in the decision to publish the results.

\section{Appendix A}

\section{A.1. Externalizing behavior on the Child Behavior Checklist and Youth Self Report}

\section{A.1.1. Items available on the Child Behavior Checklist and Youth Self Report}

Externalizing behavior of the children was assessed by the parent-reported Child Behavior Checklist (CBCL) and Youth Self Report (YSR) [2]. Both questionnaires have similar items for the 'Externalizing' scale (Supplementary Table S1). Items 73 (SexProbs), 88 (Sulks), and 106 (Vandalism) on the CBCL were not included on the YSR. The sum scores of the CBCL and YSR can therefore not be directly compared. In addition, the items 2 (Alcohol), 28 (BreaksRules), and 99 (Smoking) on the rule-breaking subscale were not on the 1999 version of CBCL administered to the siblings at baseline assessment. These three items were therefore excluded in the analysis of the CBCL scores at all three assessments, but were not excluded in the analysis of the YSR because no direct comparison is made between the CBCL and the YSR.

Supplementary Table S1. Items on the Child Behavior Checklist and the Youth Self Report.

\begin{tabular}{|c|c|c|c|}
\hline & Aggressive behavior scale & & Rule-breaking behavior scale \\
\hline 3 & Argues a lot & $2^{1}$ & $\begin{array}{l}\text { Drinks alcohol without parents' ap- } \\
\text { proval }\end{array}$ \\
\hline 16 & $\begin{array}{l}\text { Cruelty, bullying, or meanness to } \\
\text { others }\end{array}$ & 26 & $\begin{array}{l}\text { Doesn't seem to feel guilty after } \\
\text { misbehaving }\end{array}$ \\
\hline 19 & Demands a lot of attention & $28^{1}$ & $\begin{array}{l}\text { Breaks rules at home, school, or } \\
\text { elsewhere }\end{array}$ \\
\hline 20 & Destroys his/her own things & 39 & $\begin{array}{l}\text { Hangs around with other who get } \\
\text { in trouble }\end{array}$ \\
\hline 21 & $\begin{array}{l}\text { Destroys things belonging to } \\
\text { his/her family or others }\end{array}$ & 43 & Lying or cheating \\
\hline 22 & Disobedient at home & 63 & Prefers being with older kids \\
\hline 23 & Disobedient at school & 67 & Runs away from home \\
\hline 37 & Gets in many fights & 72 & Sets fires \\
\hline 57 & Physically attacks people & $73^{1}$ & Sexual problems \\
\hline 68 & Screams a lot & 81 & Steals at home \\
\hline 86 & Stubborn, sullen, or irritable & 82 & Steals outside the home \\
\hline 87 & $\begin{array}{l}\text { Sudden changes in mood or feel- } \\
\text { ings }\end{array}$ & 90 & Swearing or obscene language \\
\hline $88^{1}$ & Sulks a lot & 96 & Thinks about sex too much \\
\hline 89 & Suspicious & $99^{1}$ & Smokes, chews, sniffs tobacco \\
\hline 94 & Teases a lot & 101 & Truancy, skips school \\
\hline
\end{tabular}


95 Temper tantrums or hot temper

97 Threatens people

104 Unusually loud

1 item not available on YSR. $b$ item not available on the 1999 version of CBCL administered to the siblings at baseline assessment \#1 (age 9 years). Abbreviations (in alphabetical order): CBCL = child behavior checklist; $Y S R=$ youth self report.

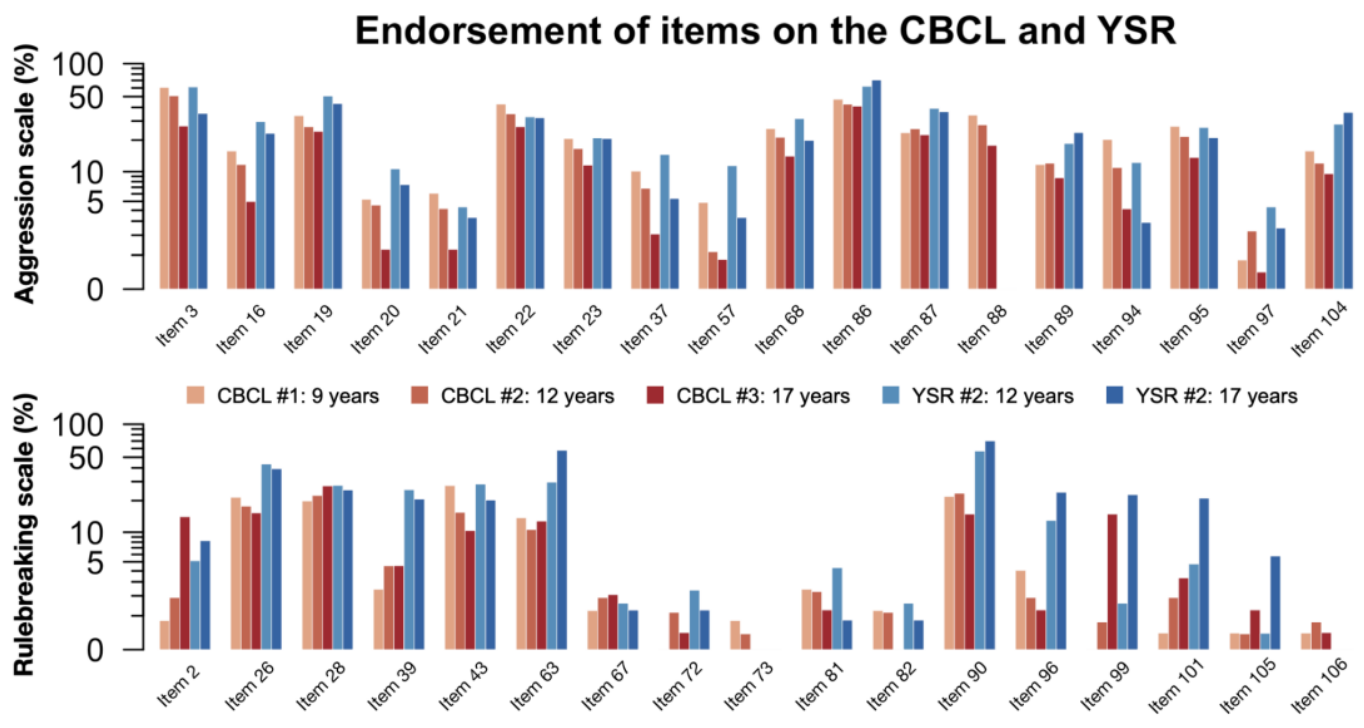

Supplementary Figure S1. Endorsement of individual items on the parent-reported Child Behavior Checklist and the self-report Youth Self Report. A response of '1: occasionally' or '2: often' was considered an endorsement. See Supplementary Table S1 for description of items. Percentage of endorsement is plotted on a logarithmic scale for visualization purposes only. Abbreviation (in alphabetical order): $\mathrm{CBCL}=$ child behavior checklist; $\mathrm{YSR}=$ youth self report.

\section{A.1.2. Distribution of the summary scores of externalizing behavior on the Child Behavior Checklist and Youth Self Report}

The distributions of the sum scores on the CBCL and YSR scales are positively skewed and have inflated zero responses (mean skewness: +1.48 ; range skewness: +0.96 to +2.20; zero responses: 3\% to 36\%; Supplementary Figure S2). A log-normal distribution described the data better than a normal distribution for most sum scores; therefore, the scores were $\log _{10}$-transformed prior to statistical analysis (Supplementary Figure S2).
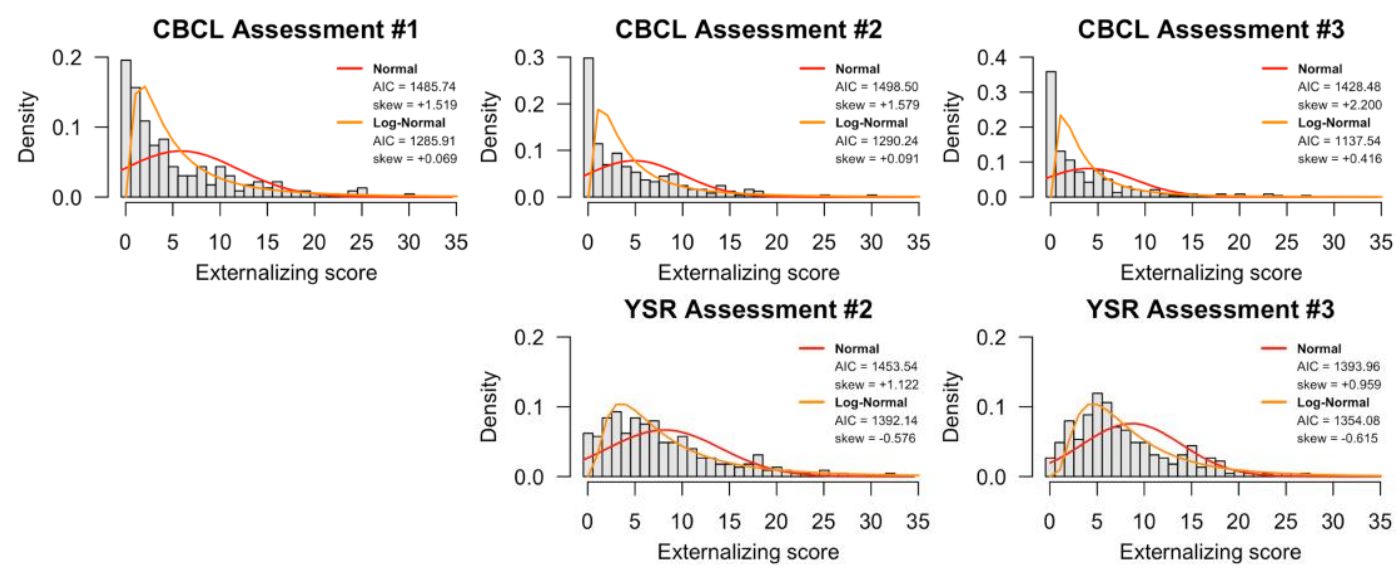

Supplementary Figure S2. Distribution of the scores on the externalizing scale of the CBCL and YSR. A log-normal distribution describes the dispersion of the scores better than a normal 
distribution and reduces the skewness for all scores. No YSR was available at baseline assessment. Abbreviations (in alphabetical order): $\mathrm{CBCL}=$ child behavior checklist; YSR = youth self report.

\section{A.2. Genetic modeling of twin and sibling data}

\section{A.2.2. Correlations of externalizing behavior between pairs of monozygotic and dizygotic twins and their sibling}

The correlation of externalizing behavior between monozygotic twin pairs is on average 1.8x larger than the correlation between dizygotic twin pairs (Supplementary Table S2). This supports the high heritability estimates computed by the genetic models (Table 2; Supplementary Table S3).

Supplementary Table S2. Correlations between members of monozygotic and dizygotic twin pairs for externalizing behavior scales on the Child Behavior Checklist and Youth Self Report.

\begin{tabular}{cccc}
\hline $\begin{array}{c}\text { Trait (Untransformed } \\
\text { scores) }\end{array}$ & MZ twins & DZ twins & Twin-Sibling \\
\hline CBCL Ext \#1 & +0.817 & +0.441 & +0.536 \\
CBCL Ext \#2 & +0.896 & +0.777 & +0.459 \\
CBCL Ext \#3 & +0.718 & +0.329 & +0.296 \\
YSR Ext \#2 & +0.768 & +0.336 & +0.166 \\
YSR Ext \#3 & +0.176 & +0.336 & +0.008 \\
\hline & & & \\
\hline Trait (log10-trans- & MZ twins & DZ twins & Twin-Sibling \\
formed scores) & & & \\
\hline CBCL Ext \#1 & +0.910 & +0.576 & +0.453 \\
CBCL Ext \#2 & +0.954 & +0.676 & +0.482 \\
CBCL Ext \#3 & +0.888 & +0.463 & +0.365 \\
YSR Ext \#2 & +0.758 & +0.371 & +0.163 \\
YSR Ext \#3 & +0.329 & +0.171 & +0.099 \\
\hline
\end{tabular}

Assessment \#1: age 10 years; \#2: age 13 years; \#3: age 18 years. Abbreviations (in alphabetical order): $C B C L$ = child behavior checklist; $\mathrm{DZ}=$ dizygotic; $M Z=$ monozygotic; $Y S R=$ youth self report .

\section{A.2.3. Heritability of the untransformed scores of externalizing behavior on the Child Behavior Checklist and Youth Self Report}

Heritability analysis of the externalizing scale on the CBCL and YSR were repeated using untransformed scores to address the potential bias introduced by a $\log _{10}$-transformation of the scores because of its multiplicative property [121]. A similar pattern of genetic and environmental influences that exists for the $\log _{10}$-transformed scores (Table 2 in main text) is also present for the untransformed scores (Supplementary Table S3). However, heritability estimates are slightly lower than estimates for the $\log _{10}$-transformed scores (average delta $=-18 \%$; range delta $=[-37 \% ;-10 \%]$ ), but remain significant across the board. Estimates for common environment are slightly increased compared to estimates for the $\log _{10}$-transformed scores (average delta $=+5 \%$; range delta $=[-1 \%$; $+18 \%]$ ), and mostly affects the externalizing scores on the parent-reported CBCL at ages 9 and 12 years that barely reached significance using the untransformed scores $\left(c^{2}=27 \%\right.$ and $15 \%$ respectively; $p \sim 0.031$ ).

Supplementary Table S3. Heritability of externalizing behavior on the Child Behavior Checklist and Youth Self Report using untransformed scores.

\begin{tabular}{cccc}
\hline Instrument & Age 10 years & Age 13 years & Age 18 years \\
\hline CBCL Externalizing & $h^{2}=\mathbf{4 3} \%[\mathbf{1 1} \% ; \mathbf{7 1} \%]$ & $h^{2}=\mathbf{7 5 \%}[\mathbf{5 7 \%} \% \mathbf{8 9 \%} \%$ & $h^{2}=\mathbf{6 2} \%[\mathbf{3 9 \%} \mathbf{7 5} \%]$ \\
& $c^{2}=\mathbf{2 7 \%}[\mathbf{3} \% ; \mathbf{5 0} \%]$ & $c^{2}=\mathbf{1 5 \%}[\mathbf{1 0} \% \mathbf{3 2} \%]$ & $c^{2}=4 \%[0 \% ; 22 \%]$ \\
& $e^{2}=30 \%[19 \% ; 47 \%]$ & $e^{2}=11 \%[7 \% ; 18 \%]$ & $e^{2}=34 \%[23 \% ; 49 \%]$
\end{tabular}


YSR Externalizing

$$
\begin{array}{cc}
h^{2}=66 \%[45 \% ; 79 \%] & h^{2}=30 \%[8 \% ; 53 \%] \\
c^{2}=0 \%[0 \% ; 14 \%] & c^{2}=0 \%[0 \% ; 17 \%] \\
e^{2}=34 \%[21 \% ; 55 \%] & e^{2}=70 \%[47 \% ; 92 \%]
\end{array}
$$

Heritability $\left(h^{2}\right)$, common environment $\left(c^{2}\right)$, unique environment $\left(e^{2}\right)$ and their $95 \%$ confidence interval is reported for the longitudinal genetic model on the untransformed scores of the externalizing scale of the CBCL and YSR. Results for the log 10 -transformed scores are reported in Table 2 of the main text. Values printed in boldface are significant $(p<0.05)$; exact $p$-values are reported in Supplementary Data File F1. Abbreviations (in alphabetical order): $C B C L=$ child behavior checklist; $Y S R=$ youth self report.

A.2.4. Phenotypic and genetic correlations between longitudinal assessments of externalizing behavior on the Child Behavior Checklist and Youth Self Report

A pairwise bivariate genetic model was used to estimate the phenotypic $\left(r_{\mathrm{ph}}\right)$, genetic $\left(r_{\mathrm{a}}\right)$, common environmental $\left(r_{\mathrm{c}}\right)$, and unique environmental $\left(r_{\mathrm{e}}\right)$ associations between the externalizing scales on the CBCL and YSR, and between longitudinal assessments of the same instrument at different ages (Supplementary Table S4). Summary scores of the questionnaires showed moderate to good phenotypic associations between assessments (range $r_{\text {ph }}$ between +0.46 to +0.64 ; Supplementary Table S4), The same genetic factor was in part responsible for the behavior assessed by each scale at different ages during adolescent development (range $r$ a between +0.44 to +0.98 ; Supplementary Table S4). Judging by the confidence intervals, the genetic factor for the YSR questionnaire between mean ages 13 and 18 years was completely overlapping. In contrast, the genetic factors for the CBCL questionnaire are only partially overlapping at the different ages, suggesting the presence of unique genetic factors specific for each age group.

\begin{tabular}{|c|c|c|c|}
\hline Instrument & Age $10 \rightarrow 13$ years & Age $13 \rightarrow 18$ years & Age $10 \rightarrow 18$ years \\
\hline \multirow{4}{*}{$\begin{array}{c}\text { CBCL Exter- } \\
\text { nalizing }\end{array}$} & $r_{p h}=+0.63[+0.53 ;+0.72]$ & $r_{p h}=+0.58[+0.47 ;+0.68]$ & $r_{p h}=+0.51[+0.38 ;+0.63]$ \\
\hline & $r_{a}=+0.63[+0.62 ;+0.76]$ & $r_{a}=+0.59[+0.50 ;+0.71]$ & $r_{a}=+0.53[+0.45 ;+0.71]$ \\
\hline & $r_{c}=+1.00[-1.00 ;+1.00]$ & $r_{c}=+1.00[-1.00 ;+1.00]$ & $r_{c}=+1.00[-1.00 ;+1.00]$ \\
\hline & $r_{e}=+0.43[-0.03 ;+0.71]$ & $r_{e}=+0.31[-0.03 ;+0.58]$ & $r_{e}=+0.16[-0.26 ;+0.52]$ \\
\hline \multirow{2}{*}{$\begin{array}{l}\text { YSR External- } \\
\text { izing }\end{array}$} & & $r_{p h}=+0.46[+0.32 ;+0.57]$ & \multirow[b]{2}{*}{$\mathrm{N} / \mathrm{A}$} \\
\hline & $\mathrm{N} / \mathrm{A}$ & $\begin{array}{l}r_{a}=+\mathbf{0 . 8 6}[+\mathbf{0 . 5 7} ;+\mathbf{1 . 0 0}] \\
r_{c}=+0.58[-1.00 ;+1.00] \\
r_{e}=-0.08[-0.40 ;+0.26]\end{array}$ & \\
\hline
\end{tabular}

Supplementary Table S4. Phenotypic, genetic and environmental correlations between longitudinal assessments of externalizing behavior on the Child Behavior Checklist and Youth Self Report.

Phenotypic correction $\left(r_{p h}\right)$, genetic correlation $\left(r_{a}\right)$, common environmental correlation $\left(r_{c}\right)$ and unique environmental correlation $\left(r_{e}\right)$ between assessments and their $95 \%$ confidence interval is reported for the longitudinal genetic model on the $\log _{10}$-transformed scores of the externalizing scale of the CBCL and YSR. Values printed in boldface are significant $(p<0.05)$; exact $p$-values are reported in Supplementary Data File F1. Abbreviations (in alphabetical order): $C B C L=$ child behavior checklist; $Y S R=$ youth self report.

\section{A.3. Magnetic resonance Imaging measures of the brain}

\section{A.3.1. Cortical and subcortical regions previously implicated in externalizing behavior}

Gray matter volumes of cortical and subcortical brain structures were obtained from Freesurfer Desikan-Killiany atlas and Aseg atlas [112]. We limit ourselves to subcortical structures and cortical regions on the frontal, temporal, and insular cortex based on previous research (Supplementary Figure S3; Supplementary Table S5) $[55-56,60,103,114]$.

Supplementary Table S5. List of cortical and subcortical gray matter volumes from FreeSurfer atlas.

\begin{tabular}{ccc}
\hline ID & Abbreviation & Region \\
\hline $1 / 2$ & SFG $[\mathrm{L} / \mathrm{R}]$ & Superior frontal gyrus \\
$3 / 4$ & cMFG $[\mathrm{L} / \mathrm{R}]$ & Caudal middle frontal gyrus
\end{tabular}




\begin{tabular}{|c|c|c|}
\hline $5 / 6$ & rMFG [L/R] & Rostral middle frontal gyrus \\
\hline $7 / 8$ & $\mathrm{FP}[\mathrm{L} / \mathrm{R}]$ & Frontal pole \\
\hline $9 / 10$ & $\mathrm{mOFG}[\mathrm{L} / \mathrm{R}]$ & Medial orbitofrontal gyrus \\
\hline $11 / 12$ & lOFG [L/R] & Lateral orbitofrontal gyrus \\
\hline $13 / 14$ & Opr [L/R] & Pars opercularis \\
\hline $15 / 16$ & Orb [L/R] & Pars orbitalis \\
\hline $17 / 18$ & Tri [L/R] & Pars triangularis \\
\hline $19 / 20$ & TTG [L/R] & Transverse temporal gyrus \\
\hline $21 / 22$ & STG [L/R] & Superior temporal gyrus \\
\hline $23 / 24$ & Bank [L/R] & Banks of superior temporal gyrus \\
\hline $25 / 26$ & MTG [L/R] & Middle temporal gyrus \\
\hline $27 / 28$ & $\mathrm{TP}$ [L/R] & Temporal pole \\
\hline $29 / 30$ & ITG [L/R] & Inferior temporal gyrus \\
\hline $31 / 32$ & Ent $[\mathrm{L} / \mathrm{R}]$ & Entorhinal gyrus \\
\hline $33 / 34$ & $\mathrm{FG}[\mathrm{L} / \mathrm{R}]$ & Fusiform gyrus \\
\hline $35 / 36$ & $\operatorname{Par}[\mathrm{L} / \mathrm{R}]$ & Parahippocampal gyrus \\
\hline $37 / 38$ & $\mathrm{ACc}[\mathrm{L} / \mathrm{R}]$ & Caudal anterior cingulate gyrus \\
\hline $39 / 40$ & $\mathrm{ACr}[\mathrm{L} / \mathrm{R}$ & Rostral anterior cingulate gyrus \\
\hline $41 / 42$ & Ins [L/R] & Insula \\
\hline $43 / 44$ & AMY [L/R] & Amygdala \\
\hline $45 / 46$ & $\mathrm{HIP}$ [L/R] & Hippocampus \\
\hline $47 / 48$ & PUT [L/R] & Putamen \\
\hline
\end{tabular}

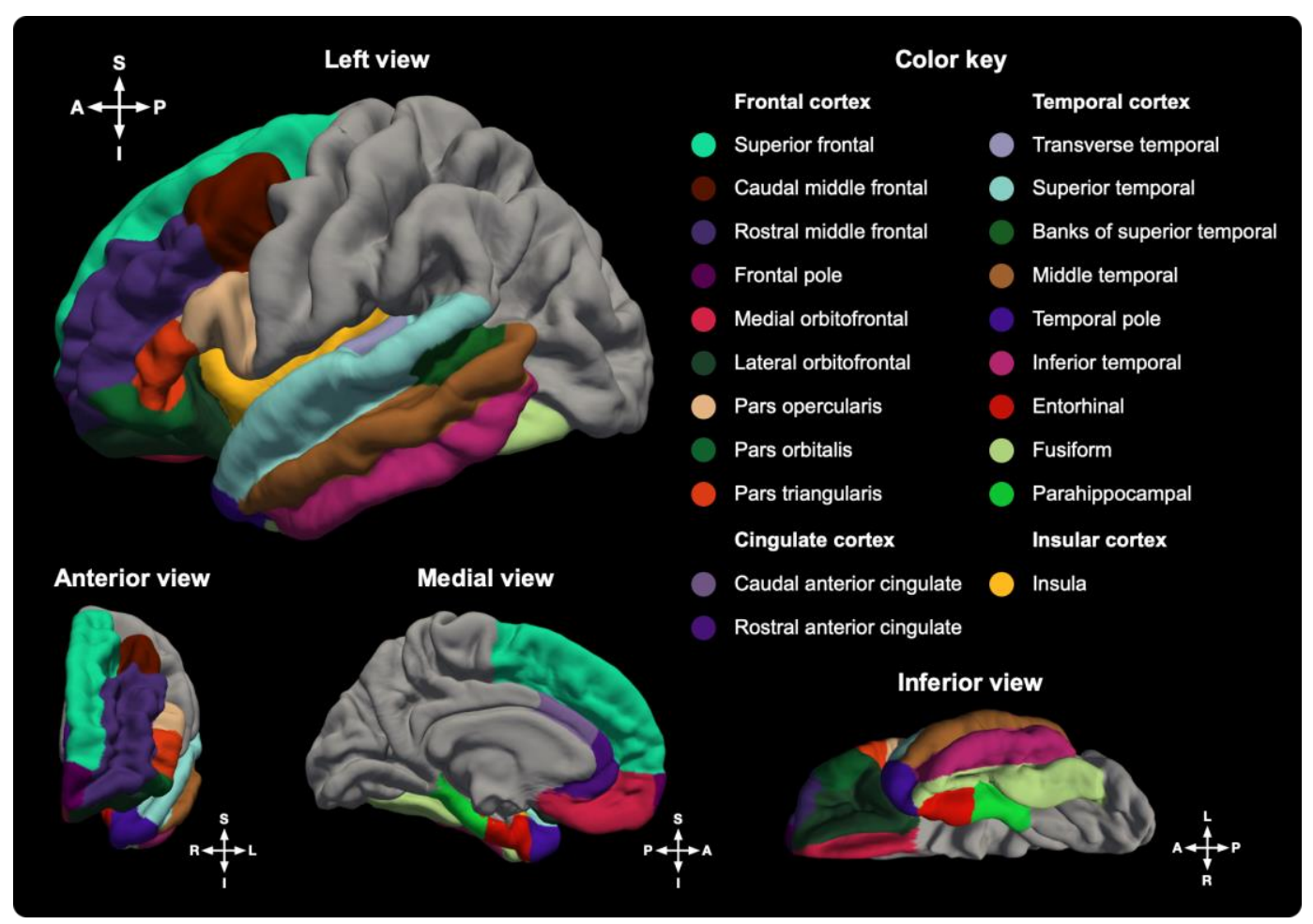




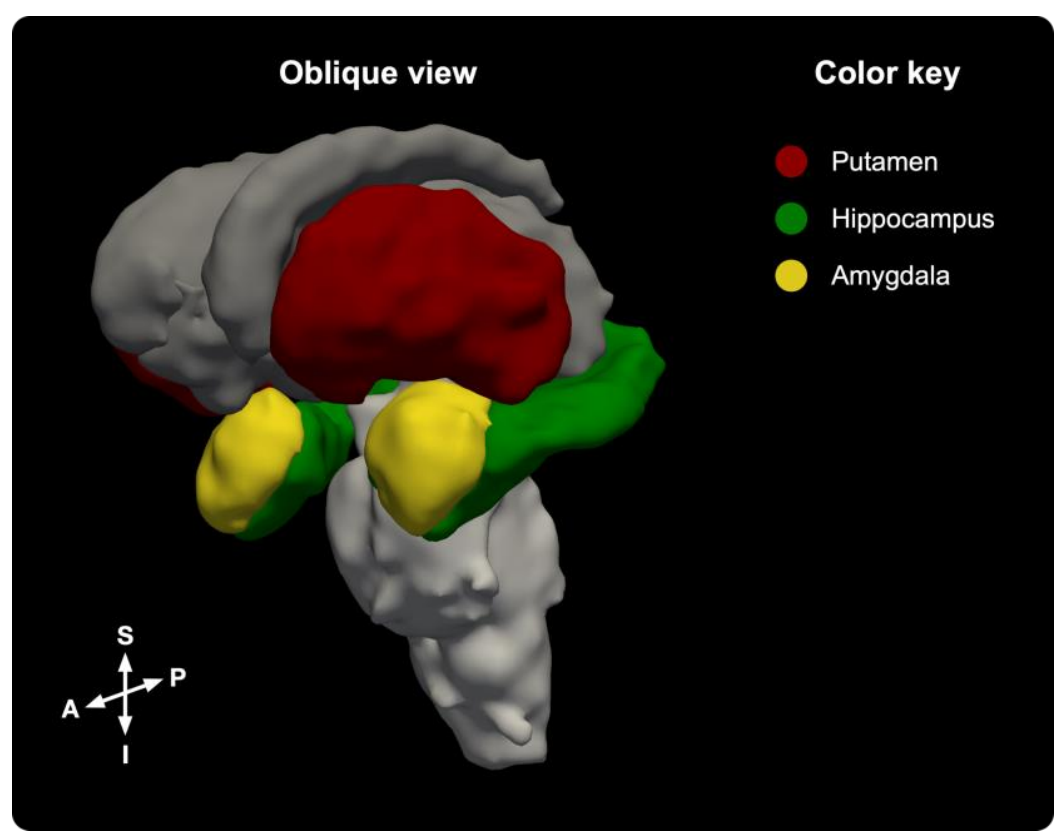

Supplementary Figure S3. A 3D representation of the cortical regions on the frontal, temporal and insular cortex and subcortical structures of the brain used in the analyses. Abbreviation (in alphabetical order): $\mathrm{A}=$ anterior; $\mathrm{I}=$ inferior; $\mathrm{L}=$ left; $\mathrm{P}=$ posterior; $\mathrm{S}=$ superior.

\section{A.3.2. Major white matter tracts of the human brain in the John Hopkins University atlas}

The John Hopkins University (JHU) white matter atlas provides manual annotation for 20 major white matter tracts (Supplementary Table S6; Supplementary Figure S4). The atlas consists of 9 bilateral tracts and 2 commissural tracts of the brain. A global brain measure is defined by the region of all white matter tracts combined.

Supplementary Table S6. List of the major white matter tracts in the John Hopkins University atlas.

\begin{tabular}{cccc}
\hline ID & Abbreviation & Full name & Volume $\left[\mathbf{m m}^{3}\right]$ \\
\hline $1 / 2$ & ATR [L/R] & Anterior thalamic radiation & $8706 / 8014$ \\
$3 / 4$ & CST [L/R] & Corticospinal tract & $5727 / 5012$ \\
$5 / 6$ & CGC [L/R] & Cingulum (cingulate gyrus) & $1903 / 974$ \\
$7 / 8$ & CGH [L/R] & Cingulum (hippocampus) & $557 / 798$ \\
$9 / 10$ & IFOF [L/R] & Inferior fronto-occipital fasciculus & $5794 / 6957$ \\
$11 / 12$ & ILF [L/R] & Inferior longitudinal fasciculus & $5826 / 3725$ \\
$13 / 14$ & SLF [L/R] & Superior longitudinal fasciculus & $9870 / 7787$ \\
$15 / 16$ & SLFtemp [L/R] & Superior longitudinal fasciculus & $76 / 298$ \\
& & (temporal part) \\
$17 / 18$ & UNC [L/R] & Uncinate fasciculus & $1201 / 784$ \\
19 & FMajor & Forceps major \\
20 & FMinor & Forceps minor & 6458 \\
- & Global & All major white matter tracts com- & 19407 \\
\multicolumn{4}{c}{ bined } \\
\hline
\end{tabular}

Abbreviations (in alphabetical order): Abbr = abbreviation; $L=$ left; $R=$ right. 


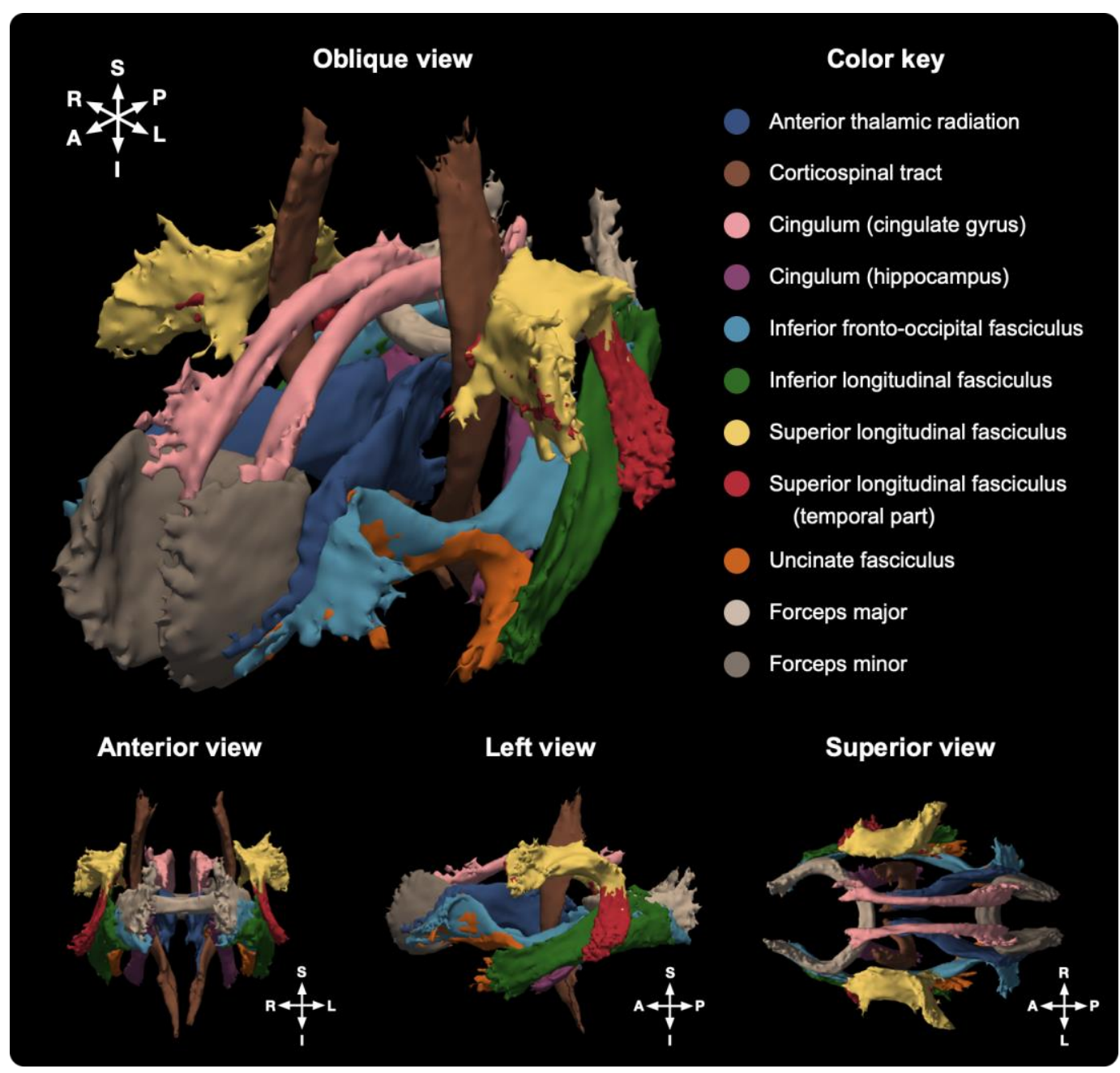

Supplementary Figure S4. A 3D representation of the major white matter tracts in the John Hopkins University atlas.

\section{A.3.3. Heritability of global brain development during adolescence}

Heritability for the six global brain measures is generally high ( $h^{2}$ range: $34 \%$ to $93 \%$; Supplementary Table S7), and influences from common environment shared between family members only significant for global mean diffusivity ( $c^{2}$ range: $10 \%$ to $28 \%$; Supplementary Table S7). Longitudinal change rates in total brain volume between all ages, and global mean diffusivity between ages 10 to 13 years are also heritable $\left(h_{\Delta}^{2}\right.$ range: $33 \%$ to $64 \%$; Supplementary Table S8). In addition, longitudinal change rates in global mean diffusivity between all ages is influenced by the common environment $\left(c_{\Delta}^{2}\right.$ range: $10 \%$ to 28\%; Supplementary Table S8).

Supplementary Table S7. Heritability estimates of global brain measures throughout adolescence.

\begin{tabular}{|c|c|c|c|}
\hline Brain s & Age 10 years & Age 13 years & Age 18 years \\
\hline Total & $\begin{array}{c}h^{2}=\mathbf{8 9} \% \text { [75\%; 94\%] } \\
c^{2}=2 \%[0 \% ; 16 \%] \\
e^{2}=8 \%[6 \% ; 13 \%]\end{array}$ & $\begin{array}{c}h^{2}=\mathbf{9 2} \%[\mathbf{7 9} \% ; \mathbf{9 5 \%}] \\
c^{2}=1 \%[0 \% ; 14 \%] \\
e^{2}=8 \%[5 \% ; 12 \%]\end{array}$ & $\begin{array}{c}h^{2}=\mathbf{9 3} \%[\mathbf{7 7 \%} ; \mathbf{9 7 \%}] \\
c^{2}=3 \%[0 \% ; 20 \%] \\
e^{2}=4 \%[2 \% ; 6 \%]\end{array}$ \\
\hline $\begin{array}{r}\text { Total } \\
\text { mat }\end{array}$ & $\begin{array}{c}h^{2}=\mathbf{6 7 \%}[49 \% ; 78 \%] \\
c^{2}=0 \%[0 \% ; 14 \%] \\
e^{2}=32 \%[21 \% ; 45 \%]\end{array}$ & $\begin{array}{c}h^{2}=\mathbf{4 9 \%}[\mathbf{2 6} \% ; \mathbf{7 7 \%}] \\
c^{2}=20 \%[0 \% ; 42 \%] \\
e^{2}=31 \%[21 \% ; 43 \%]\end{array}$ & $\begin{array}{c}h^{2}=67 \%[44 \% ; 78 \%] \\
c^{2}=3 \%[0 \% ; 25 \%] \\
e^{2}=30 \%[21 \% ; 41 \%]\end{array}$ \\
\hline $\begin{array}{l}\text { Total subcortical gray } \\
\text { matter volume }{ }^{1}\end{array}$ & $\begin{array}{c}h^{2}=\mathbf{6 1 \%}[\mathbf{3 8 \%} ; \mathbf{7 4 \%}] \\
c^{2}=5 \%[0 \% ; 22 \%] \\
e^{2}=34 \%[24 \% ; 47 \%]\end{array}$ & $\begin{array}{c}h^{2}=59 \%[32 \% ; 80 \%] \\
c^{2}=14 \%[0 \% ; 36 \%] \\
e^{2}=27 \%[18 \% ; 40 \%]\end{array}$ & $\begin{array}{c}h^{2}=63 \%[37 \% ; 83 \%] \\
c^{2}=14 \%[0 \% ; 35 \%] \\
e^{2}=23 \%[16 \% ; 35 \%]\end{array}$ \\
\hline
\end{tabular}




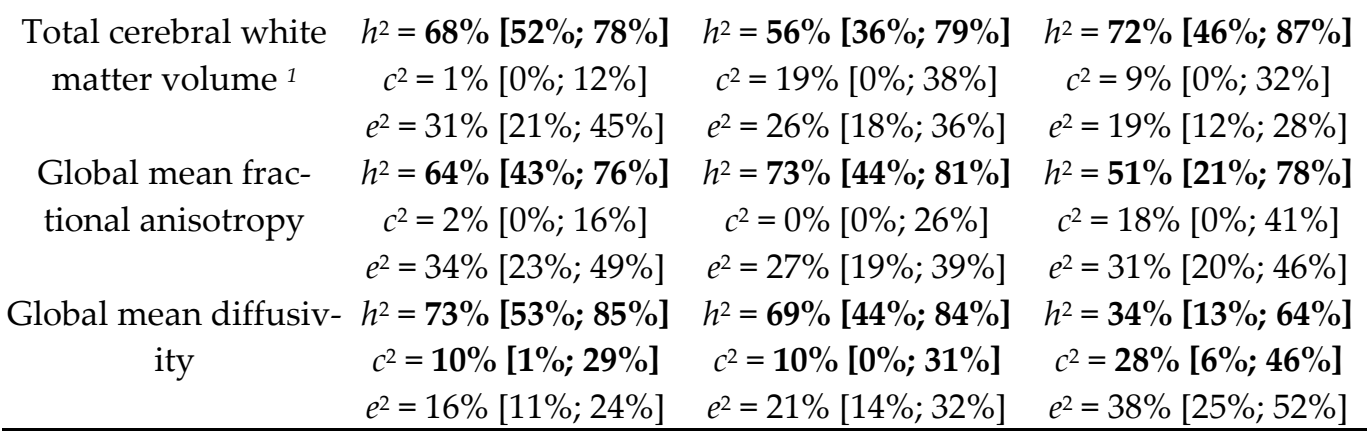

${ }^{1}$ Following regression of total brain volume.

Heritability or common environmental estimates printed in boldface are significant $(p<0.05)$; exact $p$-values are reported in Supplementary Data File F2. Abbreviations (in alphabetical order): $h^{2}=$ heritability, or proportion of phenotypic variation attributed to additive genetic influences; $c^{2}=$ proportion of phenotypic variation attributed to common environmental influences; $e^{2}=$ proportion of phenotypic variation attributed to unique environmental influences.

Supplementary Table S8. Heritability estimates of longitudinal changes in global brain measures throughout adolescence.

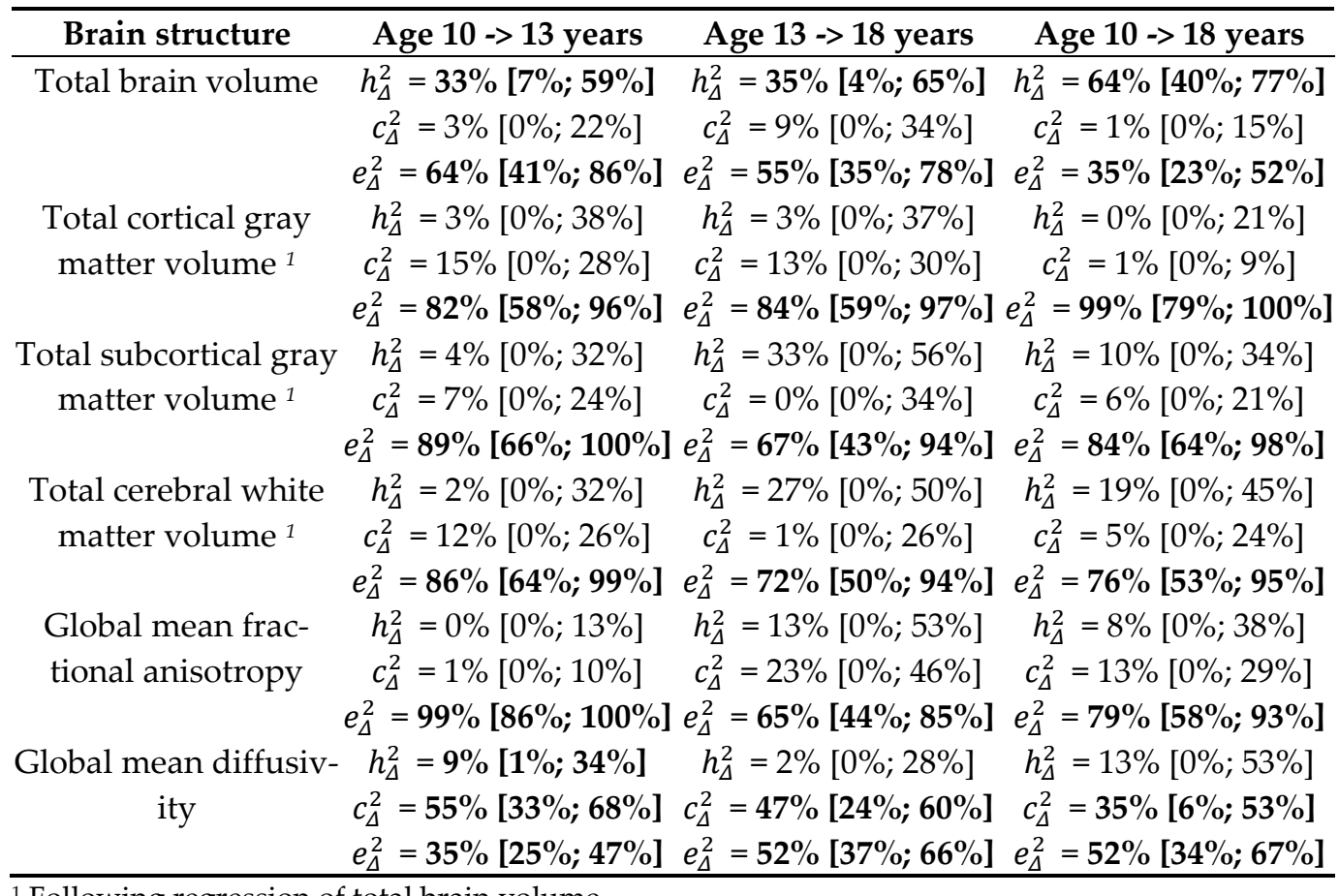

${ }^{1}$ Following regression of total brain volume.

Heritability or common or unique environmental estimates of the longitudinal change scores printed in boldface are significant $(p<0.05)$; exact $p$-values are reported in Supplementary Data File F2. Abbreviations (in alphabetical order): $h_{\Delta}^{2}=$ heritable of longitudinal change rates; $c_{\Delta}^{2}=$ proportion of common environmental influences on longitudinal change rates; $e_{\Delta}^{2}=$ proportion of unique environmental influences on longitudinal change rate.

\section{A.3.4. Longitudinal development of brain measures during adolesence}

Longitudinal development of gray matter volume of regional (sub)cortical brain structures and mean fractional anisotropy (FA) and mean diffusivity (MD) of the major white matter tracts (Supplementary Figure S5; Supplementary Figure S6). Exact values are reported in Supplementary Data File F2. 

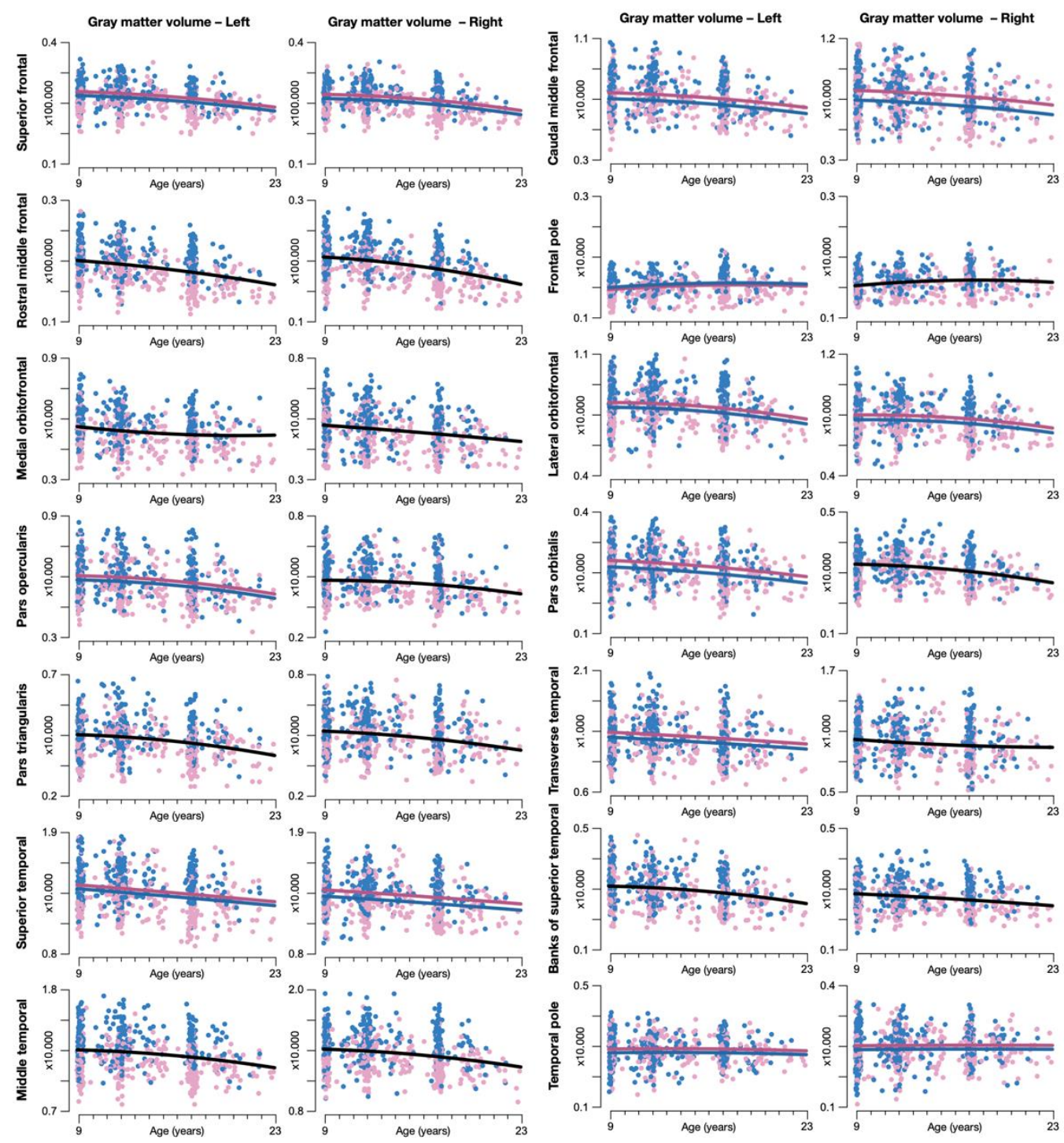

Supplementary Figure S5 (continued on next page). Development of cortical and subcortical gray matter volumes. Abbreviation (in alphabetical order): $\mathrm{CI}=$ confidence interval; $\mathrm{n} . \mathrm{s} .=$ not significant. 

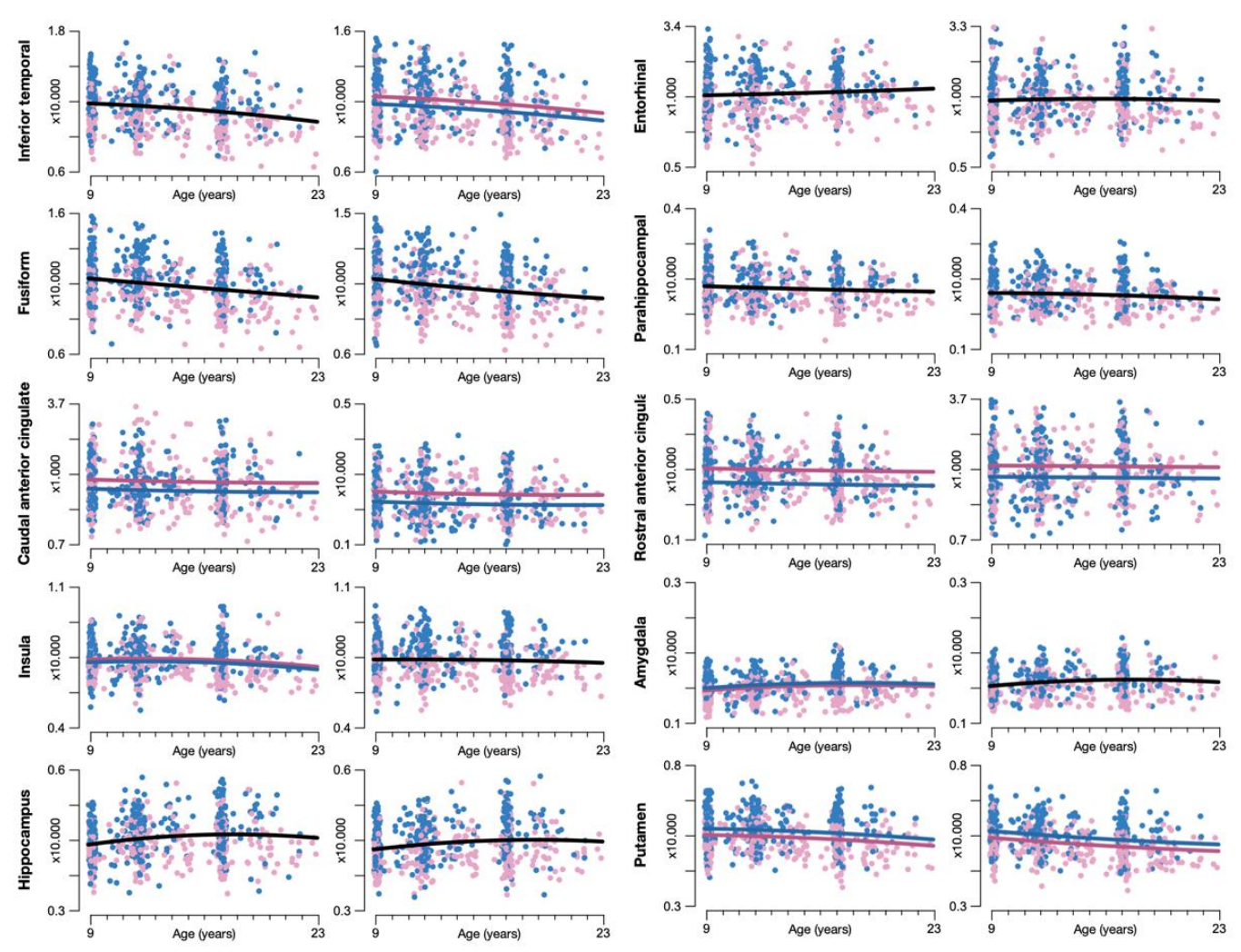

\begin{tabular}{|llll|}
\multicolumn{4}{c|}{ Legend } \\
\hline - Girls & - Sex regression girls with $95 \% \mathrm{Cl}$ & - Twins & - Age regression with $95 \% \mathrm{Cl}$ \\
- Boys & - Sex regression boys with $95 \% \mathrm{Cl}$ & $\begin{array}{l}\Delta \text { Siblings } \\
- \text { Longitudinal }\end{array}$ & $\ldots$ Age regression with $95 \% \mathrm{Cl}$ [n.s.]
\end{tabular}

Supplementary Figure S5 (continued from previous page). Development of cortical and subcortical gray matter volumes. Abbreviation (in alphabetical order): $\mathrm{CI}=$ confidence interval; $\mathrm{n} . \mathrm{s}$. $=$ not significant.
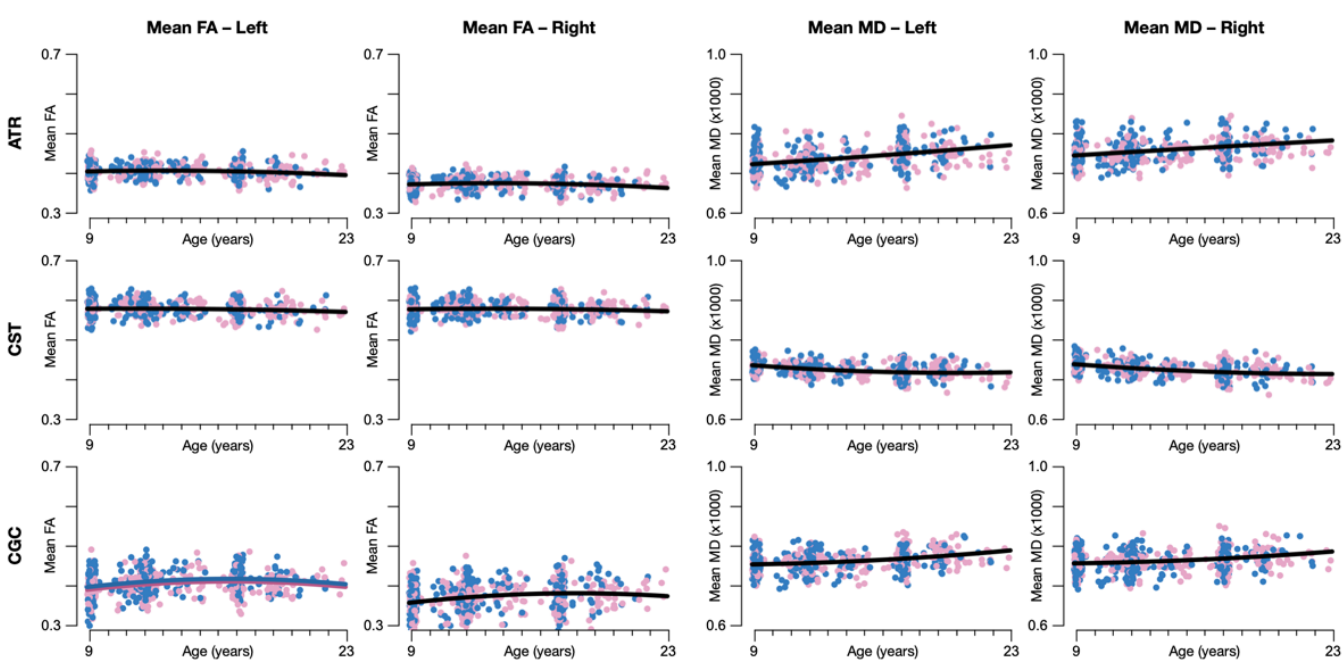

Supplementary Figure S6 (continued on next page). Development of mean fractional anisotropy and mean diffusivity of the major white matter tracts. Abbreviations (in alphabetical order): ATR = anterior thalamic radiation; $\mathrm{CGC}=$ cingulum (cingulate gyrus); $\mathrm{CGH}=$ cingulum (hippocampal); $\mathrm{CI}$ $=$ confidence interval; $\mathrm{CST}=$ corticospinal tract; FA = fractional anisotropy; Fmajor = forceps major; Fminor $=$ forceps minor; ILF $=$ inferior longitudinal fasciculus; IFOF = inferior fronto-occipital fasciculus; $\mathrm{MD}=$ mean diffusivity; $\mathrm{SLF}=$ superior longitudinal fasciculus; SLFtemp = superior longitudinal fasciculus (temporal part); $\mathrm{UNC}=$ uncinate fasciculus. 

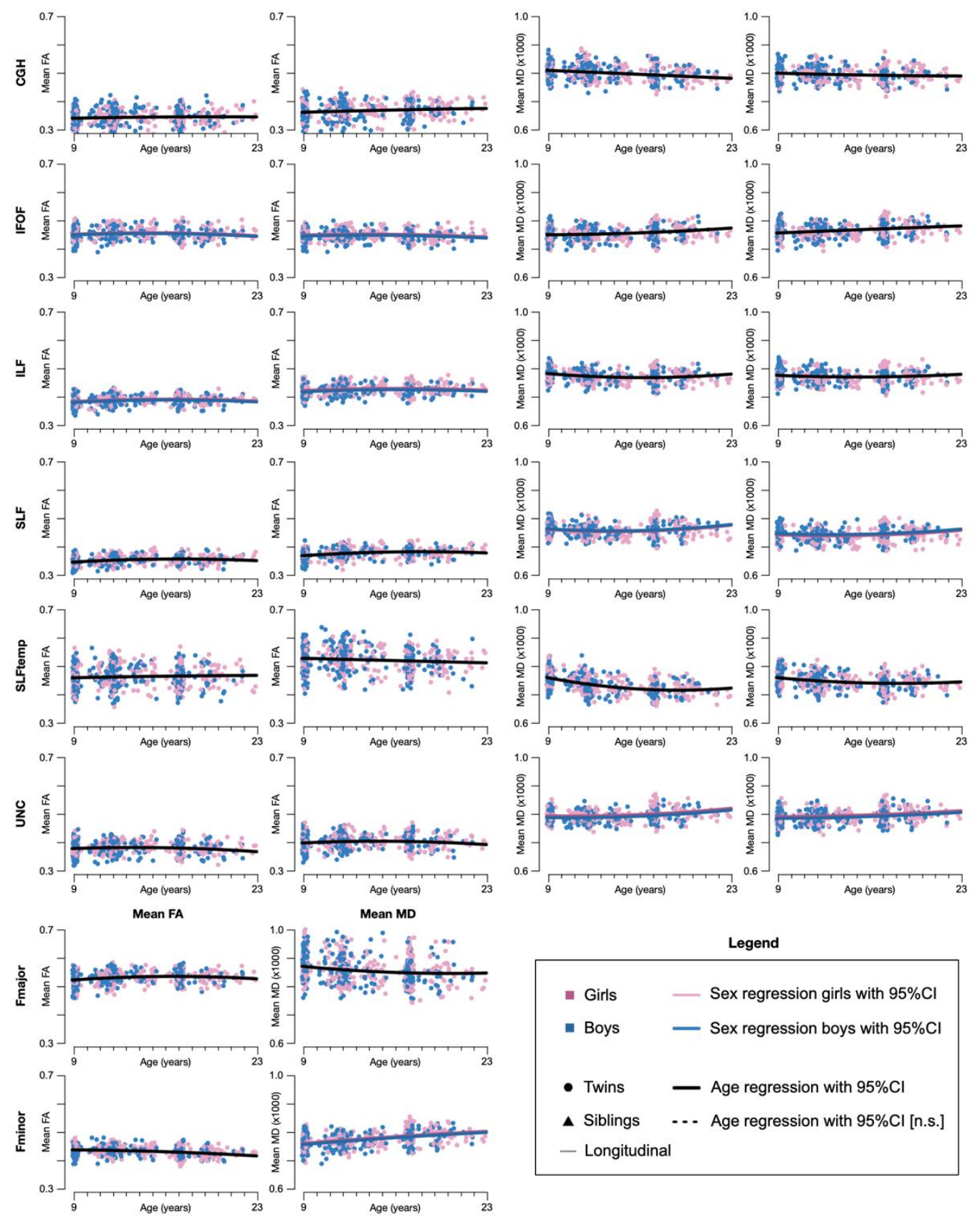

\ Siblings $\quad$-.. Age regression with $95 \% \mathrm{Cl}[$ [n.s.]

- Longitudinal

Supplementary Figure S6 (continued from previous page). Development of mean fractional anisotropy and mean diffusivity of the major white matter tracts. Abbreviations (in alphabetical order): $\mathrm{ATR}=$ anterior thalamic radiation; $\mathrm{CGC}=$ cingulum (cingulate gyrus); $\mathrm{CGH}=$ cingulum (hippocampal); $\mathrm{CI}=$ confidence interval; $\mathrm{CST}=$ corticospinal tract; $\mathrm{FA}=$ fractional anisotropy; Fmajor $=$ forceps major; Fminor = forceps minor; ILF = inferior longitudinal fasciculus; IFOF = inferior fronto-occipital fasciculus; $\mathrm{MD}$ = mean diffusivity; SLF = superior longitudinal fasciculus; SLFtemp = superior longitudinal fasciculus (temporal part); UNC = uncinate fasciculus.

\section{A.4. Associations between externalizing behavior and global brain structures}

The associations between brain structures and externalizing behavior were sparse and occurred mainly during mid-adolescence, around age 13 years, although the direction and magnitude of the associations were overall consistent throughout adolescence (Supplementary Figure S7; Supplementary Table S9; Supplementary Data File F3) 
Supplementary Table S9. Phenotypic, genetic, and environmental associations between global brain measures and externalizing behavior.

\begin{tabular}{|c|c|c|c|c|}
\hline $\begin{array}{l}\text { Brain structure vs. } \\
\text { CBCL Externalizing }\end{array}$ & & Age 10 years & Age 13 years & Age 18 \\
\hline \multirow[t]{4}{*}{ Total brain volume } & $r_{p h}=$ & $-0.06[-0.21 ;+0.09]$ & $-0.11[-0.25 ;+0.04]$ & $-0.06[-0.20 ;+0.09]$ \\
\hline & $r_{a}=$ & $-0.11[-0.30 ;+0.04]$ & $-0.12[-0.28 ;+0.05]$ & $-0.07[-0.24 ;+0.13]$ \\
\hline & $r_{c}=$ & $+0.74[-1.00 ;+1.00]$ & $+0.56[-1.00 ;+1.00]$ & $+0.36[-0.93 ;+1.00]$ \\
\hline & $r_{e}=$ & $-0.14[-0.50 ;+0.25]$ & $-0.22[-0.53 ;+0.15]$ & $-0.17[-0.48 ;+0.18]$ \\
\hline \multirow{4}{*}{$\begin{array}{l}\text { Total cortical gray } \\
\text { matter volume }{ }^{1}\end{array}$} & $r_{p h}=$ & $-0.02[-0.17 ;+0.12]$ & $-0.20[-0.35 ;-0.04]$ & $+0.07[-0.08 ;+0.21]$ \\
\hline & $r_{a}=$ & $+0.08[-0.18 ;+0.39]$ & $-0.01[-0.04 ;+0.02]$ & $+0.18[-0.05 ;+0.42]$ \\
\hline & $r_{c}=$ & $-0.91[-1.00 ;+1.00]$ & $-0.97[-1.00 ;-0.27]$ & $-0.94[-1.00 ;+1.00]$ \\
\hline & $r_{e}=$ & $+0.06[-0.34 ;+0.44]$ & $-0.12[-0.41 ;+0.18]$ & $+0.14[-0.20 ;+0.42]$ \\
\hline \multirow{4}{*}{$\begin{array}{l}\text { Total subcortical gray } \\
\text { matter volume }{ }^{1}\end{array}$} & $r_{p h}=$ & $-0.05[-0.20 ;+0.10]$ & $-0.05[-0.20 ;+0.10]$ & $-0.05[-0.20 ;+0.10]$ \\
\hline & $r_{a}=$ & $-0.11[-0.42 ;+0.17]$ & $-0.08[-0.35 ;+0.07]$ & $-0.07[-0.35 ;+0.19]$ \\
\hline & $r_{c}=$ & $+0.01[-1.00 ;+1.00]$ & $+0.12[-1.00 ;+1.00]$ & $-0.33[-1.00 ;+1.00]$ \\
\hline & $r_{e}=$ & $+0.12[-0.23 ;+0.42]$ & $-0.03[-0.33 ;+0.27]$ & $+0.17[-0.16 ;+0.45]$ \\
\hline \multirow{4}{*}{$\begin{array}{l}\text { Total cerebral white } \\
\text { matter volume }{ }^{1}\end{array}$} & $r_{p h}=$ & $+0.03[-0.11 ;+0.18]$ & $+0.15[-0.00 ;+0.31]$ & $-0.09[-0.24 ;+0.06]$ \\
\hline & $r_{a}=$ & $-0.05[-0.40 ;+0.21]$ & $+0.01[-0.24 ;+0.26]$ & $-0.19[-0.41 ;+0.07]$ \\
\hline & $r_{c}=$ & $+0.98[-1.00 ;+1.00]$ & $+0.93[-1.00 ;+1.00]$ & $+0.68[-1.00 ;+1.00]$ \\
\hline & $r_{e}=$ & $-0.06[-0.46 ;+0.35]$ & $+0.08[-0.21 ;+0.38]$ & $-0.08[-0.41 ;+0.25]$ \\
\hline \multirow{4}{*}{$\begin{array}{l}\text { Global mean frac- } \\
\text { tional anisotropy }\end{array}$} & $r_{p h}=$ & $+0.18[+0.02 ;+0.32]$ & $+0.20[+0.04 ;+0.35]$ & $-0.01[-0.16 ;+0.15]$ \\
\hline & $r_{a}=$ & $+0.09[-0.25 ;+0.37]$ & $+0.10[-0.16 ;+0.34]$ & $+0.01[-0.33 ;+0.30]$ \\
\hline & $r_{c}=$ & $+0.77[-1.00 ;+1.00]$ & $+0.98[-1.00 ;+1.00]$ & $-0.26[-1.00 ;+1.00]$ \\
\hline & $r_{e}=$ & $+0.23[-0.18 ;+0.57]$ & $+0.06[-0.25 ;+0.35]$ & $+0.13[-0.20 ;+0.43]$ \\
\hline \multirow{4}{*}{$\begin{array}{l}\text { Global mean diffu- } \\
\text { sivity }\end{array}$} & $r_{p h}=$ & $-0.13[-0.28 ;+0.03]$ & $-0.20[-0.35 ;-0.04]$ & $+0.04[-0.11 ;+0.20]$ \\
\hline & $r_{a}=$ & $-0.23[-0.50 ;+0.04]$ & $-0.26[-0.48 ;-0.17]$ & $-0.12[-0.51 ;+0.23]$ \\
\hline & $r_{c}=$ & $+0.32[-1.00 ;+1.00]$ & $+0.29[-1.00 ;+1.00]$ & $+0.87[-1.00 ;+1.00]$ \\
\hline & $r_{e}=$ & $-0.03[-0.35 ;+0.30]$ & $-0.19[-0.48 ;+0.13]$ & $-0.12[-0.41 ;+0.20]$ \\
\hline
\end{tabular}

\begin{tabular}{|c|c|c|c|c|}
\hline $\begin{array}{l}\text { Brain structure vs. } \\
\text { YSR Externalizing }\end{array}$ & & Age 10 years & Age 13 years & Age 18 years \\
\hline \multirow[t]{4}{*}{ Total brain volume } & $r_{p h}=$ & \multirow{4}{*}{$\mathrm{N} / \mathrm{A}$} & $-0.13[-0.27 ;+0.02]$ & $-0.02[-0.16 ;+0.12]$ \\
\hline & $r_{a}=$ & & $-0.14[-0.33 ;+0.08]$ & $-0.07[-0.27 ;+0.25]$ \\
\hline & $r_{c}=$ & & $+1.00[-1.00 ;+1.00]$ & $+1.00[-1.00 ;+1.00]$ \\
\hline & $r_{e}=$ & & $-0.22[-0.55 ;+0.18]$ & $-0.07[-0.38 ;+0.26]$ \\
\hline \multirow{4}{*}{$\begin{array}{l}\text { Total cortical gray } \\
\text { matter volume }{ }^{1}\end{array}$} & $r_{p h}=$ & \multirow{4}{*}{$\mathrm{N} / \mathrm{A}$} & $-0.17[-0.32 ;-0.01]$ & $+0.05[-0.10 ;+0.19]$ \\
\hline & $r_{a}=$ & & $-0.20[-0.59 ;+0.13]$ & $+0.08[-0.61 ;+0.58]$ \\
\hline & $r_{c}=$ & & $+0.98[-1.00 ;+1.00]$ & $-1.00[-1.00 ;+1.00]$ \\
\hline & $r_{e}=$ & & $-0.12[-0.46 ;+0.24]$ & $+0.04[-0.25 ;+0.33]$ \\
\hline \multirow{4}{*}{$\begin{array}{c}\text { Total subcortical gray } \\
\text { matter volume }{ }^{1}\end{array}$} & $r_{p h}=$ & \multirow{4}{*}{$\mathrm{N} / \mathrm{A}$} & $-0.07[-0.22 ;+0.08]$ & $-0.13[-0.27 ;+0.02]$ \\
\hline & $r_{a}=$ & & $-0.14[-0.60 ;-0.14]$ & $-0.08[-0.73 ;+0.59]$ \\
\hline & $r_{c}=$ & & $-0.73[-1.00 ;+1.00]$ & $-1.00[-1.00 ;+1.00]$ \\
\hline & $r_{e}=$ & & $+0.19[-0.14 ;+0.50]$ & $+0.02[-0.28 ;+0.31]$ \\
\hline \multirow{4}{*}{$\begin{array}{l}\text { Total cerebral white } \\
\text { matter volume }^{1}\end{array}$} & $r_{p h}=$ & \multirow{4}{*}{$\mathrm{N} / \mathrm{A}$} & $+0.20[+0.04 ;+0.35]$ & $-0.00[-0.14 ;+0.14]$ \\
\hline & $r_{a}=$ & & $+0.22[-0.16 ;+0.67]$ & $+0.02[-0.47 ;+0.65]$ \\
\hline & $r_{c}=$ & & $+0.81[-1.00 ;+1.00]$ & $-0.66[-1.00 ;+1.00]$ \\
\hline & $r_{e}=$ & & $+0.16[-0.22 ;+0.50]$ & $+0.02[-0.28 ;+0.31]$ \\
\hline \multirow{4}{*}{$\begin{array}{l}\text { Global mean frac- } \\
\text { tional anisotropy }\end{array}$} & $r_{p h}=$ & \multirow{4}{*}{$\mathrm{N} / \mathrm{A}$} & $+0.18[+0.02 ;+0.33]$ & $+0.13[-0.02 ;+0.27]$ \\
\hline & $r_{a}=$ & & $+0.42[+0.42 ;+0.99]$ & $+0.32[-0.43 ;+1.00]$ \\
\hline & $r_{c}=$ & & $+0.74[-1.00 ;+1.00]$ & $-0.19[-1.00 ;+1.00]$ \\
\hline & $r_{e}=$ & & $-0.36[-0.62 ;+0.00]$ & $-0.01[-0.32 ;+0.31]$ \\
\hline
\end{tabular}


Global mean diffu- $\quad r_{p h}=$ sivity $r_{a h}=$

$r_{c}=$

$r_{e}=$
$-0.20[-0.34 ;-0.04]-0.20[-0.34 ;-0.05]$

$\mathbf{- 0 . 3 3}[-\mathbf{0 . 7 7} ; \mathbf{- 0 . 2 8}]-0.56[-0.99 ;+0.00]$

$-0.29[-1.00 ;+1.00]+0.76[-1.00 ;+1.00]$

$+0.22[-0.16 ;+0.54]+0.04[-0.23 ;+0.30]$

${ }^{1}$ After regression of total brain volume.

Values printed in boldface were significant ( $p<0.05$ ); exact $p$-values are reported in Supplementary Data File F3. Abbreviations (in alphabetical order): $r_{p h}=$ phenotypic association; $r_{a}=$ genetic association; $r_{c}=$ common environment association; $r_{e}=$ unique environment association.

\section{A.4.1. Assocations between externalizing behavior and regional brain measures}

\section{A.4.1.1. Phenotypic associations}

Most uncorrected significant associations were seen during mid-adolescence for both CBCL (at age 10: 9/88; at age 13: 26/88; at age 18: 2/88) and for YSR (at age 13: 23/88; at age 18: 13/88), generally featuring the same direction of association as the corresponding global brain structure, with a majority of the associations related to white matter integrity (variance explained $\mathrm{R}^{2}$ up to 9\%; Supplementary Figure S7; Supplementary Data File F3). In addition, twelve phenotypic associations between the longitudinal change rates of externalizing behavior and change rate in brain measures were significant prior to correction for multiple testing ( $\mathrm{R}^{2}$ up to 5\%; Supplementary Data File F3). However, none of the associations at the regional level survived corrections for multiple comparisons.

\section{Age-specific genetic and environmental associations}
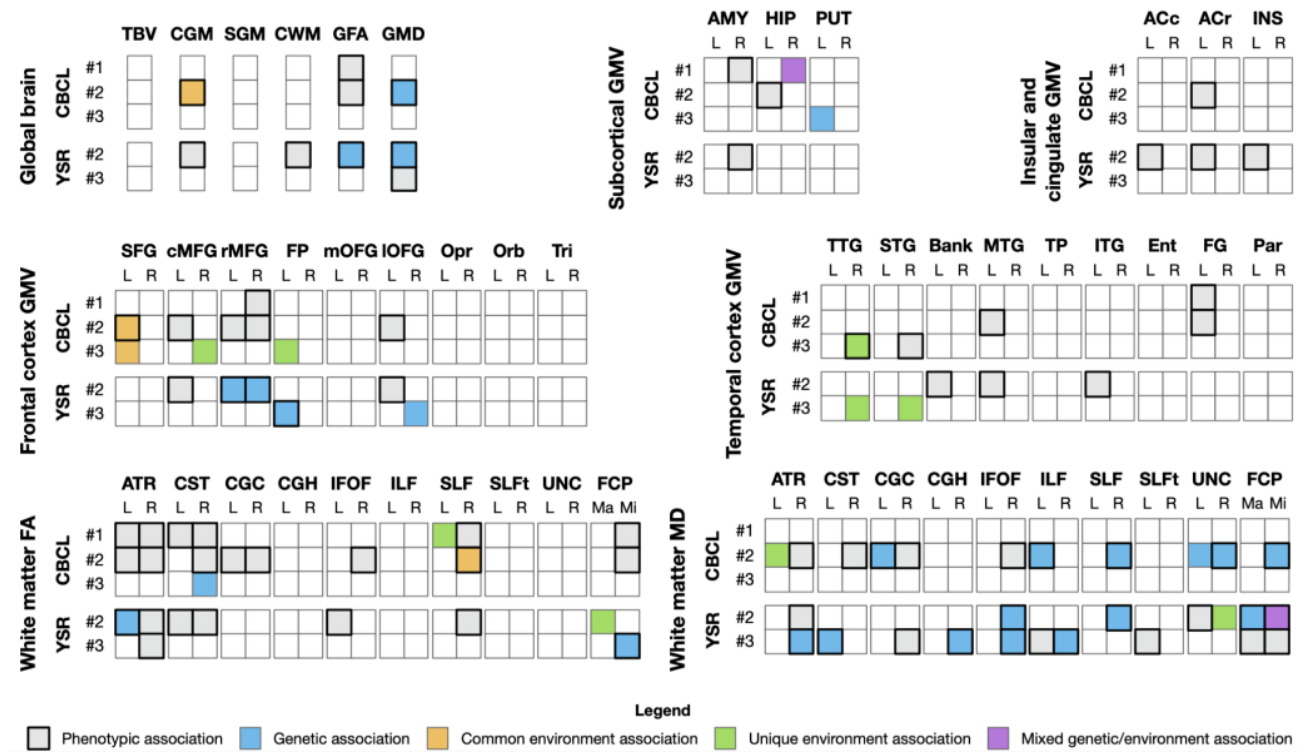

Mixed genetic/environment association

Supplementary Figure S7. Overview of phenotypic, genetic, and environmental associations between brain measures and externalizing behavior. All brain measures except for total brain volume (TBV), global fractional anisotropy (GFA) and global mean diffusivity (GMD) were corrected for the effect of the corresponding global brain measure. Reported associations were significant at uncorrected $p<0.05$; see Supplementary Data File F3. Abbreviations (in alphabetical order): $C B C L=$ child behavior checklist; FA = fractional anisotropy; GMV = gray matter volume; $\mathrm{L}=$ left; $\mathrm{MD}=$ mean diffusivity; $\mathrm{R}$ = right; YSR = youth self report; see Supplementary Table S5 and Supplementary Table $\mathbf{S 6}$ for the abbreviations used for the brain structures.

\section{A.4.1.2. Genetic associations}

At a regional level, a shared genetic factor between externalizing behavior and regional brain measures was seen primarily for regional white matter diffusivity ( $r$ a ranging from -0.23 to -0.78 ; uncorrected $p<0.05$; Supplementary Figure S7; Supplementary Data File F3). In addition, of the twelve phenotypic associations between longitudinal change rates of externalizing behavior and brain measures that were significant prior to correction 
for multiple testing, only white matter diffusivity of the right superior longitudinal fasciculus had a shared genetic factor with externalizing behavior on the CBCL for their longitudinal change rates between ages 13 and 18 years $\left(r_{\mathrm{a}}=-0.60\right.$; uncorrected $p=0.044$; Supplementary Data File F3), and only gray matter volume of the left pars orbitalis on the frontal cortex had a shared genetic factor with externalizing behavior on the CBCL for their longitudinal change rates between ages 10 and 18 years $\left(r_{\mathrm{a}}=+0.78\right.$; uncorrected $p=$ 0.017; Supplementary Data File F3).

\section{A.4.1.3. Environmental associations}

Several environmental associations between externalizing behavior and regional brain measures were significant prior to correction for multiple testing, primarily at age 13 years (Supplementary Data File F3). Influences from common environment shared between the twins and siblings of the same family partially explained the associations of externalizing behavior on the CBCL with gray matter volume of the left superior frontal gyrus $\left(r_{\mathrm{c}}=-0.99\right.$; uncorrected $\left.p=0.028\right)$ and with white matter fractional anisotropy of the right superior longitudinal fasciculus $\left(r_{c}=+0.90\right.$; uncorrected $\left.p=0.041\right)$ at age 13 years. Four phenotypic associations were partially due to influences from the same environmental factors unique to each individual: those between externalizing behavior on the CBCL and right transverse temporal gyrus $\left(r_{\mathrm{e}}=+0.31\right.$; uncorrected $\left.p=0.031\right)$, between externalizing behavior on the YSR and white matter mean diffusivity of the forceps major tract at age 13 years $\left(r_{\mathrm{e}}=+0.39\right.$; uncorrected $\left.p=0.045\right)$, between externalizing behavior on the YSR and cortical gray matter volume of the left frontal pole at 18 years $\left(r_{\mathrm{e}}=+0.24\right.$; uncorrected $p=0.045$ ), and between longitudinal change rates of externalizing behavior on the CBCL and subcortical gray matter volume of the left putamen between ages 13 and 18 years $\left(r_{\mathrm{e}}\right.$ $=+0.37$; uncorrected $p=0.034$ ).

\section{A.5. Supplementary data files}

\section{A.5.1. Supplementary Data File F1}

The Supplementary Data File F1 contains four sheets with the phenotypic summary statistics, the heritability estimates, the longitudinal phenotypic, genetic, and environmental associations, and the heritability of the longitudinal change scores of externalizing behavior on the Child Behavior Checklist and the Youth Self Report questionnaire.

\section{A.5.2. Supplementary Data File F2}

The Supplementary Data File F2 contains four sheets with the phenotypic summary statistics, the heritability estimates, the longitudinal phenotypic, genetic, and environmental associations, and the heritability of the longitudinal change scores of the global and regional brain measures.

\section{A.5.3. Supplementary Data File F3}

The Supplementary Data File F3 contains four sheets with the phenotypic, genetic, and environmental associations between externalizing behavior on the Child Behavior Checklist or Youth Self Report with the global or regional brain measures, and phenotypic, genetic, and environmental associations between the longitudinal change scores in externalizing behavior and brain measures.

\section{References}

1. Christenson, J.D., Crane, D.R., Malloy, J., Parker, S., 2016. The Cost of Oppositional Defiant Disorder and Disruptive Behavior: A Review of the Literature. J Child Fam Stud 25, 2649-2658. https://doi.org/10.1007/s10826-016-0430-9

2. Achenbach, T.M., Reschorla, L.A., 2001. Manual for the ASEBA school-age forms and profiles. Achenbach, Burlington, VT.

3. Bongers, I.L., Koot, H.M., Ende, J.V.D., Verhulst, F.C., 2004. Developmental Trajectories of Externalizing Behaviors in Childhood and Adolescence. Child Dev 75, 1523-1537. https://doi.org/10.1111/j.1467-8624.2004.00755.x

4. van Lier, P.A.C., Verhulst, F.C., Ende, J., Crijnen, A.A.M., 2003. Classes of disruptive behaviour in a sample of young elementary school children. J Child Psychol Psyc 44, 377-387. https://doi.org/10.1111/1469-7610.00128 
5. van Hazebroek, B.C.M.V., Blokland, A.A.J., Wermink, H.T., Keijser, J.W.D., Popma, A., Domburgh, L.V., 2019. Delinquent Development Among Early-Onset Offenders: Identifying and Characterizing Trajectories Based on Frequency Across Types of Offending. Crim Justice Behav 46, 1542-1565. https://doi.org/10.1177/0093854819876306

6. Eme, R.F., 2007. Sex differences in child-onset, life-course-persistent conduct disorder. A review of biological influences. Clin Psychol Rev 27, 607-627. https://doi.org/10.1016/j.cpr.2007.02.001

7. Demmer, D.H., Hooley, M., Sheen, J., McGillivray, J.A., Lum, J.A.G., 2017. Sex Differences in the Prevalence of Oppositional Defiant Disorder During Middle Childhood: a Meta-Analysis. J Abnorm Child Psych 45, 313-325. https://doi.org/10.1007/s10802-016-0170-8

8. Ormel, J., Raven, D., Oort, F. van, Hartman, C.A., Reijneveld, S.A., Veenstra, R., Vollebergh, W.A.M., Buitelaar, J., Verhulst, F.C., Oldehinkel, A.J., 2015. Mental health in Dutch adolescents: a TRAILS report on prevalence, severity, age of onset, continuity and co-morbidity of DSM disorders. Psychol Med 45, 345-360. https://doi.org/10.1017/s0033291714001469

9. Zwirs, B.W.C., Burger, H., Schulpen, T.W.J., Wiznitzer, M., Fedder, H., Buitelaar, J.K., 2007. Prevalence of Psychiatric Disorders Among Children of Different Ethnic Origin. J Abnorm Child Psych 35, 556-566. https://doi.org/10.1007/s10802-007-9112-9

10. Fairchild, G., Hawes, D.J., Frick, P.J., Copeland, W.E., Odgers, C.L., Franke, B., Freitag, C.M., Brito, S.A.D., 2019. Conduct disorder. Nat Rev Dis Primers 5, 43. https://doi.org/10.1038/s41572-019-0095-y

11. Pandey, A., Hale, D., Das, S., Goddings, A.-L., Blakemore, S.-J., Viner, R.M., 2018. Effectiveness of Universal Self-regulationBased Interventions in Children and Adolescents: A Systematic Review and Meta-analysis. JAMA Pediatr $172,566$. https://doi.org/10.1001/jamapediatrics.2018.0232

12. Masi, G., Milone, A., Brovedani, P., Pisano, S., Muratori, P., 2018. Psychiatric evaluation of youths with Disruptive Behavior Disorders and psychopathic traits: A critical review of assessment measures. Neurosci Biobehav Rev 91, 21-33. https://doi.org/10.1016/j.neubiorev.2016.09.023

13. Blair, R.J.R., Leibenluft, E., Pine, D.S., 2014. Conduct Disorder and Callous-Unemotional Traits in Youth. New Engl J Medicine 371, 2207-2216. https://doi.org/10.1056/nejmra1315612

14. Frick, P.J., Viding, E., 2009. Antisocial behavior from a developmental psychopathology perspective. Dev Psychopathol 21, 1111-1131. https://doi.org/10.1017/s0954579409990071

15. Corrado, R.R., McCuish, E.C., Hart, S.D., DeLisi, M., 2015. The role of psychopathic traits and developmental risk factors on offending trajectories from early adolescence to adulthood: A prospective study of incarcerated youth. J Crim Just 43, 357-368. https://doi.org/10.1016/j.jcrimjus.2015.04.007

16. van der Valk, J. C. van der, Oord, E.J.C.G. van den, Verhulst, F.C., Boomsma, D.I., 2003. Using Shared and Unique Parental Views to Study the Etiology of 7-Year-Old Twins' Internalizing and Externalizing Problems. Behav Genet 33, 409-420. https://doi.org/10.1023/a:1025369525924

17. Spatola, C.A.M., Rende, R., Battaglia, M., 2010. Genetic and environmental influences upon the CBCL/6-18 DSM-oriented scales: similarities and differences across three different computational approaches and two age ranges. Eur Child Adoles Psy 19, 647658. https://doi.org/10.1007/s00787-010-0102-z

18. Hicks, B.M., Foster, K.T., Iacono, W.G., McGue, M., 2013. Genetic and Environmental Influences on the Familial Transmission of Externalizing Disorders in Adoptive and Twin Offspring. JAMA Psychiat 70, 1076-1083. https://doi.org/10.1001/jamapsychiatry.2013.258

19. Kerekes, N., Lundström, S., Chang, Z., Tajnia, A., Jern, P., Lichtenstein, P., Nilsson, T., Anckarsäter, H., 2014. Oppositional defiant- and conduct disorder-like problems: neurodevelopmental predictors and genetic background in boys and girls, in a nationwide twin study. Peerj 2, e359. https://doi.org/10.7717/peerj.359

20. Porsch, R.M., Middeldorp, C.M., Cherny, S.S., Krapohl, E., Beijsterveldt, C.E.M. van, Loukola, A., Korhonen, T., Pulkkinen, L., Corley, R., Rhee, S., Kaprio, J., Rose, R.R., Hewitt, John.K., Sham, P., Plomin, R., Boomsma, D.I., Bartels, M., 2016. Longitudinal heritability of childhood aggression. Am J Medical Genetics Part B Neuropsychiatric Genetics 171, 697-707. https://doi.org/10.1002/ajmg.b.32420

21. Wesseldijk, L.W., Bartels, M., Vink, J.M., Beijsterveldt, C.E.M. van, Ligthart, L., Boomsma, D.I., Middeldorp, C.M., 2018. Genetic and environmental influences on conduct and antisocial personality problems in childhood, adolescence, and adulthood. Eur Child Adoles Psy 27, 1123-1132. https://doi.org/10.1007/s00787-017-1014-y

22. Luningham, J.M., Hendriks, A.M., Krapohl, E., Ip, H.F., Beijsterveldt, C.E.M., Lundström, S., Vuoksimaa, E., Korhonen, T., Lichtenstein, P., Plomin, R., Pulkkinen, L., Rose, R.J., Kaprio, J., Bartels, M., Boomsma, D.I., Lubke, G.H., 2020. Harmonizing behavioral outcomes across studies, raters, and countries: application to the genetic analysis of aggression in the ACTION Consortium. J Child Psychol Psyc 61, 807-817. https://doi.org/10.1111/jcpp.13188

23. Polderman, T.J.C., Benyamin, B., Leeuw, C.A. de, Sullivan, P.F., Bochoven, A. van, Visscher, P.M., Posthuma, D., 2015. Metaanalysis of the heritability of human traits based on fifty years of twin studies. Nat Genet 47, 702-709. https://doi.org/10.1038/ng.3285

24. Gard, A.M., Dotterer, H.L., Hyde, L.W., 2019. Genetic influences on antisocial behavior: recent advances and future directions. Curr Opin Psychology 27, 46-55. https://doi.org/10.1016/j.copsyc.2018.07.013

25. Odintsova, V.V., Roetman, P.J., Ip, H.F., Pool, R., Laan, C.M.V. der, Tona, K.-D., Vermeiren, R.R.J.M., Boomsma, D.I., 2019. Genomics of human aggression: current state of genome-wide studies and an automated systematic review tool. Psychiatr Genet 29, 170-190. https://doi.org/10.1097/ypg.0000000000000239 
26. van der Valk, J.C., van den Oord, E.J.C.G., Verhulst, F.C., Boomsma, D.I., 2003. Genetic and Environmental Contributions to Stability and Change in Children's Internalizing and Externalizing Problems. J Am Acad Child Adolesc Psychiatry 42, 12121220. https://doi.org/10.1097/00004583-200310000-00012

27. Haberstick, B.C., Schmitz, S., Young, S.E., Hewitt, J.K., 2005. Contributions of Genes and Environments to Stability and Change in Externalizing and Internalizing Problems During Elementary and Middle School. Behav Genet 35, $381-396$. https://doi.org/10.1007/s10519-004-1747-5

28. Lubke, G.H., McArtor, D.B., Boomsma, D.I., Bartels, M., 2018. Genetic and Environmental Contributions to the Development of Childhood Aggression. Dev Psychol 54, 39-50. https://doi.org/10.1037/dev0000403

29. Carroll, S.L., Clark, D.A., Hyde, L.W., Klump, K.L., Burt, S.A., 2021. Continuity and Change in the Genetic and Environmental Etiology of Youth Antisocial Behavior. Behav Genet 51, 1-12. https://doi.org/10.1007/s10519-021-10066-8

30. Hatoum, A.S., Rhee, S.H., Corley, R.P., Hewitt, J.K., Friedman, N.P., 2018. Etiology of Stability and Growth of Internalizing and Externalizing Behavior Problems Across Childhood and Adolescence. Behav Genet 48, 298-314. https://doi.org/10.1007/s10519018-9900-8

31. Klein, M., Onnink, M., Donkelaar, M. van, Wolfers, T., Harich, B., Shi, Y., Dammers, J., Arias-Vásquez, A., Hoogman, M., Franke, B., 2017. Brain imaging genetics in ADHD and beyond - Mapping pathways from gene to disorder at different levels of complexity. Neurosci Biobehav Rev 80, 115-155. https://doi.org/10.1016/j.neubiorev.2017.01.013

32. Giedd, J.N., Blumenthal, J., Jeffries, N.O., Castellanos, F.X., Liu, H., Zijdenbos, A., Paus, T., Evans, A.C., Rapoport, J.L., 1999. Brain development during childhood and adolescence: a longitudinal MRI study. Nat Neurosci 2, 861-863. https://doi.org/10.1038/13158

33. Blakemore, S.-J., 2012. Imaging brain development: The adolescent brain. Neuroimage 61, 397-406. https://doi.org/10.1016/j.neuroimage.2011.11.080

34. Hedman, A.M., Haren, N.E.M. van, Schnack, H.G., Kahn, R.S., Hulshoff Pol, H.E., 2012. Human brain changes across the life span: A review of 56 longitudinal magnetic resonance imaging studies. Hum Brain Mapp 33, $1987-2002$. https://doi.org/10.1002/hbm.21334

35. Lenroot, R.K., Giedd, J.N., 2006. Brain development in children and adolescents: Insights from anatomical magnetic resonance imaging. Neurosci Biobehav Rev 30, 718-729. https://doi.org/10.1016/j.neubiorev.2006.06.001

36. Shaw, P., Kabani, N.J., Lerch, J.P., Eckstrand, K., Lenroot, R., Gogtay, N., Greenstein, D., Clasen, L., Evans, A., Rapoport, J.L., Giedd, J.N., Wise, S.P., 2008. Neurodevelopmental Trajectories of the Human Cerebral Cortex. J Neurosci 28, $3586-3594$. https://doi.org/10.1523/jneurosci.5309-07.2008

37. Teeuw, J., Brouwer, R.M., Koenis, M.M.G., Swagerman, S.C., Boomsma, D.I., Hulshoff Pol, H.E., 2018. Genetic Influences on the Development of Cerebral Cortical Thickness During Childhood and Adolescence in a Dutch Longitudinal Twin Sample: The Brainscale Study. Cereb Cortex 29, 978-993. https://doi.org/10.1093/cercor/bhy005

38. Gogtay, N., Giedd, J.N., Lusk, L., Hayashi, K.M., Greenstein, D., Vaituzis, A.C., Nugent, T.F., Herman, D.H., Clasen, L.S., Toga, A.W., Rapoport, J.L., Thompson, P.M., 2004. Dynamic mapping of human cortical development during childhood through early adulthood. P Natl Acad Sci Usa 101, 8174-8179. https://doi.org/10.1073/pnas.0402680101

39. Brouwer, R.M., Mandl, R.C.W., Schnack, H.G., Soelen, I.L.C. van, Baal, G.C. van, Peper, J.S., Kahn, R.S., Boomsma, D.I., Hulshoff Pol, H.E., 2012. White Matter Development in Early Puberty: A Longitudinal Volumetric and Diffusion Tensor Imaging Twin Study. Plos One 7, e32316. https://doi.org/10.1371/journal.pone.0032316

40. Lebel, C., Treit, S., Beaulieu, C., 2017. A review of diffusion MRI of typical white matter development from early childhood to young adulthood. Nmr Biomed 32, e3778. https://doi.org/10.1002/nbm.3778

41. Blokland, G.A.M., Zubicaray, G.I. de, McMahon, K.L., Wright, M.J., 2012. Genetic and Environmental Influences on Neuroimaging Phenotypes: A Meta-Analytical Perspective on Twin Imaging Studies. Twin Res Hum Genet 15, $351-371$. https://doi.org/10.1017/thg.2012.11

42. Douet, V., Chang, L., Cloak, C., Ernst, T., 2014. Genetic influences on brain developmental trajectories on neuroimaging studies: from infancy to young adulthood. Brain Imaging Behav 8, 234-250. https://doi.org/10.1007/s11682-013-9260-1

43. Jansen, A.G., Mous, S.E., White, T., Posthuma, D., Polderman, T.J.C., 2015. What Twin Studies Tell Us About the Heritability of Brain Development, Morphology, and Function: A Review. Neuropsychol Rev 25, 27-46. https://doi.org/10.1007/s11065-0159278-9

44. Strike, L.T., Couvy-Duchesne, B., Hansell, N.K., Cuellar-Partida, G., Medland, S.E., Wright, M.J., 2015. Genetics and Brain Morphology. Neuropsychol Rev 25, 63-96. https://doi.org/10.1007/s11065-015-9281-1

45. van Soelen, I.L.C. van, Brouwer, R.M., Baal, G.C.M. van, Schnack, H.G., Peper, J.S., Collins, D.L., Evans, A.C., Kahn, R.S., Boomsma, D.I., Hulshoff Pol, H.E., 2012. Genetic influences on thinning of the cerebral cortex during development. Neuroimage 59, 3871-3880. https://doi.org/10.1016/j.neuroimage.2011.11.044

46. van Soelen, I.L.C. van, Brouwer, R.M., Baal, G.C.M. van, Schnack, H.G., Peper, J.S., Chen, L., Kahn, R.S., Boomsma, D.I., Hulshoff Pol, H.E., 2013. Heritability of volumetric brain changes and height in children entering puberty. Hum Brain Mapp 34, 713-725. https://doi.org/10.1002/hbm.21468

47. Brouwer, R.M., Panizzon, M.S., Glahn, D.C., Hibar, D.P., Hua, X., Jahanshad, N., Abramovic, L., Zubicaray, G.I. de, Franz, C.E., Hansell, N.K., Hickie, I.B., Koenis, M.M.G., Martin, N.G., Mather, K.A., McMahon, K.L., Schnack, H.G., Strike, L.T., Swagerman, S.C., Thalamuthu, A., Wen, W., Gilmore, J.H., Gogtay, N., Kahn, R.S., Sachdev, P.S., Wright, M.J., Boomsma, D.I., Kremen, W.S., Thompson, P.M., Hulshoff Pol, H.E., 2017. Genetic influences on individual differences in longitudinal changes in global and 
subcortical brain volumes: Results of the ENIGMA plasticity working group. Hum Brain Mapp 38, $4444-4458$. https://doi.org/10.1002/hbm.23672

48. Brans, R.G.H., Haren, N.E.M. van, Baal, G.C.M. van, Schnack, H.G., Kahn, R.S., Hulshoff Pol, H.E., 2008. Heritability of Changes in Brain Volume Over Time in Twin Pairs Discordant for Schizophrenia. Arch Gen Psychiat 65, 1259-1268. https://doi.org/10.1001/archpsyc.65.11.1259

49. Brans, R.G.H., Kahn, R.S., Schnack, H.G., Baal, G.C.M. van, Posthuma, D., Haren, N.E.M. van, Lepage, C., Lerch, J.P., Collins, D.L., Evans, A.C., Boomsma, D.I., Hulshoff Pol, H.E., 2010. Brain Plasticity and Intellectual Ability Are Influenced by Shared Genes. J Neurosci 30, 5519-5524. https://doi.org/10.1523/jneurosci.5841-09.2010

50. Brouwer, R.M., Hedman, A.M., Haren, N.E.M. van, Schnack, H.G., Brans, R.G.H., Smit, D.J.A., Kahn, R.S., Boomsma, D.I., Pol, H.E.H., 2014. Heritability of brain volume change and its relation to intelligence. Neuroimage 100, 676-683. https://doi.org/10.1016/j.neuroimage.2014.04.072

51. Hedman, A.M., Haren, N.E.M. van, Baal, G.C.M. van, Brouwer, R.M., Brans, R.G.H., Schnack, H.G., Kahn, R.S., Hulshoff Pol, H.E., 2016. Heritability of cortical thickness changes over time in twin pairs discordant for schizophrenia. Schizophr Res 173, 192-199. https://doi.org/10.1016/j.schres.2015.06.021

52. Johanson, M., Vaurio, O., Tiihonen, J., Lähteenvuo, M., 2020. A Systematic Literature Review of Neuroimaging of Psychopathic Traits. Frontiers Psychiatry 10, 1027. https://doi.org/10.3389/fpsyt.2019.01027

53. Blair, R.J.R., Zhang, R., 2020. Recent neuro-imaging findings with respect to conduct disorder, callous-unemotional traits and psychopathy. Curr Opin Psychiatr 33, 45-50. https://doi.org/10.1097/yco.0000000000000559

54. Waller, R., Dotterer, H.L., Murray, L., Maxwell, A.M., Hyde, L.W., 2017. White-matter tract abnormalities and antisocial behavior: A systematic review of diffusion tensor imaging studies across development. Neuroimage Clin 14, $201-215$. https://doi.org/10.1016/j.nicl.2017.01.014

55. Noordermeer, S.D.S., Luman, M., Oosterlaan, J., 2016. A Systematic Review and Meta-analysis of Neuroimaging in Oppositional Defiant Disorder (ODD) and Conduct Disorder (CD) Taking Attention-Deficit Hyperactivity Disorder (ADHD) Into Account. Neuropsychol Rev 26, 44-72. https://doi.org/10.1007/s11065-015-9315-8

56. Baker, R.H., Clanton, R.L., Rogers, J.C., Brito, S.A.D., 2015. Neuroimaging findings in disruptive behavior disorders. CNS Spectrums 20, 369-381. https://doi.org/10.1017/s1092852914000789

57. Raine, A., Lencz, T., Bihrle, S., LaCasse, L., Colletti, P., 2000. Reduced Prefrontal Gray Matter Volume and Reduced Autonomic Activity in Antisocial Personality Disorder. Arch Gen Psychiat 57, 119-127. https://doi.org/10.1001/archpsyc.57.2.119

58. Cohn, M.D., Viding, E., McCrory, E., Pape, L., Brink, W. van den, Doreleijers, T.A.H., Veltman, D.J., Popma, A., 2016. Regional grey matter volume and concentration in at-risk adolescents: Untangling associations with callous-unemotional traits and conduct disorder symptoms. Psychiatry Res Neuroimaging 254, 180-187. https://doi.org/10.1016/j.pscychresns.2016.07.003

59. Bayard, F., Thunell, C.N., Abé, C., Almeida, R., Banaschewski, T., Barker, G., Bokde, A.L.W., Bromberg, U., Büchel, C., Quinlan, E.B., Desrivières, S., Flor, H., Frouin, V., Garavan, H., Gowland, P., Heinz, A., Ittermann, B., Martinot, J.-L., Martinot, M.-L.P., Nees, F., Orfanos, D.P., Paus, T., Poustka, L., Conrod, P., Stringaris, A., Struve, M., Penttilä, J., Kappel, V., Grimmer, Y., Fadai, T., Noort, B. van, Smolka, M.N., Vetter, N.C., Walter, H., Whelan, R., Schumann, G., Petrovic, P., Consortium, I., 2020. Distinct brain structure and behavior related to ADHD and conduct disorder traits. Mol Psychiatr 25, 3020-3033. https://doi.org/10.1038/s41380-018-0202-6

60. Waller, R., Hawes, S.W., Byrd, A.L., Dick, A.S., Sutherland, M.T., Riedel, M.C., Tobia, M.J., Bottenhorn, K.L., Laird, A.R., Gonzalez, R., 2020. Disruptive Behavior Problems, Callous-Unemotional Traits, and Regional Gray Matter Volume in the ABCD Study. Biological Psychiatry Cognitive Neurosci Neuroimaging 5, 481-489. https://doi.org/10.1016/j.bpsc.2020.01.002

61. Durham, E.L., Jeong, H.J., Moore, T.M., Dupont, R.M., Cardenas-Iniguez, C., Cui, Z., Stone, F.E., Berman, M.G., Lahey, B.B., Kaczkurkin, A.N., 2021. Association of gray matter volumes with general and specific dimensions of psychopathology in children. Neuropsychopharmacol 1-7. https://doi.org/10.1038/s41386-020-00952-w

62. Raine, A., Lencz, T., Taylor, K., Hellige, J.B., Bihrle, S., Lacasse, L., Lee, M., Ishikawa, S., Colletti, P., 2003. Corpus Callosum Abnormalities in Psychopathic Antisocial Individuals. Arch Gen Psychiat 60, 1134-1142. https://doi.org/10.1001/archpsyc.60.11.1134

63. Pape, L.E., Cohn, M.D., Caan, M.W.A., Wingen, G. van, Brink, W. van den, Veltman, D.J., Popma, A., 2015. Psychopathic traits in adolescents are associated with higher structural connectivity. Psychiatry Res Neuroimaging 233, 474-480. https://doi.org/10.1016/j.pscychresns.2015.07.023

64. Bolhuis, K., Muetzel, R.L., Stringaris, A., Hudziak, J.J., Jaddoe, V.W.V., Hillegers, M.H.J., White, T., Kushner, S.A., Tiemeier, H., 2019. Structural Brain Connectivity in Childhood Disruptive Behavior Problems: A Multidimensional Approach. Biol Psychiat 85, 336-344. https://doi.org/10.1016/j.biopsych.2018.07.005

65. Bolhuis, K., Viding, E., Muetzel, R.L., Marroun, H.E., Kocevska, D., White, T., Tiemeier, H., Cecil, C.A.M., 2019. Neural Profile of Callous Traits in Children: A Population-Based Neuroimaging Study. Biol Psychiat 85, $399-407$. https://doi.org/10.1016/j.biopsych.2018.10.015

66. Neumann, A., Muetzel, R.L., Lahey, B.B., Bakermans-Kranenburg, M.J., IJzendoorn, M.H. van, Jaddoe, V.W., Hillegers, M.H.J., White, T., Tiemeier, H., 2020. White Matter Microstructure and the General Psychopathology Factor in Children. J Am Acad Child Adolesc Psychiatry 59, 1285-1296. https://doi.org/10.1016/j.jaac.2019.12.006

67. Andre, Q.R., Geeraert, B.L., Lebel, C., 2020. Brain structure and internalizing and externalizing behavior in typically developing children and adolescents. Brain Struct Funct 225, 1369-1378. https://doi.org/10.1007/s00429-019-01973-y 
68. Huttenlocher, P.R., 1979. Synaptic density in human frontal cortex - Developmental changes and effects of aging. Brain Res 163, 195-205. https://doi.org/10.1016/0006-8993(79)90349-4

69. Paus, T., 2010. Growth of white matter in the adolescent brain: Myelin or axon? Brain Cognition 72, 26-35. https://10.1016/j.bandc.2009.06.002

70. Deoni, S.C.L., Dean, D.C., Remer, J., Dirks, H., O'Muircheartaigh, J., 2015. Cortical maturation and myelination in healthy toddlers and young children. Neuroimage 115, 147-161. https://doi.org/10.1016/j.neuroimage.2015.04.058

71. Ameis, S.H., Ducharme, S., Albaugh, M.D., Hudziak, J.J., Botteron, K.N., Lepage, C., Zhao, L., Khundrakpam, B., Collins, D.L., Lerch, J.P., Wheeler, A., Schachar, R., Evans, A.C., Karama, S., 2014. Cortical Thickness, Cortico-Amygdalar Networks, and Externalizing Behaviors in Healthy Children. Biol Psychiat 75, 65-72. https://doi.org/10.1016/j.biopsych.2013.06.008

72. Caldwell, J.Z.K., Armstrong, J.M., Hanson, J.L., Sutterer, M.J., Stodola, D.E., Koenigs, M., Kalin, N.H., Essex, M.J., Davidson, R.J., 2015. Preschool Externalizing Behavior Predicts Gender-Specific Variation in Adolescent Neural Structure. Plos One 10, e0117453. https://doi.org/10.1371/journal.pone.0117453

73. Oostermeijer, S., Whittle, S., Suo, C., Allen, N.B., Simmons, J.G., Vijayakumar, N., Ven, P.M. van de, Jansen, L.M.C., Yücel, M., Popma, A., 2016. Trajectories of adolescent conduct problems in relation to cortical thickness development: a longitudinal MRI study. Transl Psychiat 6, e841-e841. https://doi.org/10.1038/tp.2016.111

74. Bos, M.G.N., Wierenga, L.M., Blankenstein, N.E., Schreuders, E., Tamnes, C.K., Crone, E.A., 2018. Longitudinal structural brain development and externalizing behavior in adolescence. J Child Psychol Psyc 59, 1061-1072. https://doi.org/10.1111/jcpp.12972

75. Whittle, S., Vijayakumar, N., Simmons, J.G., Allen, N.B., 2020. Internalizing and Externalizing Symptoms Are Associated With Different Trajectories of Cortical Development During Late Childhood. J Am Acad Child Adolesc Psychiatry 59, $177-185$. https://doi.org/10.1016/j.jaac.2019.04.006

76. Roberts, H., Pozzi, E., Vijayakumar, N., Richmond, S., Bray, K., Deane, C., Whittle, S., 2021. Structural Brain Development and Aggression: A Longitudinal Study in Late Childhood. Cognitive Affect Behav Neurosci 1-11. https://doi.org/10.3758/s13415021-00871-3

77. Tanzer, M., Derome, M., Morosan, L., Salaminios, G., Debbané, M., 2020. Cortical thickness of the insula and prefrontal cortex relates to externalizing behavior: Cross-sectional and prospective findings. Dev Psychopathol 1-11. https://doi.org/10.1017/s0954579420000619

78. Muetzel, R.L., Blanken, L.M.E., Ende, J. van der, Marroun, H.E., Shaw, P., Sudre, G., Lugt, A. van der, Jaddoe, V.W.V., Verhulst, F.C., Tiemeier, H., White, T., 2018. Tracking Brain Development and Dimensional Psychiatric Symptoms in Children: A Longitudinal Population-Based Neuroimaging Study. Am J Psychiat 175, 54-62. https://doi.org/10.1176/appi.ajp.2017.16070813

79. Jones, S.A., Morales, A.M., Nagel, B.J., 2019. Resilience to Risk for Psychopathology: The Role of White Matter Microstructural Development in Adolescence. Biological Psychiatry Cognitive Neurosci Neuroimaging 4, $180-189$. https://doi.org/10.1016/j.bpsc.2018.08.006

80. Garic, D., Broce, I., Graziano, P., Mattfeld, A., Dick, A.S., 2019. Laterality of the frontal aslant tract (FAT) explains externalizing behaviors through its association with executive function. Developmental Sci 22, e12744. https://doi.org/10.1111/desc.12744

81. Telzer, E.H., McCormick, E.M., Peters, S., Cosme, D., Pfeifer, J.H., Duijvenvoorde, A.C.K. van, 2018. Methodological considerations for developmental longitudinal fMRI research. Dev Cogn Neuros-neth 33, 149-160. https://doi.org/10.1016/j.dcn.2018.02.004

82. Peper, J.S., Schnack, H.G., Brouwer, R.M., Baal, G.C.M.V., Pjetri, E., Székely, E., Leeuwen, M. van, Berg, S.M. van den, Collins, D.L., Evans, A.C., Boomsma, D.I., Kahn, R.S., Hulshoff Pol, H.E., 2009. Heritability of regional and global brain structure at the onset of puberty: A magnetic resonance imaging study in 9-year-old twin pairs. Hum Brain Mapp 30, $2184-2196$. https://doi.org/10.1002/hbm.20660

83. Brouwer, R.M., Mandl, R.C.W., Peper, J.S., Baal, G.C.M. van, Kahn, R.S., Boomsma, D.I., Hulshoff Pol, H.E., 2010. Heritability of DTI and MTR in nine-year-old children. Neuroimage 53, 1085-1092. https://doi.org/10.1016/j.neuroimage.2010.03.017

84. Swagerman, S.C., Brouwer, R.M., Geus, E.J.C. de, Hulshoff Pol, H.E., Boomsma, D.I., 2014. Development and heritability of subcortical brain volumes at ages 9 and 12. Genes Brain Behav 13, 733-742. https://doi.org/10.1111/gbb.12182

85. Teeuw, J., Brouwer, R.M., Guimarães, J.P.O.F.T., Brandner, P., Koenis, M.M.G., Swagerman, S.C., Verwoert, M., Boomsma, D.I., Hulshoff Pol, H.E., 2019. Genetic and environmental influences on functional connectivity within and between canonical cortical resting-state networks throughout adolescent development in boys and girls. Neuroimage 202, 116073. https://doi.org/10.1016/j.neuroimage.2019.116073

86. Koenis, M.M.G., Brouwer, R.M., Heuvel, M.P. van den, Mandl, R.C.W., Soelen, I.L.C. van, Kahn, R.S., Boomsma, D.I., Hulshoff Pol, H.E., 2015. Development of the brain's structural network efficiency in early adolescence: A longitudinal DTI twin study. Hum Brain Mapp 36, 4938-4953. https://doi.org/10.1002/hbm.22988

87. Koenis, M.M.G., Brouwer, R.M., Swagerman, S.C., Soelen, I.L.C. van, Boomsma, D.I., Hulshoff Pol, H.E., 2018. Association between structural brain network efficiency and intelligence increases during adolescence. Hum Brain Mapp 39, 822-836. https://doi.org/10.1002/hbm.23885

88. Bartels M., Boomsma D.I., Hudziak J.J., Rietveld M.J.H., van Beijsterveldt T.C.E.M., van den Oord E.J.C.G., 2004. Disentangling Genetic, Environmental, and Rater Effects on Internalizing and Externalizing Problem Behavior in 10-year-old Twins. Twin Res 7, 162-175. https://doi.org/10.1375/twin.7.2.162

89. Wichers, M., Gardner, C., Maes, H.H., Lichtenstein, P., Larsson, H., Kendler, K.S., 2013. Genetic Innovation and Stability in Externalizing Problem Behavior Across Development: A Multi-Informant Twin Study. Behav Genet 43, $191-201$. https://doi.org/10.1007/s10519-013-9586-x 
90. Niv, S., Tuvblad, C., Raine, A., Baker, L.A., 2013. Aggression and rule-breaking: Heritability and stability of antisocial behavior problems in childhood and adolescence. J Crim Just 41, 285-291. https://doi.org/10.1016/j.jcrimjus.2013.06.014

91. Achterberg, M., Peper, J.S., Duijvenvoorde, A.C.K. van, Mandl, R.C.W., Crone, E.A., 2016. Frontostriatal White Matter Integrity Predicts Development of Delay of Gratification: A Longitudinal Study. J Neurosci 36, 1954-1961. https://doi.org/10.1523/jneurosci.3459-15.2016

92. Zhang, J., Zhu, Xueling, Wang, X., Gao, J., Shi, H., Huang, B., Situ, W., Yi, J., Zhu, X., Yao, S., 2014. Increased Structural Connectivity in Corpus Callosum in Adolescent Males With Conduct Disorder. J Am Acad Child Adolesc Psychiatry 53, 466-475.e1. https://doi.org/10.1016/j.jaac.2013.12.015

93. Zhang, J., Gao, J., Shi, H., Huang, B., Wang, X., Situ, W., Cai, W., Yi, J., Zhu, X., Yao, S., 2014. Sex Differences of Uncinate Fasciculus Structural Connectivity in Individuals with Conduct Disorder. Biomed Res Int 2014, 1-9. https://doi.org/10.1155/2014/673165

94. Passamonti, L., Fairchild, G., Fornito, A., Goodyer, I.M., Nimmo-Smith, I., Hagan, C.C., Calder, A.J., 2012. Abnormal Anatomical Connectivity between the Amygdala and Orbitofrontal Cortex in Conduct Disorder. Plos One 7, e48789. https://doi.org/10.1371/journal.pone.0048789

95. Sarkar, S., Craig, M.C., Catani, M., Dell'Acqua, F., Fahy, T., Deeley, Q., Murphy, D.G.M., 2013. Frontotemporal white-matter microstructural abnormalities in adolescents with conduct disorder: a diffusion tensor imaging study. Psychol Med 43, 401411. https://doi.org/10.1017/s003329171200116x

96. Sarkar, S., Dell'Acqua, F., Walsh, S.F., Blackwood, N., Scott, S., Craig, M.C., Deeley, Q., Murphy, D.G.M., 2016. A Whole-Brain Investigation of White Matter Microstructure in Adolescents with Conduct Disorder. Plos One 11, e0155475. https://doi.org/10.1371/journal.pone.0155475

97. Menks, W.M., Furger, R., Lenz, C., Fehlbaum, L.V., Stadler, C., Raschle, N.M., 2017. Microstructural White Matter Alterations in the Corpus Callosum of Girls With Conduct Disorder. J Am Acad Child Adolesc Psychiatry 56, 258-265.e1. https://doi.org/10.1016/j.jaac.2016.12.006

98. Jiang, W., Shi, F., Liu, H., Li, G., Ding, Z., Shen, H., Shen, C., Lee, S.-W., Hu, D., Wang, W., Shen, D., 2017. Reduced White Matter Integrity in Antisocial Personality Disorder: A Diffusion Tensor Imaging Study. Sci Rep 7, 43002. https://doi.org/10.1038/srep43002

99. Pujol, J., Harrison, B.J., Contreras-Rodriguez, O., Cardoner, N., 2019. The contribution of brain imaging to the understanding of psychopathy. Psychol Med 49, 20-31. https://doi.org/10.1017/s0033291718002507

100. Pappa, I., Pourcain, B.S., Benke, K., Cavadino, A., Hakulinen, C., Nivard, M.G., Nolte, I.M., Tiesler, C.M.T., Bakermans-Kranenburg, M.J., Davies, G.E., Evans, D.M., Geoffroy, M., Grallert, H., Groen-Blokhuis, M.M., Hudziak, J.J., Kemp, J.P., KeltikangasJärvinen, L., McMahon, G., Mileva-Seitz, V.R., Motazedi, E., Power, C., Raitakari, O.T., Ring, S.M., Rivadeneira, F., Rodriguez, A., Scheet, P.A., Seppälä, I., Snieder, H., Standl, M., Thiering, E., Timpson, N.J., Veenstra, R., Velders, F.P., Whitehouse, A.J.O., Smith, G.D., Heinrich, J., Hypponen, E., Lehtimäki, T., Middeldorp, C.M., Oldehinkel, A.J., Pennell, C.E., Boomsma, D.I., Tiemeier, H., 2016. A genome-wide approach to children's aggressive behavior: The EAGLE consortium. Am J Medical Genetics Part B Neuropsychiatric Genetics 171, 562-572. https://doi.org/10.1002/ajmg.b.32333

101. Tielbeek, J.J., Johansson, A., Polderman, T.J.C., Rautiainen, M.-R., Jansen, P., Taylor, M., Tong, X., Lu, Q., Burt, A.S., Tiemeier, H., Viding, E., Plomin, R., Martin, N.G., Heath, A.C., Madden, P.A.F., Montgomery, G., Beaver, K.M., Waldman, I., Gelernter, J., Kranzler, H.R., Farrer, L.A., Perry, J.R.B., Munafò, M., LoParo, D., Paunio, T., Tiihonen, J., Mous, S.E., Pappa, I., Leeuw, C. de, Watanabe, K., Hammerschlag, A.R., Salvatore, J.E., Aliev, F., Bigdeli, T.B., Dick, D., Faraone, S.V., Popma, A., Medland, S.E., Posthuma, D., collaborators, B.A.B.C., 2017. Genome-Wide Association Studies of a Broad Spectrum of Antisocial Behavior. JAMA Psychiat 74, 1242. https://doi.org/10.1001/jamapsychiatry.2017.3069

102. Demontis, D., Walters, R.K., Rajagopal, V.M., Waldman, I.D., Grove, J., Als, T.D., Dalsgaard, S., Ribasés, M., Bybjerg-Grauholm, J., Bækvad-Hansen, M., Werge, T., Nordentoft, M., Mors, O., Mortensen, P.B., Andreassen, O.A., Arranz, M.J., Banaschewski, T., Bau, C., Bellgrove, M., Biederman, J., Brikell, I., Buitelaar, J.K., Burton, C.L., Casas, M., Crosbie, J., Doyle, A.E., Ebstein, R.P., Elia, J., Elizabeth, C.C., Grevet, E., Grizenko, N., Havdahl, A., Hawi, Z., Hebebrand, J., Hervas, A., Hohmann, S., Haavik, J., Joober, R., Kent, L., Kuntsi, J., Langley, K., Larsson, H., Lesch, K.-P., Leung, P.W.L., Liao, C., Loo, S.K., Martin, J., Martin, N.G., Medland, S.E., Miranda, A., Mota, N.R., Oades, R.D., Ramos-Quiroga, J.A., Reif, A., Rietschel, M., Roeyers, H., Rohde, L.A., Rothenberger, A., Rovira, P., Sánchez-Mora, C., Schachar, R.J., Sengupta, S., Artigas, M.S., Steinhausen, H.-C., Thapar, A., Witt, S.H., Yang, L., Zayats, T., Zhang-James, Y., Cormand, B., Hougaard, D.M., Neale, B.M., Franke, B., Faraone, S.V., Børglum, A.D., 2021. Risk variants and polygenic architecture of disruptive behavior disorders in the context of attention-deficit/hyperactivity disorder. Nat Commun 12, 576. https://doi.org/10.1038/s41467-020-20443-2

103. Ip, H.F., Laan, C.M. van der, Krapohl, E.M.L., Brikell, I., Sánchez-Mora, C., Nolte, I.M., Pourcain, B.S., Bolhuis, K., Palviainen, T., Zafarmand, H., Colodro-Conde, L., Gordon, S., Zayats, T., Aliev, F., Jiang, C., Wang, C.A., Saunders, G., Karhunen, V., Hammerschlag, A.R., Adkins, D.E., Border, R., Peterson, R.E., Prinz, J.A., Thiering, E., Seppälä, I., Vilor-Tejedor, N., Ahluwalia, T.S., Day, F.R., Hottenga, J.-J., Allegrini, A.G., Rimfeld, K., Chen, Q., Lu, Y., Martin, J., Artigas, M.S., Rovira, P., Bosch, R., Español, G., Quiroga, J.A.R., Neumann, A., Ensink, J., Grasby, K., Morosoli, J.J., Tong, X., Marrington, S., Middeldorp, C., Scott, J.G., Vinkhuyzen, A., Shabalin, A.A., Corley, R., Evans, L.M., Sugden, K., Alemany, S., Sass, L., Vinding, R., Ruth, K., Tyrrell, J., Davies, G.E., Ehli, E.A., Hagenbeek, F.A., Zeeuw, E.D., Beijsterveldt, T.C.E.M.V., Larsson, H., Snieder, H., Verhulst, F.C., Amin, N., Whipp, A.M., Korhonen, T., Vuoksimaa, E., Rose, R.J., Uitterlinden, A.G., Heath, A.C., Madden, P., Haavik, J., Harris, J.R., Helgeland, Ø., Johansson, S., Knudsen, G.P.S., Njolstad, P.R., Lu, Q., Rodriguez, A., Henders, A.K., Mamun, A., Najman, J.M., Brown, S., Hopfer, C., Krauter, K., Reynolds, C., Smolen, A., Stallings, M., Wadsworth, S., Wall, T.L., Silberg, J.L., Miller, A., 
Keltikangas-Järvinen, L., Hakulinen, C., Pulkki-Råback, L., Havdahl, A., Magnus, P., Raitakari, O.T., Perry, J.R.B., Llop, S., Lopez-Espinosa, M.-J., Bønnelykke, K., Bisgaard, H., Sunyer, J., Lehtimäki, T., Arseneault, L., Standl, M., Heinrich, J., Boden, J., Pearson, J., Horwood, L.J., Kennedy, M., Poulton, R., Eaves, L.J., Maes, H.H., Hewitt, J., Copeland, W.E., Costello, E.J., Williams, G.M., Wray, N., Järvelin, M.-R., McGue, M., Iacono, W., Caspi, A., Moffitt, T.E., Whitehouse, A., Pennell, C.E., Klump, K.L., Burt, S.A., Dick, D.M., Reichborn-Kjennerud, T., Martin, N.G., Medland, S.E., Vrijkotte, T., Kaprio, J., Tiemeier, H., Smith, G.D., Hartman, C.A., Oldehinkel, A.J., Casas, M., Ribasés, M., Lichtenstein, P., Lundström, S., Plomin, R., Bartels, M., Nivard, M.G., Boomsma, D.I., 2021. Genetic association study of childhood aggression across raters, instruments, and age. Transl Psychiat 11, 413. https://doi.org/10.1038/s41398-021-01480-x

104. Satizabal, C.L., Adams, H.H.H., Hibar, D.P., White, C.C., Knol, M.J., Stein, J.L., Scholz, M., Sargurupremraj, M., Jahanshad, N., Roshchupkin, G.V., Smith, A.V., Bis, J.C., Jian, X., Luciano, M., Hofer, E., Teumer, A., Lee, S.J. van der, Yang, J., Yanek, L.R., Lee, T.V., Li, S., Hu, Y., Koh, J.Y., Eicher, J.D., Desrivières, S., Arias-Vasquez, A., Chauhan, G., Athanasiu, L., Rentería, M.E., Kim, S., Hoehn, D., Armstrong, N.J., Chen, Q., Holmes, A.J., Braber, A. den, Kloszewska, I., Andersson, M., Espeseth, T., Grimm, O., Abramovic, L., Alhusaini, S., Milaneschi, Y., Papmeyer, M., Axelsson, T., Ehrlich, S., Roiz-Santiañez, R., Kraemer, B., Håberg, A.K., Jones, H.J., Pike, G.B., Stein, D.J., Stevens, A., Bralten, J., Vernooij, M.W., Harris, T.B., Filippi, I., Witte, A.V., Guadalupe, T., Wittfeld, K., Mosley, T.H., Becker, J.T., Doan, N.T., Hagenaars, S.P., Saba, Y., Cuellar-Partida, G., Amin, N., Hilal, S., Nho, K., Mirza-Schreiber, N., Arfanakis, K., Becker, D.M., Ames, D., Goldman, A.L., Lee, P.H., Boomsma, D.I., Lovestone, S., Giddaluru, S., Hellard, S.L., Mattheisen, M., Bohlken, M.M., Kasperaviciute, D., Schmaal, L., Lawrie, S.M., Agartz, I., Walton, E., Tordesillas-Gutierrez, D., Davies, G.E., Shin, J., Ipser, J.C., Vinke, L.N., Hoogman, M., Jia, T., Burkhardt, R., Klein, M., Crivello, F., Janowitz, D., Carmichael, O., Haukvik, U.K., Aribisala, B.S., Schmidt, H., Strike, L.T., Cheng, C.-Y., Risacher, S.L., Pütz, B., Fleischman, D.A., Assareh, A.A., Mattay, V.S., Buckner, R.L., Mecocci, P., Dale, A.M., Cichon, S., Boks, M.P., Matarin, M., Penninx, B.W.J.H., Calhoun, V.D., Chakravarty, M.M., Marquand, A.F., Macare, C., Masouleh, S.K., Oosterlaan, J., Amouyel, P., Hegenscheid, K., Rotter, J.I., Schork, A.J., Liewald, D.C.M., Zubicaray, G.I. de, Wong, T.Y., Shen, L., Sämann, P.G., Brodaty, H., Roffman, J.L., Geus, E.J.C. de, Tsolaki, M., Erk, S., Eijk, K.R. van, Cavalleri, G.L., Wee, N.J.A. van der, McIntosh, A.M., Gollub, R.L., Bulayeva, K.B., Bernard, M., Richards, J.S., Himali, J.J., Loeffler, M., Rommelse, N., Hoffmann, W., Westlye, L.T., Hernández, M.C.V., Hansell, N.K., Erp, T.G.M. van, Wolf, C., Kwok, J.B.J., Vellas, B., Heinz, A., Loohuis, L.M.O., Delanty, N., Ho, B.C., Ching, C.R.K., Shumskaya, E., Singh, B., Hofman, A., Meer, D. van der, Homuth, G., Psaty, B.M., Bastin, M.E., Montgomery, G.W., Foroud, T.M., Reppermund, S., Hottenga, J.-J., Simmons, A., Meyer-Lindenberg, A., Cahn, W., Whelan, C.D., Donkelaar, M.M.J. van, Yang, Q., Hosten, N., Green, R.C., Thalamuthu, A., Mohnke, S., Hulshoff Pol, H.E., Lin, H., Jack, C.R., Schofield, P.R., Mühleisen, T.W., Maillard, P., Potkin, S.G., Wen, W., Fletcher, E., Toga, A.W., Gruber, O., Huentelman, M., Smith, G.D., Launer, L.J., Nyberg, L., Jönsson, E.G., Crespo-Facorro, B., Koen, N., Greve, D.N., Uitterlinden, A.G., Weinberger, D.R., Steen, V.M., Fedko, I.O., Groenewold, N.A., Niessen, W.J., Toro, R., Tzourio, C., Longstreth, W.T., Ikram, M.K., Smoller, J.W., Tol, M.J. van, Sussmann, J.E., Paus, T., Lemaître, H., Schroeter, M.L., Mazoyer, B., Andreassen, O.A., Holsboer, F., Depondt, C., Veltman, D.J., Turner, J.A., Pausova, Z., Schumann, G., Rooij, D. van, Djurovic, S., Deary, I.J., McMahon, K.L., Müller-Myhsok, B., Brouwer, R.M., Soininen, H., Pandolfo, M., Wassink, T.H., Cheung, J.W., Wolfers, T., Martinot, J.-L., Zwiers, M.P., Nauck, M., Melle, I., Martin, N.G., Kanai, R., Westman, E., Kahn, R.S., Sisodiya, S.M., White, T., Saremi, A., Bokhoven, H. van, Brunner, H.G., Völzke, H., Wright, M.J., Ent, D. van 't, Nöthen, M.M., Ophoff, R.A., Buitelaar, J.K., Fernández, G., Sachdev, P.S., Rietschel, M., Haren, N.E.M. van, Fisher, S.E., Beiser, A.S., Francks, C., Saykin, A.J., Mather, K.A., Romanczuk-Seiferth, N., Hartman, C.A., DeStefano, A.L., Heslenfeld, D.J., Weiner, M.W., Walter, H., Hoekstra, P.J., Nyquist, P.A., Franke, B., Bennett, D.A., Grabe, H.J., Johnson, A.D., Chen, C., Duijn, C.M. van, Lopez, O.L., Fornage, M., Wardlaw, J.M., Schmidt, R., DeCarli, C., Jager, P.L.D., V illringer, A., Debette, S., Gudnason, V., Medland, S.E., Shulman, J.M., Thompson, P.M., Seshadri, S., Ikram, M.A., 2019. Genetic architecture of subcortical brain structures in 38,851 individuals. Nat Genet 51, 1624-1636. https://doi.org/10.1038/s41588-0190511-y

105. Grasby, K.L., Jahanshad, N., Painter, J.N., Colodro-Conde, L., Bralten, J., Hibar, D.P., Lind, P.A., Pizzagalli, F., Ching, C.R.K., McMahon, M.A.B., Shatokhina, N., Zsembik, L.C.P., Thomopoulos, S.I., Zhu, A.H., Strike, L.T., Agartz, I., Alhusaini, S., Almeida, M.A.A., Alnæs, D., Amlien, I.K., Andersson, M., Ard, T., Armstrong, N.J., Ashley-Koch, A., Atkins, J.R., Bernard, M., Brouwer, R.M., Buimer, E.E.L., Bülow, R., Bürger, C., Cannon, D.M., Chakravarty, M., Chen, Q., Cheung, J.W., Couvy-Duchesne, B., Dale, A.M., Dalvie, S., Araujo, T.K. de, Zubicaray, G.I. de, Zwarte, S.M.C. de, Braber, A. den, Doan, N.T., Dohm, K., Ehrlich, S., Engelbrecht, H.-R., Erk, S., Fan, C.C., Fedko, I.O., Foley, S.F., Ford, J.M., Fukunaga, M., Garrett, M.E., Ge, T., Giddaluru, S., Goldman, A.L., Green, M.J., Groenewold, N.A., Grotegerd, D., Gurholt, T.P., Gutman, B.A., Hansell, N.K., Harris, M.A., Harrison, M.B., Haswell, C.C., Hauser, M., Herms, S., Heslenfeld, D.J., Ho, N.F., Hoehn, D., Hoffmann, P., Holleran, L., Hoogman, M., Hottenga, J.-J., Ikeda, M., Janowitz, D., Jansen, I.E., Jia, T., Jockwitz, C., Kanai, R., Karama, S., Kasperaviciute, D., Kaufmann, T., Kelly, S., Kikuchi, M., Klein, M., Knapp, M., Knodt, A.R., Krämer, B., Lam, M., Lancaster, T.M., Lee, P.H., Lett, T.A., Lewis, L.B., Lopes-Cendes, I., Luciano, M., Macciardi, F., Marquand, A.F., Mathias, S.R., Melzer, T.R., Milaneschi, Y., Mirza-Schreiber, N., Moreira, J.C.V., Mühleisen, T.W., Müller-Myhsok, B., Najt, P., Nakahara, S., Nho, K., Loohuis, L.M.O., Orfanos, D.P., Pearson, J.F., Pitcher, T.L., Pütz, B., Quidé, Y., Ragothaman, A., Rashid, F.M., Reay, W.R., Redlich, R., Reinbold, C.S., Repple, J., Richard, G., Riedel, B.C., Risacher, S.L., Rocha, C.S., Mota, N.R., Salminen, L., Saremi, A., Saykin, A.J., Schlag, F., Schmaal, L., Schofield, P.R., Secolin, R., Shapland, C.Y., Shen, L., Shin, J., Shumskaya, E., Sønderby, I.E., Sprooten, E., Tansey, K.E., Teumer, A., Thalamuthu, A., Tordesillas-Gutiérrez, D., Turner, J.A., Uhlmann, A., Vallerga, C.L., Meer, D. van der, Donkelaar, M.M.J. van, Eijk, L. van, Erp, T.G.M. van, Haren, N.E.M. van, Rooij, D. van, Tol, M.-J. van, Veldink, J.H., Verhoef, E., Walton, E., Wang, M., Wang, Y., Wardlaw, J.M., Wen, W., Westlye, L.T., Whelan, C.D., Witt, S.H., Wittfeld, K., Wolf, C., Wolfers, T., Wu, J.Q., Yasuda, C.L., Zaremba, D., Zhang, Z., Zwiers, M.P., Artiges, E., Assareh, A.A., Ayesa-Arriola, R., Belger, A., Brandt, 
C.L., Brown, G.G., Cichon, S., Curran, J.E., Davies, G.E., Degenhardt, F., Dennis, M.F., Dietsche, B., Djurovic, S., Doherty, C.P., Espiritu, R., Garijo, D., Gil, Y., Gowland, P.A., Green, R.C., Häusler, A.N., Heindel, W., Ho, B.-C., Hoffmann, W.U., Holsboer, F., Homuth, G., Hosten, N., JackJr., C.R., Jang, M., Jansen, A., Kimbrel, N.A., Kolskår, K., Koops, S., Krug, A., Lim, K.O., Luykx, J.J., Mathalon, D.H., Mather, K.A., Mattay, V.S., Matthews, S., Son, J.M.V., McEwen, S.C., Melle, I., Morris, D.W., Mueller, B.A., Nauck, M., Nordvik, J.E., Nöthen, M.M., O’Leary, D.S., Opel, N., Martinot, M.-L.P., Pike, G.B., Preda, A., Quinlan, E.B., Rasser, P.E., Ratnakar, V., Reppermund, S., Steen, V.M., Tooney, P.A., Torres, F.R., Veltman, D.J., Voyvodic, J.T., Whelan, R., White, T., Yamamori, H., Adams, H.H.H., Bis, J.C., Debette, S., Decarli, C., Fornage, M., Gudnason, V., Hofer, E., Ikram, M.A., Launer, L., Longstreth, W.T., Lopez, O.L., Mazoyer, B., Mosley, T.H., Roshchupkin, G.V., Satizabal, C.L., Schmidt, R., Seshadri, S., Yang, Q., InitiativeII, A.D.N., Consortium II, C., ConsortiumII, E., ConsortiumII, I., ConsortiumII, S., InitiativeIl, P.P.M., Alvim, M.K.M., Ames, D., Anderson, T.J., Andreassen, O.A., Arias-Vasquez, A., Bastin, M.E., Baune, B.T., Beckham, J.C., Blangero, J., Boomsma, D.I., Brodaty, H., Brunner, H.G., Buckner, R.L., Buitelaar, J.K., Bustillo, J.R., Cahn, W., Cairns, M.J., Calhoun, V., Carr, V.J., Caseras, X., Caspers, S., Cavalleri, G.L., Cendes, F., Corvin, A., Crespo-Facorro, B., Dalrymple-Alford, J.C., Dannlowski, U., Geus, E.J.C. de, Deary, I.J., Delanty, N., Depondt, C., Desrivières, S., Donohoe, G., Espeseth, T., Fernández, G., Fisher, S.E., Flor, H., Forstner, A.J., Francks, C., Franke, B., Glahn, D.C., Gollub, R.L., Grabe, H.J., Gruber, O., Håberg, A.K., Hariri, A.R., Hartman, C.A., Hashimoto, R., Heinz, A., Henskens, F.A., Hillegers, M.H.J., Hoekstra, P.J., Holmes, A.J., Hong, L.E., Hopkins, W.D., Hulshoff Pol, H.E., Jernigan, T.L., Jönsson, E.G., Kahn, R.S., Kennedy, M.A., Kircher, T.T.J., Kochunov, P., Kwok, J.B.J., Hellard, S.L., Loughland, C.M., Martin, N.G., Martinot, J.-L., McDonald, C., McMahon, K.L., Meyer-Lindenberg, A., Michie, P.T., Morey, R.A., Mowry, B., Nyberg, L., Oosterlaan, J., Ophoff, R.A., Pantelis, C., Paus, T., Pausova, Z., Penninx, B.W.J.H., Polderman, T.J.C., Posthuma, D., Rietschel, M., Roffman, J.L., Rowland, L.M., Sachdev, P.S., Sämann, P.G., Schall, U., Schumann, G., Scott, R.J., Sim, K., Sisodiya, S.M., Smoller, J.W., Sommer, I.E., Pourcain, B.S., Stein, D.J., Toga, A.W., Trollor, J.N., Wee, N.J.A.V. der, Ent, D. van 't, Völzke, H., Walter, H., Weber, B., Weinberger, D.R., Wright, M.J., Zhou, J., Stein, J.L., Thompson, P.M., Medland, S.E., group, E.N.G. through M.-A.C. (ENIGMA)-Genetics working, 2020. The genetic architecture of the human cerebral cortex. Science 367, eaay6690. https://doi.org/10.1126/science.aay6690

106. Thompson, P.M., Jahanshad, N., Ching, C.R.K., Salminen, L.E., Thomopoulos, S.I., Bright, J., Baune, B.T., Bertolín, S., Bralten, J., Bruin, W.B., Bülow, R., Chen, J., Chye, Y., Dannlowski, U., Kovel, C.G.F. de, Donohoe, G., Eyler, L.T., Faraone, S.V., Favre, P., Filippi, C.A., Frodl, T., Garijo, D., Gil, Y., Grabe, H.J., Grasby, K.L., Hajek, T., Han, L.K.M., Hatton, S.N., Hilbert, K., Ho, T.C., Holleran, L., Homuth, G., Hosten, N., Houenou, J., Ivanov, I., Jia, T., Kelly, S., Klein, M., Kwon, J.S., Laansma, M.A., Leerssen, J., Lueken, U., Nunes, A., Neill, J.O., Opel, N., Piras, Fabrizio, Piras, Federica, Postema, M.C., Pozzi, E., Shatokhina, N., SorianoMas, C., Spalletta, G., Sun, D., Teumer, A., Tilot, A.K., Tozzi, L., Merwe, C. van der, Someren, E.J.W.V., Wingen, G.A. van, Völzke, H., Walton, E., Wang, L., Winkler, A.M., Wittfeld, K., Wright, M.J., Yun, J.-Y., Zhang, G., Zhang-James, Y., Adhikari, B.M., Agartz, I., Aghajani, M., Aleman, A., Althoff, R.R., Altmann, A., Andreassen, O.A., Baron, D.A., Bartnik-Olson, B.L., BasHoogendam, J.M., Baskin-Sommers, A.R., Bearden, C.E., Berner, L.A., Boedhoe, P.S.W., Brouwer, R.M., Buitelaar, J.K., Caeyenberghs, K., Cecil, C.A.M., Cohen, R.A., Cole, J.H., Conrod, P.J., Brito, S.A.D., Zwarte, S.M.C. de, Dennis, E.L., Desrivieres, S., Dima, D., Ehrlich, S., Esopenko, C., Fairchild, G., Fisher, S.E., Fouche, J.-P., Francks, C., Frangou, S., Franke, B., Garavan, H.P., Glahn, D.C., Groenewold, N.A., Gurholt, T.P., Gutman, B.A., Hahn, T., Harding, I.H., Hernaus, D., Hibar, D.P., Hillary, F.G., Hoogman, M., Hulshoff Pol, H.E., Jalbrzikowski, M., Karkashadze, G.A., Klapwijk, E.T., Knickmeyer, R.C., Kochunov, P., Koerte, I.K., Kong, X.-Z., Liew, S.-L., Lin, A.P., Logue, M.W., Luders, E., Macciardi, F., Mackey, S., Mayer, A.R., McDonald, C.R., McMahon, A.B., Medland, S.E., Modinos, G., Morey, R.A., Mueller, S.C., Mukherjee, P., Namazova-Baranova, L., Nir, T.M., Olsen, A., Paschou, P., Pine, D.S., Pizzagalli, F., Rentería, M.E., Rohrer, J.D., Sämann, P.G., Schmaal, L., Schumann, G., Shiroishi, M.S., Sisodiya, S.M., Smit, D.J.A., Sønderby, I.E., Stein, D.J., Stein, J.L., Tahmasian, M., Tate, D.F., Turner, J.A., Heuvel, O.A. van den, Wee, N.J.A. van der, Werf, Y.D. van der, Erp, T.G.M. van, Haren, N.E.M. van, Rooij, D. van, Velzen, L.S. van, Veer, I.M., Veltman, D.J., Villalon-Reina, J.E., Walter, H., Whelan, C.D., Wilde, E.A., Zarei, M., Zelman, V., 2020. ENIGMA and global neuroscience: A decade of large-scale studies of the brain in health and disease across more than 40 countries. Transl Psychiat 10, 100. https://doi.org/10.1038/s41398-020-0705-1

107. Brouwer, R.M., Klein, M., Grasby, K.L., Schnack, H.G., Jahanshad, N., Teeuw, J., Thomopoulos, S.I., Sprooten, E., Franz, C.E., Gogtay, N., Kremen, W.S., Panizzon, M.S., Loohuis, L.M.O., Whelan, C.D., Aghajani, M., Alloza, C., Alnæs, D., Artiges, E., Ayesa-Arriola, R., Barker, G.J., Blok, E., Bøen, E., Breukelaar, I.A., Bright, J.K., Buimer, E.E.L., Bülow, R., Cannon, D.M., Ciufolini, S., Crossley, N.A., Damatac, C.G., Dazzan, P., Mol, C.L. de, Zwarte, S.M.C. de, Desrivières, S., Díaz-Caneja, C.M., Doan, N.T., Dohm, K., Fröhner, J.H., Goltermann, J., Grigis, A., Grotegerd, D., Han, L.K.M., Hartman, C.A., Heany, S.J., Heindel, W., Heslenfeld, D.J., Hohmann, S., Ittermann, B., Jansen, P.R., Janssen, J., Jia, T., Jiang, J., Jockwitz, C., Karali, T., Keeser, D., Koevoets, M.G.J.C., Lenroot, R.K., Malchow, B., Mandl, R.C.W., Medel, V., Meinert, S., Morgan, C.A., Mühleisen, T.W., Nabulsi, L., Opel, N., Foz, V.O.-G. de la, Overs, B.J., Martinot, M.-L.P., Quinlan, E.B., Redlich, R., Marques, T.R., Repple, J., Roberts, G., Roshchupkin, G.V., Setiaman, N., Shumskaya, E., Stein, F., Sudre, G., Takahashi, S., Thalamuthu, A., Tordesillas-Gutiérrez, D., Lugt, A. van der, Haren, N.E.M. van, Wen, W., Westeneng, H.-J., Wittfeld, K., Zugman, A., Armstrong, N.J., Bralten, J., Dalvie, S., Forti, M.D., Ding, L., Donohoe, G., Forstner, A.J., Gonzalez-Peñas, J., Guimaraes, J.P.O.F.T., Homuth, G., Hottenga, J.-J., Knol, M.J., Kwok, J.B.J., Hellard, S.L., Mather, K.A., Milaneschi, Y., Morris, D.W., Nöthen, M.M., Papiol, S., Rietschel, M., Santoro, M.L., Steen, V.M., Stein, J.L., Streit, F., Tankard, R.M., Teumer, A., Ent, D. van 't, Meer, D. van der, Eijk, K.R. van, Vassos, E., Vázquez-Bourgon, J., Witt, S.H., Initiative, A.D.N., Adams, H.H.H., Agartz, I., Ames, D., Amunts, K., Andreassen, O.A., Arango, C., Banaschewski, T., Baune, B.T., Belangero, S.I., Bokde, A.L.W., Boomsma, D.I., Bressan, R.A., Brodaty, H., Buitelaar, J.K., Cahn, W., Caspers, S., Cichon, S., Facorro, B.C., Dannlowski, U., Elvsåshagen, T., Espeseth, T., Falkai, P.G., Fisher, S.E., Flor, H., Fullerton, J.M., Garavan, H., Gowland, P.A., Grabe, H.J., Hahn, T., Heinz, A., Hillegers, M., Hoare, J., Hoekstra, P.J., Ikram, 
M.A., Jackowski, A.P., Jansen, A., Jönsson, E.G., Kahn, R.S., Kircher, T., Korgaonkar, M.S., Krug, A., Lemaitre, H., Malt, U.F., Martinot, J.-L., McDonald, C., Mitchell, P.B., Muetzel, R.L., Murray, R.M., Nees, F., Nenadic, I., Oosterlaan, J., Ophoff, R.A., Pan, P.M., Penninx, B.W.J.H., Poustka, L., Sachdev, P.S., Salum, G.A., Schofield, P.R., Schumann, G., Shaw, P., Sim, K., Smolka, M.N., Stein, D.J., Trollor, J., Berg, L.H. van den, Veldink, J.H., Walter, H., Westlye, L.T., Whelan, R., White, T., Wright, M.J., Medland, S.E., Franke, B., Thompson, P.M., Hulshoff Pol, H.E., 2021. Dynamics of Brain Structure and its Genetic Architecture over the Lifespan. Biorxiv 2020.04.24.031138. https://doi.org/10.1101/2020.04.24.031138

108. Soelen, Inge L. C. van, Brouwer, R.M., Peper, J.S., Leeuwen, M. van, Koenis, M.M.G., Beijsterveldt, T.C.E.M. van, Swagerman, S.C., Kahn, R.S., Hulshoff Pol, H.E., Boomsma, D.I., 2012. Brain SCALE: Brain Structure and Cognition: an Adolescent Longitudinal Twin Study into the Genetic Etiology of Individual Differences. Twin Res Hum Genet 15, $453-467$. https://doi.org/10.1017/thg.2012.4

109. Boomsma, D.I., de Geus, E.J.C., Vink, J.M., Stubbe, J.H., Distel, M.A., Hottenga, J.-J., Posthuma, D., Beijsterveldt, T.C.E.M., Hudziak, J.J., Bartels, M., Willemsen, G., 2006. Netherlands Twin Register: From Twins to Twin Families. Twin Research and Human Genetics 9(6), 849-857. https://doi.org/10.1375/twin.9.6.849

110. Beijsterveldt, C.E.M. van, Groen-Blokhuis, M., Hottenga, J.J., Franić, S., Hudziak, J.J., Lamb, D., Huppertz, C., Zeeuw, E. de, Nivard, M., Schutte, N., Swagerman, S., Glasner, T., Fulpen, M. van, Brouwer, C., Stroet, T., Nowotny, D., Ehli, E.A., Davies, G.E., Scheet, P., Orlebeke, J.F., Kan, K.-J., Smit, D., Dolan, C.V., Middeldorp, C.M., Geus, E.J.C. de, Bartels, M., Boomsma, D.I., 2013. The Young Netherlands Twin Register (YNTR): Longitudinal Twin and Family Studies in Over 70,000 Children. Twin Res Hum Genet 16, 252-267. https://doi.org/10.1017/thg.2012.118

111. Ligthart, L., Beijsterveldt, C.E.M. van, Kevenaar, S.T., Zeeuw, E. de, Bergen, E. van, Bruins, S., Pool, R., Helmer, Q., Dongen, J. van, Hottenga, J.-J., Ent, D. van't, Dolan, C.V., Davies, G.E., Ehli, E.A., Bartels, M., Willemsen, G., Geus, E.J.C. de, Boomsma, D.I., 2019. The Netherlands Twin Register: Longitudinal Research Based on Twin and Twin-Family Designs. Twin Res Hum Genet 22, 623-636. https://doi.org/10.1017/thg.2019.93

112. Fischl, B., 2012. FreeSurfer. Neuroimage 62, 774-781. https://doi.org/10.1016/j.neuroimage.2012.01.021

113. Rogers, J.C., Brito, S.A.D., 2015. Cortical and Subcortical Gray Matter Volume in Youths with Conduct Problems: A Meta-analysis. JAMA Psychiat 73, 1-10. https://doi.org/10.1001/jamapsychiatry.2015.2423

114. Aoki, Y., Inokuchi, R., Nakao, T., Yamasue, H., 2014. Neural bases of antisocial behavior: a voxel-based meta-analysis. Soc Cogn Affect Neur 9, 1223-1231. https://doi.org/10.1093/scan/nst104

115. Jenkinson, M., Beckmann, C.F., Behrens, T.E.J., Woolrich, M.W., Smith, S.M., 2012. FSL. Neuroimage 62, 782-790. https://doi.org/10.1016/j.neuroimage.2011.09.015

116. Andersson, J.L.R., Skare, S., 2002. A Model-Based Method for Retrospective Correction of Geometric Distortions in DiffusionWeighted EPI. Neuroimage 16, 177-199. https://doi.org/10.1006/nimg.2001.1039

117. Leemans, A., Jones, D.K., 2009. The B-matrix must be rotated when correcting for subject motion in DTI data. Magnet Reson Med 61, 1336-1349. https://doi.org/10.1002/mrm.21890

118. Basser, P.J., Pierpaoli, C., 1996. Microstructural and Physiological Features of Tissues Elucidated by Quantitative-DiffusionTensor MRI. J Magnetic Reson Ser B 111, 209-219. https://doi.org/10.1006/jmrb.1996.0086

119. Boomsma D, Busjahn A, Peltonen L. 2002. Classical twin studies and beyond. Nat Rev Genet. 3:872-882.

120. Posthuma, D., Geus, E.J.C. de, Neale, M.C., Hulshoff Pol, H.E., Baaré, W.E.C., Kahn, R.S., Boomsma, D., 2000. Multivariate Genetic Analysis of Brain Structure in an Extended Twin Design. Behav Genet 30, $311-319$. https://doi.org/10.1023/a:1026501501434

121. Falconer, D.S., MacKay, T.F.C., 1996. Introduction to quantitative genetics. Pearson, Prentice Hall, Harlow.

122. Neale, M.C., Hunter, M.D., Pritikin, J.N., Zahery, M., Brick, T.R., Kirkpatrick, R.M., Estabrook, R., Bates, T.C., Maes, H.H., Boker, S.M., 2016. OpenMx 2.0: Extended Structural Equation and Statistical Modeling. Psychometrika 81, 535-549. https://doi.org/10.1007/s11336-014-9435-8

123. R Core Team, 2020. R: A Language and Environment for Statistical Computing version 4.0.3.

124. Dominicus, A., Skrondal, A., Gjessing, H.K., Pedersen, N.L., Palmgren, J., 2016 Likelihood Ratio Tests in Behavioral Genetics: Problems and Solutions. Behav Genet 36, 331. https://doi.org/10.1007/s10519-005-9034-7

125. Genovese, C.R., Lazar, N.A., Nichols, T., 2002. Thresholding of Statistical Maps in Functional Neuroimaging Using the False Discovery Rate. Neuroimage 15, 870-878. https://doi.org/10.1006/nimg.2001.1037 